
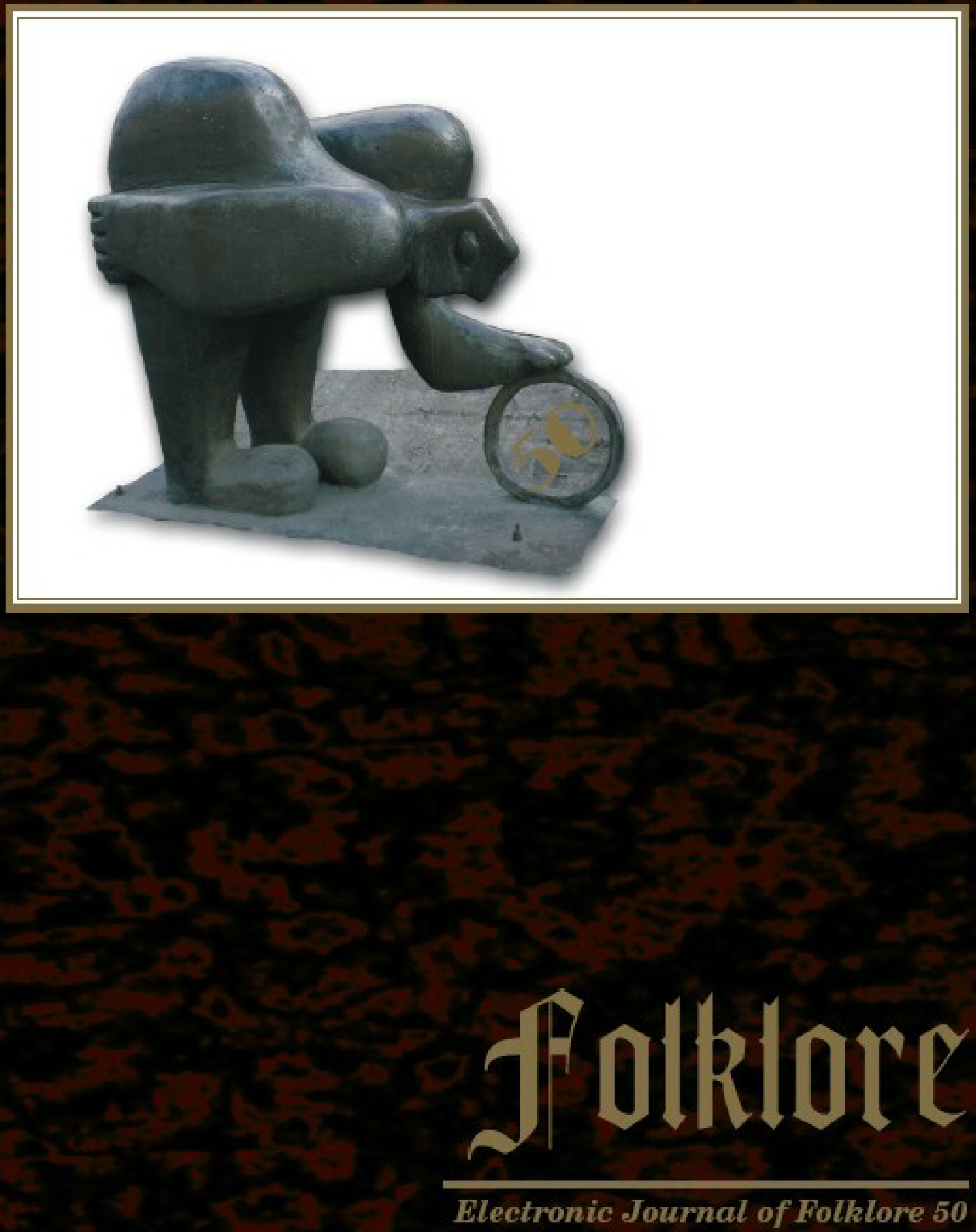


\section{Folklore}

Electronic Journal of Folklore

http://www.folklore.ee/folklore Printed version

Vol. 50

2012 
Folk Belief and Media Group of the Estonian Literary Museum

Estonian Institute of Folklore

\section{Folklore}

Electronic Journal of Folklore Vol. 50

Edited by Mare Kõiva \& Andres Kuperjanov Guest editor: Anneli Baran

Tartu 2012 
Editor in chief

Co-editor

Guest editor

Copy editor

Language editor

Design

Layout
Mare Kõiva

Andres Kuperjanov

Anneli Baran

Tiina Mällo

Gordon Allan Leman

Andres Kuperjanov

Diana Kahre

Editorial board 2008-2014: Dan Ben-Amos (University of Pennsylvania, USA), Larisa Fialkova (University of Haifa, Israel), Diane Goldstein (Memorial University of Newfoundland, Canada), Terry Gunnell (University of Iceland), Jawaharlal Handoo (University of Mysore, India), Frank Korom (Boston University, USA), Monika Kropej (Institute of Slovenian Ethnology), Kristin Kuutma (University of Tartu, Estonia), Aado Lintrop (Estonian Literary Museum), Wolfgang Mieder (University of Vermont, USA), Irina Sedakova (Russian Academy of Sciences).

Electronic version is supported by Estonian Science Foundation (grant no. 8137).

Printed version is supported by state programme projects EKKM09-168 and EKKM09-170.

Indexed in EBSCO Publishing Humanities International Complete, Thomson Reuters Arts \& Humanities Citation Index, MLA International Bibliography, Ulrich's Periodicals Directory, Internationale Volkskundliche Bibliographie / International Folklore Bibliography / Bibliographie Internationale d'Ethnologie), DOAJ, C.E.E.O.L., ERIH (B)

\section{Editorial address:}

Folklore: Electronic Journal of Folklore

Vanemuise 42-235

51003 Tartu

Estonia

phone: $\quad+3727377740$

fax: $\quad+3727377706$

e-mail: folklore@folklore.ee

home page: http://www.folklore.ee/folklore

All rights reserved

(C) Folk Belief and Media Group of the Estonian Literary Museum

EKM Teaduskirjastus/ELM Scholarly Press

Estonian Institute of Folklore

Authors

Design Andres Kuperjanov

ISSN 1406-0957 


\section{CONTENTS}

$\begin{array}{ll}\text { Foreword } & 7\end{array}$

Anneli Baran

Identity and Stereotypes: Humor Manifestations

Rita Repšienè, Laima Anglickienè

"You've Lived in X Too Long, When...": A View of the World

through Comic Lists (Expatriates' Humour on Ru.net)

Maria Yelenevskaya

The Popular Nobel Prize Award Banquet: Distanced

Participation of an Interacting TV-Audience

Marlene Hugoson

Humour Theories and the Archetype of the Trickster in Folklore:

63

An Analytical Psychology Point of View

Ana Stefanova

Ethnic Humour: What do Portuguese People Laugh at?

Pedro Martins

The Joke Cycle Island of Cannibals: Structure, Functions,

Messages

Grigor Haralampiev Grigorov

Discussion

Visual Jokes about Christmas and Santa Claus on the Internet -

Why and Why not?

Guntis Pakalns

Folklore Introduces: Ingrid Slavec Gradišnik 


\section{NEWS IN BRIEF}

All-Estonian Competition for Nursery School Lore Collection. Piret Voolaid

International Conference Tradition and Cultural Heritage: Challenges for

Creativity and Performance. Ingrid Slavec Gradišnik

MEDICA VIII. Interdisciplinary Conference Medical Pluralism in the Era of

Digimodernism. Ave Tupits

International Conference on Charms, Charmers and Charming.

Ekaterina Kuznetsova, Andrei Toporkov

Rituals and Customs as Cultural Heritage through the Eyes of Researchers and Performers. Irina Sedakova, Svetlana Sidneva

Estonian Folklorists' 7th Winter Conference. Mare Kalda

Thesis Defence: Andreas Kalkun. Seto Singing Culture in the Studies of

Estonian Folklore: A Supplement to the History of Representation.

Thomas A. DuBois

\section{BOOK REVIEW}

Profound Insight into the American World of Spirits and Ghosts. Reet Hiiemäe 


\section{FOREWORD}

In the autumn of 2009 an international conference under the heading "From Language to Mind 3" took place at the Estonian Literary Museum to celebrate the 70th jubilee of Academician Arvo Krikmann, senior researcher of the Department of Folkloristics. The articles in this special issue of Folklore are based on the papers delivered at this conference. In all, 45 presenters from 14 countries participated. The core research fields of the interdisciplinary conference were the ones that A. Krikmann has been delving into during decades of research: the short forms of folklore - proverbs, riddles, phraseological expressions, folk songs, and folk humour (anecdotes and jokes). Some of the articles written on the basis of these presentations - 8 altogether - were included in Folklore 46. The current issue comprises a selection of presentations on humour.

As a common feature, several of these articles focus on humour and ethnic stereotypes. Also, the empirical material in the majority of these papers originates in the most significant source of modern folklore - the Internet. The articles in the collection will definitely contribute to the heated discussions about contemporary humour research.

Laima Anglickienè (Department of Ethnology and Folklore, Faculty of Humanities, Vytautas Magnus University) and Rita Repšienè (Department of Modern Lithuanian Culture, Lithuanian Culture Research Institute) explore the coexistence of stereotypes and humour on the Internet and disclose this phenomenon through ethnonyms and anecdotes directed at the nearest neighbours.

Maria Yelenevskaya (Department of Humanities and Arts, Technion - Israel Institute of Technology) speaks about the stereotypical ideas of the so-called others on the Internet, focussing her attention, above all, upon the creation spread among the Russian diaspora.

Pedro Martins (University of Siena) dwells upon ethnic humour and tries to elicit the peculiarities of Portuguese humour.

Ana Stefanova (Institute of Ethnology and Folklore Studies with Ethnographic Museum, Bulgarian Academy of Sciences) dwells upon the tricksterimage popular in the folklore of different peoples. Proceeding from the psychological point of view, the author is trying to unfold the relations between humour and the universality of the archetype of the trickster.

Marlene Hugoson (Institute for Language and Folklore in Uppsala, Sweden) takes a look at the Nobel Prize Award Ceremonies, yet, from a very different 
angle; namely, she discusses the different forms of humour in people's understandings of this extremely traditional event.

Grigor Haralampiev Grigorov (Institute of Ethnology and Folklore Studies with Ethnographic Museum, Bulgarian Academy of Sciences) scrutinises selfreflexive forms of humour on the basis of a concrete joke cycle.

Guntis Pakalns (Archives of Latvian Folklore, Institute of Literature, Folklore and Art, University of Latvia) discusses the visual depiction of Santa Clause on Internet sites. He is also trying to find an answer to the question why people do it through humour.

The conference "From Language to Mind 3" was organised as a joint effort of the Estonian Literary Museum, Academy of Sciences of the Republic of Estonia, and the Cultural Endowment of Estonia.

Anneli Baran 


\title{
IDENTITY AND STEREOTYPES: HUMOR MANIFESTATIONS
}

\author{
Rita Repšienè, Laima Anglickienè
}

\begin{abstract}
The traditional understanding of humor as being tolerant, full of nonaggressive life curiosities, funny situations, mocking national or human vices, and related to an optimistic and contemplative attitude towards reality, has changed its main supportive points: the optimistic view of reality has been altered into a pessimistic and destructive one, forbearing ridicule has turned into severe offence, strangeness into stupidity, funny situations into futile misunderstanding. Everything is regarded as a dramatic possibility to survive or an endless situational tragedy where the most strict evaluation criteria, censorship, and dogmatism are empowered, meaning that, in the current times of widely propagated tolerance and overwhelming comprehension, it is extremely dangerous to offend somebody with an innocent joke or light mockery, to evoke an urge to contradict or negate when ideological aspirations are beyond "decency" limits. One of the most advocated rules in the Lithuanian press is: "Joke carefully with foreign nationals" from an interview with Barry Tomelin, London "International house" consultant and teaching director, the author of the book "World's Business Cultures: And How to Unlock Them" (with Michael Nicks) ${ }^{1}$. Identity is to be saved and nourished as the highest sanctity but its formation, meaningfulness and spread are not always attuned to the official approach.

Our life is full of stereotypes and our neighboring countries are not to be excluded - we have a preconceived notion of them. Using the national stereotype term we characterize relatively stable generalized opinions, in an open or hidden form, containing one or another assessment of a nation.

Our attitude towards neighbors is revealed in nicknames given to them non-official ethnonyms usually bearing a negative connotation. Some monikers have already lasted for centuries while others have been coined during the last decades. Anecdotes with the most popular foreign-born Russians and Estonians are discussed.
\end{abstract}

Key words: folklore, humor, identity, nicknames, stereotype 
It should perhaps be mentioned at the outset that the concept of national character is itself somewhat suspect. Is there in fact such a thing as national character? Or is it simply a figment of individual imaginations?

Alan Dundes

\section{EUROPEAN EVERYDAY LIFE OR RECONCILIATION (CONFORMATION) POLICY}

The installation, by the Czech artist David Černý, "Entropa" hanging over the entrance into the European Union (EU) building in Brussels, became one of the biggest misunderstandings of 2009. The installation, dedicated to the begin-

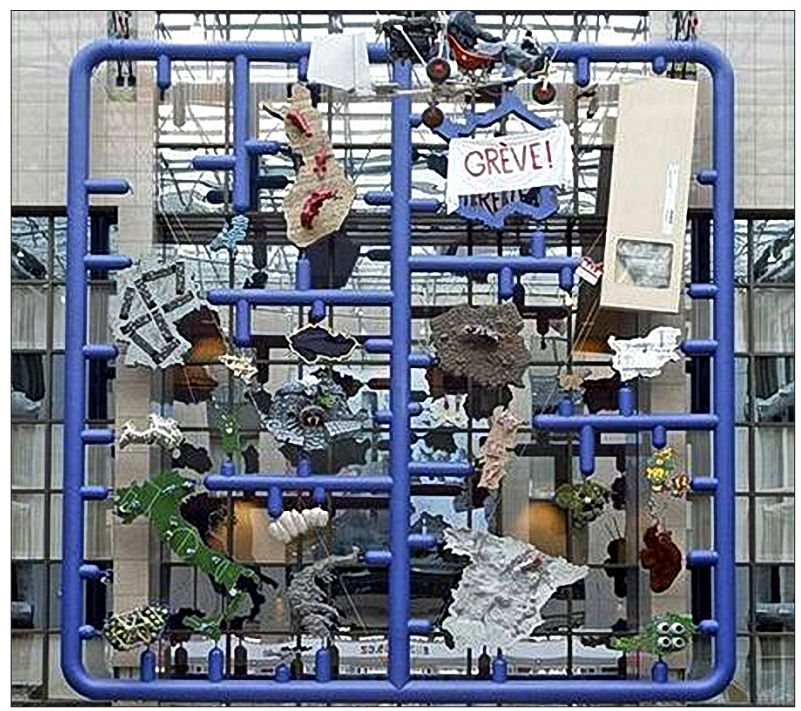

Figure 1. David Černý, "Entropa”. (Source: http://www.davidcerny.cz/start.html)

ning of Czech presidency in the EU, was a symbolic European map presenting stereotypes related to the 27 bloc members. The artwork occupied 16 sq. meters and depicted Netherlands as being flooded, with protruding minarets of mosques, France was shown as caught in strikes, Italy as a large football field, Germany's shape resembled the swastika, Romania - as a Dracula park full of ghastly sounds, Luxembourg was for sale, Polish priests were flying a gay flag. United Kingdom - as a Euro-skeptical country was missing there at all ${ }^{2}$. 
There were Euro-skeptical statements by Vaclav Klaus in the Czech Republic where he was asking his people to "renounce openly" the installation because he could not agree with its content and found an offensive and disputable meaning in it. A part of the controversial installation, where Bulgaria was portrayed as the land of squat toilets, was covered with black cloth at night.

The artist D. Černý himself rendered his apologies to Bulgaria saying he was just wondering if Europe was able to laugh at itself: "If I had meant to offend somebody it was Vaclav Klaus. Because Klaus is offending Czechs"3 - he said. By using irony on notional clichés the artist sought turning serious things into playful ones.

Once we admit that one of the 20th century art goals is to shock the audience and to provoke discussion it must be recognized that the Czech artist's installation has done its job. Generally, this installation triggered endless stories and their interpretations received the most diverse evaluations. After getting the order Černý intended to invite an artist from every EU country but finally fulfilled the task with two of his friends - that was another part of the scandal. Assumingly, Lithuania was represented by Vilma Stasiulyte whose installation shows five men in military uniform urinating on the Lithuanian - Byelorussian border. Allusions to the pissing Brussels boy "Manneken Pis" are related to interest in the fate of totalitarian monuments and their substitution by new generation monuments whereas the symbol has been adapted to the situation

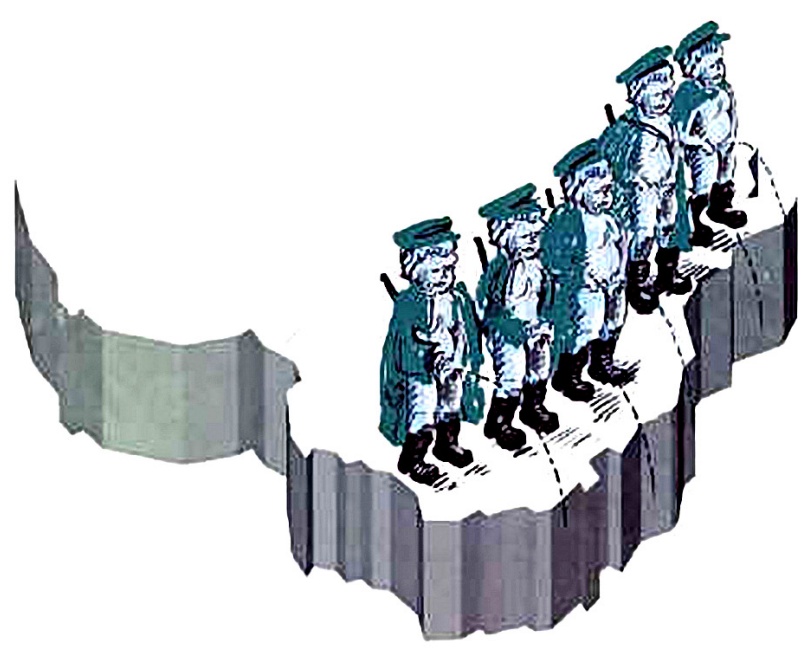

Figure 2. Entropa Lithuania. (Source: www.eu2009.cz) 
in Lithuania. "The project can be perceived as an alternative monument to the Independence of Lithuania and as a way to get rid of the injustice experienced in the past"- says, supposedly, the artist herself in her fictitious website (Entorpos booklet: fictitious authors and their creation $\left.{ }^{4}\right)$.

The installation gained serious assessments among politicians and the press. EU representatives even considered an option to deconstruct the installation but gave up avoiding accusations about art censorship. In the Lithuanian press a popular reviewer, taking everything for granted, compared Lithuanian and Estonian (supposedly of Sirje Sukmit) visions:

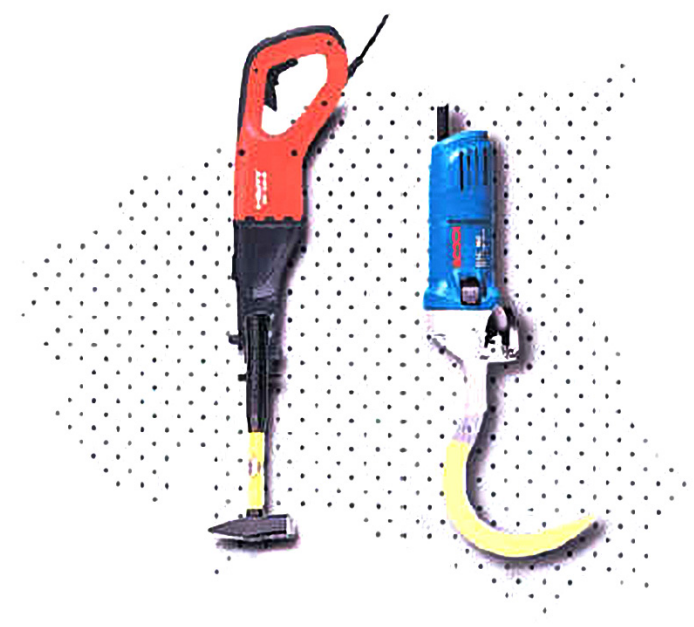

Figure 3. Entropa Estonia. (Source: www.eu2009.cz)

"Of course, I am not an artist but I was not delighted with the view. As a matter of fact I understand the allusion to the Brussels boy but I can't get why Lithuanians look like "pissing" soldiers with guns... You might disagree but it seems to me that one should know how to laugh at himself. Besides, I also suppose that a smile or irony should differ from contempt and self-humiliation."

The Estonian vision was noticed to be a perfect one: "It seems so simple - "modern Soviet". There's such a lot of information at the same time and... it is very beautiful. Yes, a stereotype, yes a mocking one, but the message 
transferred by this creation is absolutely different from the Lithuanian case. Because it is not a conjuncture, because it does not seek to please somebody, does not seek political correctness as in some works by the authors from other states. In addition, its persistent value is much higher. Brilliantly simple... Oh, these Estonians..."6

Thus, the traps of ideological clichés can catch everyone who is not aware of the context and disregards conditionality of the genre.

Should art be assessed as a means to become cured of national complexes? The subtitle of "Entropa" installation ran as: "Stereotypes are barriers to be demolished". This art creation ridiculing banalities with no scruples, according to the author, made a parody of the notion of "EU without borders". It is an ironical approach towards the EU integration and stereotypes tagged to every country.

On the other hand, this installation received considerable support. "I don't see any provocation - it is rather a mirror hanging in front of us," thinks Karin Resetarits from Austria (Alliance of Liberals and Democrats for Europe). "Maybe we need a direction to see complicated things in a simpler manner. And our predispositions are the most elementary simplification." EU Culture Committee Chairwoman Katerina Batzeli (Socialist group, Greece) says she does not like stereotypes since they are the old way to convey a message. But in the later phase, she changed her opinion: "After seeing the creation I realized that art has to provoke, to shake the system." 7

"It is hard to accept manipulations by the Czech artist - by pretending to work in the project along with artists from all EU countries and stereotypically depicting some member states he seems to be crossing the limits of good form," reflects Tadeusz Zwiefka, member of the Polish group of the European People's Party - European Democrats in the European Parliament, noting that the artistic element of the piece outweighed the controversial one: "I appreciate the artistic freedom of expression and thus I accept the large liberties taken by artists." 8

"After the economic crisis humor must be a priority of daily life," said Ms Batzeli.

Generally, an interesting idea was raised: "In times of economic crisis it is a healthy thing to develop a cynical sense of humor. If Europe is not able to accept cynical humor its future seems to be bleak," ${ }^{9}$ - said Resetarits. Is humor accepted in the contemporary world? Is it tolerated? Does it help to get rid of stereotypes? 


\section{STEREOTYPES: TRADITIONAL LEGACY}

Folklore is also a reflection of life and at the same time of culture, mentality and life style values. Attitudes towards representatives of other nations in folklore often turn out to be ironic, mocking or even offensive and scornful ones. In unofficial language neighboring nations are often called not by their official ethnonyms but nicknamed. Some monikers for neighboring countries (Anglickienè 2005: 7-17) have already lasted for several centuries while others are only coined during recent decades. These unofficial nicknames have negative connotations and are used for mockery or even to humiliate and to scorn. According to philologist Alvydas Butkus, "language phonetics of a certain ethnos, a more popular word or transformation of an official ethnonym can be used for identification" (Butkus 2009: 13). Let us make a review of the nicknames given by Lithuanians to their neighbors.

One of the oldest living ethnonyms surviving for several centuries already is Gudas. Both in Lithuanian spoken language and in folklore people of the Slavonic nation are called Gudas (pl. Gudai). Linguists have raised a number of hypotheses concerning the origin of the word (Karaliūnas 1999). By Gudai Lithuanians refer to Byelorussians, but sometimes also to the Polish or Russians, or even people talking another dialect from a different area of Lithuania are given the same name. Simas Karaliūnas argues that Gudas is not geographically related to any territory or nation, by the same token that no nation calls itself by this name, i.e. it is not a real ethnonym or an ethnic selfname, but rather a quasi-ethnonym, heteronym, used by Lithuanians to refer to other Lithuanians speaking other dialects, and to other nations. This usage tendency spreads to the East (Karaliūnas 1999: 25-26). During the inter-war period, the official Lithuanian language adopted the tradition of calling Byelorussians and Byelorussia as Gudai and Gudija. Sometimes they were called Baltgudzhiai (Baltgudija). After 1990 the old name came back into use again and this is why we can find Gudas / Gudija in today's press.

Nowadays Byelorussians are nicknamed bulbasai/bulbashai. Butkus's guess is that the nickname got its origin in the frequent mentioning of potato (bulve potato) in Byelorussian folk songs (Butkus 2009: 14). The Bulbash nickname is also used by Russians. Their explanation is that it is because of Byelorussians liking potatoes very much (in Byelorussian bulba). Still, in the Soviet times Byelorussia was famous as the biggest potato growing republic. Also, we should mention that when trying to humiliate somebody the names of animals (such as gander, goat, cock, swine etc.) or plants (such as beetroot, cabbage head etc.) are being frequently used. 
During several centuries of common living or being neighbors there were plenty of nicknames created for Russians. It is obvious that Lithuanians' relations with Russians were tense due to geographical, historical, political reasons and hostile relations are always reflected in a sharper manner than when living side by side with friendly neighbors. Different names have always been used to describe Russian confessions - burliokai (in Byelorussian - бурлак), sentikiai - Old Believers, maskolis (in Byelorussian - москаль) (women - maskaukos) Orthodox Russians. These nicknames have by now turned into archaisms. The nicknames of kacap and kazak have been known since long ago. Today Russians are mostly nicknamed as ruskiai, kacapai ${ }^{10}$, and more rarely as - Ivan.

Poles are nicknamed as paliokai or pshekai, and this is the way in which Polish phonetics is mimicked (Zavjalova \& Anglickienè 2005: 149; Butkus 2009: 14). Such a difference in phonetics was noticed by Russians as well and they also call the Poles psheki. There is one more archaic Polish nickname-shlekta which means 'nobleman' but this word is used in a pejorative sense.

The best known Latvian nickname nowadays is zhirgo galva ('horse's head'). Butkus argues that zhirgo galva stresses the affinity of our Baltic languages (common lexis) and the peculiarity of Latvian phonetics ( $z$ instead of Lithuanian $z h-\check{z}$ ). This nickname has already survived for a second century but its origin is not clear. One of the versions claims that in the 19th century, after the abolition of serfdom, commercial ties between Latvians and Lithuanians intensified and Lithuanians started visiting Latvian markets more frequently. Latvian horses used to be larger and better-looking, so Lithuanians started nicknaming their owners out of envy. But a contrary assumption is more likely that Latvians themselves gave this name to Lithuanians thus stressing their foolishness. Often hearing this phrase Lithuanians re-addressed it to Latvians (Butkus 2009: 14-15).

In recent years Latvians are entitled braliukas - a word bearing a positive meaning (braliukas means 'brother' and it is a diminutive form of this word). The origin of this name goes back to the Eurovision song festival of 2007 when a Latvian announcer of the results addressed Lithuanians in such a positive manner. The phrase, dropped casually by the announcer, seemingly unexpectedly, but really sincerely, "achieved more than a year's work of all Latvian diplomats in their attempts to create a positive image of their country in Lithuania" (Butkus 2007). Lithuanians readily accepted this word, with a perfectly nice Lithuanian resonance, and started using it for Latvians themselves. To show their gratitude for this flattering address and the given high score several cafés in Kaunas raised Latvian national flags and gave noticeable discounts for Latvian customers when they were ordering their meals. Thus, braliukas is used in a positive context and zhirgo galva in a negative one. 
The most popular nickname for Estonians now is kuliamaje/kulemaje. It appeared, comparatively, not so long ago and originated from the Estonian basketball player Gert Kullamäe - the first foreign legionnaire playing in "Žalgiris" in 1993-1994. This nickname sneers at the phonetics of the Estonian language (the same as in anecdotes) and besides that it fits in for a contemptuous moniker because of its links to obscene Lithuanian lexis (Butkus 2009: 15). The Estonian character "Duujookaukee Kiiuuulemiaja" (Gas-Mask Kulemmaje) was made up in the black humor radio show and thus became popular. ${ }^{11}$ We can find Kulemaje used today to characterize Estonians in Internet forums, articles related to basketball, commentaries.

The case with the popularized Estonian name demonstrates that media today helps to create new, and to strengthen already existing, stereotypes. Currently a popular humor show in Lithuania "Dviračio šou" (Bike show) features Estonian and Polish characters (to tell the truth there is mostly a Lithuanian Pole presented there) that usually appear whenever there are some problems or misunderstandings between the countries or nations. It is a live process - humiliating or offensive nicknames are brought back to the scene with an escalation of mutual relations between neighboring countries.

Scornful nicknames can be abundantly found in Internet forums and portals with commentaries on articles in one or another way depicting neighboring nations. Even when a theme or a title is more or less neutral, commentaries of internauts are nicknaming and mocking with regard to the depicted country. Nicknames "help", with the least effort, to degrade representatives of these countries.

\section{NOWADAYS' ANOMALIES: “LAUGHTER" THERAPY}

Traditional things in today's world have become hostages of time. One of the best investigated phenomena in these days is gelotophobia - fear to joke, to trick, and to quip. An exhaustive research has been carried out in 73 countries and the results were published in February 2009 in the international journal of humor research, Humor ${ }^{12}$. Despite cultural differences the problem is obvious for the whole world. After questioning more than 22 thousand respondents it turned out that "laughter invokes fear". People with no sense of humor consider laughing as a threat or assault. Does laughter help one to take a socially active position or are we able to laugh only at one another?

The culture of laughter is inseparable from traditional historical phenomena: carnival time understanding, original opposition, self-sufficiency and freedom. Laughter obeys the logic of imagination which is not identical to the logic of 
reason and this is why it is so hard to define - it is just live, pulsating energy creating world vision of its own (Bergson 1900). The liberating power of laughter, and a survival skill of (auto) ironic attitude have become a deficit, yet people would sometimes simply want to laugh.

According to Mikhail Bakhtin, laughter is not only socially but also culturally purposeful: comicality (especially satire) determines renewal of genres and literary language - liberates people from stiff canons, adds modernity and live actuality to any literary genre (Bakhtin 1990: 12).

It is important to preserve a healthy sense and positive sense of humor while assessing ourselves and judging others. In Gerard Delanty's words, the eccentric European identity spurs widening of outlook and emancipation from stiff stereotypical evaluations.

\section{NEW IMAGES - HOSTAGES OF STENCILS, SCHEMES AND CLICHÉS}

In 2008, efforts were made to create a new and attractive image of Lithuania; the concept of Lithuania as "a brave country" was proposed. It provoked numerous discussions and ironical reactions truly uncharacteristic of Lithuanians: "No, but we are seriously a brave country!" (Zemkauskas 2008) or "Maybe, according to the current fashion in Lithuania we will decide to establish a Braveness Monitoring Institute which would observe and watch very closely how much we gained in braveness in one year in comparison to Latvians and how much cowardly we look when comparing our courage to Estonians?" (Bončkutė 2008)

In addition, a courageous proposition was made to change the name of Lithuania in English since the actual "Lithuania" is too long and hard to pronounce for many foreigners. In 2009, the Lithuanian State Auditor Rasa Budbergyte stated an obvious truth that the image creation campaign had no clear landmarks (Image of country 2009).

Historical imagination has vanished from the national world-view and it is rather sad. Being national is becoming a privilege of favorites while the majority of the nation lives with illusions about the majestic past, stereotyped thinking is programmed by way of stories about heroes, paladins and their feats. Compatriots with stereotyped thinking do not necessarily need to live in Lithuania, instead, they can also reside somewhere in foggy Albion. It changes nothing. On the other hand, a stereotyped attitude towards the agricultural nation, so pleasing to Lithuanian hearts long ago, has by now lost its basic elements.

It is extremely hard to get rid of stereotypes. In January 2007, a public campaign "Let's be modern and defeat stereotypes" was launched. 500 posters 


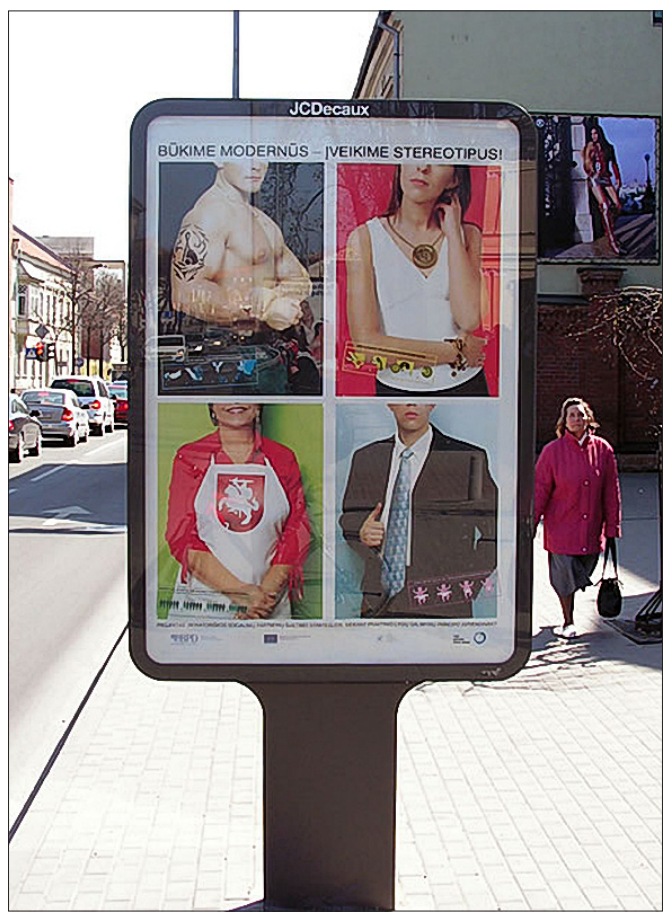

Figure 4. Poster "Let's Be Modern and Defeat Stereotypes". Photo by Karolis Pocius (2007).

were displayed and their goal was to attract society's attention to gender stereotypes and to encourage change. There were photos of a man with a vacuum cleaner tattoo on his hands, a woman with automobile keys hanging on her neck, or another one wearing an apron with the coat of arms of the Lithuanian Republic, a man in a suit surrounded by babies. Every photo had captions like: "Women can take part in politics", "Women can do hard work", "Men can do house-cleaning" and "Men can be baby-sitters". But the chosen way of impact was rather traditional, conservative and very stereotyped.

Similarly to any other public social action this initiative was also aimed at mass consciousness. Collective stereotypes are passed from generation to generation, ideologized and they are hardly susceptible to transformations, but their evaluation horizons can be broadened by forming and changing the direction of thinking. Simultaneously, the campaign urged people to try "to overcome failure by collective efforts" (Smith 1994: 60). Solidarity, sociality, sense of collective identity unfolds multiple positive suggestions, nurture important skills of social community. Despite the utopian expectations of nationalism, the emphasis was on optimism and practical ability to seek national maturity and unity. 


\section{NATIONAL TRAITS IN ANECDOTES}

Many Internet websites contain sections with anecdotes about representatives of various nations. Some websites group anecdotes from different nations which contain jokes about people of other nationalities. The Delfi website is useful because they have anecdotes about all nations and we can try to differentiate them by the way Lithuanians joke about them. The table presents the ten most popular nations of the past several years.

Table. The most popular nations in Lithuanian anecdotes (Delfi website 2007 data)

\begin{tabular}{|l|l|l|}
\hline Nationality & $\begin{array}{l}\text { Number of } \\
\text { anecdotes }\end{array}$ & $\mathbf{\%}$ \\
\hline Russians / New Russians & 105 & 13 \\
\hline $\begin{array}{l}\text { Lithuanians / Representatives from ethnographical regions } \\
\text { of Lithuania }\end{array}$ & 86 & 10 \\
\hline Chukchi & 68 & 8 \\
\hline Jews & 62 & 7 \\
\hline Estonians & 52 & 7 \\
\hline Americans & 37 & 4 \\
\hline Georgians & 36 & 4 \\
\hline Chinese & 22 & 3 \\
\hline Armenians / Armenian radio & 18 & 2 \\
\hline Arabs & 16 & 2 \\
\hline 2-5 nationalities & 187 & 22 \\
\hline Other nations & 164 & 18 \\
\hline \multicolumn{1}{|c|}{ Total } & 835 & 100 \\
\hline
\end{tabular}

In addition, similar tendencies in ethnic anecdotes - the same nationalities, identical anecdotic situations - can be found in Estonian (Laineste 2008: 135), Russian (Krikmann 2009: 75) and Polish (Brzozowska 2009) folklore. This article presents descriptive characteristics of two popular nations: Russians are interesting because of their long lasting tradition of having been depicted in Lithuanian folklore and Estonians gaining popularity therein only after 1990.

Contemporary folklore and popular anecdotes disclose stereotypic character traits of every nation, their inter-relations and differences between countries. Today's anecdotes and folklore genres are international, migrating and lively reacting to actualities. Plots and stereotypes migrate between nations. Stereotyped characteristics of one or another country are often related to their constant artistic image in folklore rather than to reality. This is why anecdotes tend to exploit some particular nationality traits for many years. 


\section{RUSSIANS}

Several reasons can be outlined why a Russian is popular in contemporary Lithuanian anecdotes and other folklore genres:

1. Anecdotes about Russians used to be popular in Soviet times.

2. The majority of Lithuanians understand Russian. Part of anecdotes are told or forwarded by e-mail in the Russian language, even until now.

3. Russian TV and radio broadcasts with humorous content are popular among Lithuanians, according to statistics, and this kind of culture is being widely cultivated. Russian humor is easily understood because just 20 years ago we shared, with Russians, the same state.

4. It is customary to have a lot of anecdotes about large countries as smaller states cannot escape dealing with their big neighbors, either directly or indirectly. Power states make their impact on the economic and political life of other minor countries.

One of the most popular anecdotic plots is showing the Russian as an alcoholic. The image of a Russian being alcoholic is very old. Russians themselves are very quick to mock this example of their supposed vice. The stereotype is very vivid all over the world and there is a real super-abundance of anecdotes told about Russian boozing:

What is a Russian booze up?

- A box of vodka, a couple of beer bottles, a piece of smoked pork fat and a $\operatorname{dog} . .$.

- And the dog what for?

- Well, someone has to eat the pork fat... ${ }^{13}$

Bearing in mind the Russians' inclination towards alcoholism, anecdotes were created such as:

"Kodak" firm launched into Russian market a special new camera removing not only "red-eye" but also "red-nose" effect. ${ }^{14}$

Russian citizens practice a very simple health criterion - one is either capable of drinking or is not. ${ }^{15}$

Sometimes there are really weird things in Russia - like vodka advertising. ${ }^{16}$

Another frequent subject of anecdotes is about bad roads in Russia, indicating that these anecdotes are mostly created and told by traveling people: 
As it is known $20 \%$ of Russian roads are impenetrable. The remaining $80 \%$ are called roads only by Russians themselves. ${ }^{17}$

Russian road constructors proposed to introduce a new sign "Road" to persuade foreigners. ${ }^{18}$

Where asphalt ends - Russia starts. ${ }^{19}$

In the course of the last two years Russian roads improved significantly - it is a rare case now for a tank to get stuck. ${ }^{20}$

It is interesting that we failed to find similar anecdotes about Polish roads disappointing Lithuanian travelers on their way to Western Europe. It might be an indication that anecdotes about Russian roads are created not by Lithuanians. The anecdotes must be created by other West European drivers and then just adopted by Lithuanians.

The last anecdote cited demonstrates one more feature - Russia being famous for militarism and fond of showing off its military force proving it to be the most powerful country in this area.

"Volkswagen" concern promised to create a winged automobile applied specially for the Russian market. It is going to be a tank. ${ }^{21}$

Comparatively, there are not many political and social anecdotes being told now, however, these anecdotes used to be very popular in the Soviet times. Several reasons might be given for that. The peculiarities of the socialist order and the relevant political guidelines are not comprehensible enough for the younger generation grown up now in an independent Lithuania. At the same time it possibly demonstrates that despite the escalated threat from Russia the majority of Lithuanians do not follow what is taking place in this neighboring country and only the most important Russian events, shaking the entire world, attract the attention of Lithuanians. Old political anecdotes are remembered and being told only in connection with more critical political situations in current times.

More often stories with a new content, revealing the actual political situation, are being created:

A real Russian President must build the Duma, grow a ruling party and seat (put behind bars) an oligarch. ${ }^{22}$ (C.f. - "A real man must build a house, grow a son and plant a tree").

Russian/Russia's stereotype is best expressed by short wordplays:

The United States of America fight for peace and Russia fights for State Security. ${ }^{23}$ 
Russia is like Amur: naked, armed and importuning everybody with love. ${ }^{24}$ Nearly half of the anecdotes are about New Russians, but it is not even a name of a new nationality. This is rather a phenomenon of Post-Soviet countries. "New Russians" refers to the Nouveau Riche - those who have acquired considerable wealth recently; they are a bit foolish but manage to get quick and possibly dirty money, wondering how to impress others with their fortunes and exceptionality. These genre-wise examples do not even need to be made up - anecdotic situations with members of the Nouveau Riche in the world overwhelm tabloids, journals and internet portals. Anecdotes about them are migrating and every country can substitute their heroes by the New Lithuanian, Latvian or Polish. But due to their peculiarity New Russians are unbeatable: their scale in anecdotes is much larger than that of small Lithuania.

\section{ESTONIANS}

The nation which became well-known in recent decades is depicted very stereotypically not only in anecdotes but also in other folklore genres. Their slow and phlegmatic temper is nearly always mocked in anecdotes:

Who is standing over there for half of an hour? Oh, these are Estonians on the run...25

Which nation is the richest in the world?

Estonians.

Why?

They are always short of time to spend their salary! ${ }^{26}$

Today's anecdotes often mention new technologies:

Estonians have created a brand new computer and started exporting it abroad. 400 people have died waiting until it starts. (VDU ER 1246)

"Estonian Telecom" is the richest organization in Estonia because it is the only one providing $1 \mathrm{~kb} / \mathrm{s}$ internet. (VDU ER 1246)

The Estonian name is often substituted by already mentioned Kuullemmajja:

The Estonian marathon is 42 meters. Janis Kuullemmajja is all times record-holder - 2 h 35 min. 3 sec. (VDU ER 1246)

Besides this character trait the phonetic and morphological peculiarities of the Estonian language are imitated and mimicked not only in live spoken language 
but in virtual space as well by way of using doubled or even tripled letters, changing the media style with surds.

Estonian casino. Croupier at roulette is announcing:

- Moooost hooonoooureeed laaadieeees and gentlemeeen, we aaareeee staaarting petttsss fooor tomooorrooow... ${ }^{27}$

Estonian Director says to his Lithuanian secretary:

- Tyyypppe slooower, becauuse I faaall beeehind to tiiictaaate. ${ }^{28}$

Analogous anecdotes about sluggish, phlegmatic Estonians are also told by Latvians and Russians. As the Estonians have a similar image among the population of the larger area, the number of such anecdotes is even more abundant. (see Krikmann 2009). Besides, the image of the slow Estonian in folklore for Lithuanians serves as a compensation for the live actual stereotype fixated after 1990 about Estonians as living better, nicer and richer, being more rational than Lithuanians.

Another point is that these anecdotes are often short, consisting of one sentence only. Obviously, it is because of the very monotonous style of an Estonian in anecdote - once a teller mentions there is going to be an anecdote about Estonians, listeners associate it with other anecdotes. As noticed by Liisi Laineste: "Serial jokes present the listener with a "chewed" pair of oppositions ready for "instant digestion". It does not take much time and energy to understand the joke” (Laineste 2008: 139).

\section{CULTURE OF INNOVATIONS OR THE MYTHICAL CONTENT OF NATIONALITY}

Nationality in the 21st century is rather distant from the romantic definitions of the 19th century: deductive thinking introduced by the Enlightenment was replaced with intuition, imagination, sensuality, and even irrationality as part of Romanticism. Today there is a return to the origins of rationality. Ideas of national awakening, having lost their sweeping energy characteristic of liberating movements, found themselves in a deadlock, because the nationality notion still remains in the 19 th century robes although contemporary times dictate completely new programs, myths and realities (Hobsbawm 1990).

Central and Eastern European "liberation fantasies" in search of opportunities to substitute undefined, misty, rising anxiety and distorted realities with something more rational, related to the need to bring meaning into existence, 
in a similar way as with the help of myths it is possible to explain transition from principles to actions (Tismaneanu 2003).

With concentrated forces to form and spread nationality as actual contemporary power we would reveal new identity layers. That would help to expand, train or at least to awaken national consciousness. Sunk in historic and selfmade patterns, imprisoned in their schemes, lost in complex labyrinths we cannot be open to a different opinion or other truth quests. Worshipping of heroes raised by ideology, praising unseen gods or fake heroes resembles fables about an ideal country, fictitious land of dreams. "Magical thinking enables the human being not to feel responsibility, to sacrifice independent will to cranks and adventurers. While a legal state is still in its birth process and corruption is spread everywhere, magical thinking opens the easiest way to embody guilt, demonize strangers and to create an unreal but freshening community feeling." (Tismaneanu 2003: 96)

New narratives do not appear by themselves, they need to be based on substantial insights or openly approbated rules: "When traditional political identities are ruined an alternative of collective identity not contradicting national identity is needed" (Delanty 2002: 214). Freedom of choice can also become a millstone around our necks if we are oriented towards one day inspirations...

Concurrently with the start of the 21 st century and the economic depression followed by hard times, a new need for identity emerged, and nationality is currently regaining its lost position. The world is as if creating itself - a security mechanism in the conditions of globalization, cosmopolitism and unification, in times of universal indifference and total disorientation when values are being lost and identity leveled. Naturally, the nationality dimension has changed; it became not only communal but also a personal landmark, modern meaningful position, integrating factor or illusion, so that even in pragmatic times of spiritual decline it is possible to revive "lost" traditions, exceptional rights or at least romantic sentiments. The objective of nationality is modeled as if in a classical situational comedy and reveals important aspects of values, arouses various insinuations and stimulates personal expression, identity quests avoiding its aggressive or even dangerous forms.

Historical memory, as a common axiom, cannot be eliminated from the everyday field. It is not merely a personal matter what hierarchy has been set, regarding the values of the past. It is important for all of us to watch constantly to where our chosen road is leading. 


\section{NOTES}

1 Interview with Barry Tomelin: Rūta Sturonaitè "Su kitataučiais juokaukite atsargiai". Published on 18/09/2008. www.projekona.lt/get_file.php?id=112, last accessed on 2 March 2012.

2 Entropa: Czech artist David Černý speaks out, in EUX.TV. http://www.youtube.com/ watch?v=HXzEMAEKT8k, last accessed on 2 March 2012.

${ }^{3}$ Entropa Installation, published on 14/01/2009. http://www.origin.ie/blog/?p=150, last accessed on 2 March 2012.

4 "Entropa": Europos atvaizdas ar meninè provokacija? [Entropa: European Image or Artistic Provocation?] http://www.europarl.europa.eu/news/public/story_page/03748734-040-02-07-906-20090206STO48713-2009-09-02-2009/default_lt.htm, last accessed on 2 March 2012.

${ }^{5}$ Račas Artūras. Lietuva versus Estija: pasijuokti iš savęs irgi reikia mokèti. Published on 13/01/2009. http://racas.lt/lietuva-versus-estija-pasijuokti-is-saves-irgi-reikiamoketi/, last accessed on 2 March 2012.

${ }^{6}$ Račas Artūras. Lietuva versus Estija: pasijuokti iš savęs irgi reikia mokèti. Published on 13/01/2009. http://racas.lt/lietuva-versus-estija-pasijuokti-is-saves-irgi-reikiamoketi/, last accessed on 2 March 2012.

7 http://www.europarl.europa.eu/news/public/story_page/037-48734-040-02-07-90620090206STO48713-2009-09-02-2009/default_lt.htm, last accessed on 2 March 2012.

8 http://www.europarl.europa.eu/news/public/story_page/037-48734-040-02-07-90620090206STO48713-2009-09-02-2009/default_lt.htm, last accessed on 2 March 2012.

9 http://www.europarl.europa.eu/news/public/story_page/037-48734-040-02-07-90620090206STO48713-2009-09-02-2009/default_lt.htm, last accessed on 2 March 2012.

10 The nickname kacap is international. Its origin is explained in double way: more popular is opinion that in old times the Ukrainians in such way named bearded Russians (for example they have expression kak cap - 'as goat'). The other etymology word kacap derives from Tartarian kasab 'butcher, flayer', that in a figurative sense means 'murderer'- such a nickname was used by Muscovite Russians with regard to Tartars, but because of the frequent use of this nickname, the Russians themselves were later named in such way by the Tartars (Butkus 2009: 14).

11 "Prie arbatos su Algiu Greitai: šaipymasis iš tradicinių vertybių nemaišo būti konservatoriumi" [Interview with Algis Greitai], published on 09/04/2004. http://www. mountainrock.lt/index.php?subaction $=$ showfull $\&$ id $=1081489540 \&$ archive $=\&$ sta rt_from=\&ucat=2\&, last accessed on 2 March 2012. In addition, see TV broadcasting "Radijo šou moko tarti Žalgirio žaidejo vardą" [Radio show gives lesson to pronounce the name of a player in "Žalgiris"] http://www.youtube.com/watch?v=To4YulNhyUc $\&$ feature=related, last accessed on 2 March 2012.

${ }^{12}$ http://www.hnu.edu/ishs/JournalCenter.htm 
${ }^{13} \mathrm{http} / / / \mathrm{www} \cdot d e l f i . l t / j o k e s / i n d e x . p h p ?$ sdate=\&category=20653\&top=\&search=\&no=685, last accessed on 26 March 2010.

${ }^{14} \mathrm{http} / / / \mathrm{www} \cdot d e l f .1 t / j o k e s /$ index.php?sdate $=\&$ category=20653\&top=\&search $=\& n o=290$, last accessed on 26 March 2010.

${ }^{15} \mathrm{http}: / /$ www.delfi.lt/jokes/index.php?sdate=\&category=20653\&top=\&search=\&no=410, last accessed on 26 March 2010.

${ }^{16} \mathrm{http}: / /$ www.delfi.lt/jokes/index.php?sdate=\&category=20653\&top=\&search $=\&$ no $=480$, last accessed on 26 March 2010.

${ }^{17} \mathrm{http}: / /$ www.delfi.lt/jokes/index.php?sdate=\&category=20653\&top=\&search=\&no=245, last accessed on 26 March 2010.

${ }^{18} \mathrm{http}: / /$ www.delfi.lt/jokes/index.php?sdate=\&category=20653\&top=\&search=\&no=395, last accessed on 26 March 2010.

${ }^{19} \mathrm{http} / / /$ inksmai.lt/index2.php?id=jokes\&jokeid=national\&page=20, last accessed on 2 March 2012

${ }^{20} \mathrm{http} / / / \mathrm{www} \cdot d e l f i .1 t / j o k e s / i n d e x \cdot p h p ? \mathrm{sdate}=\&$ category $=20653 \&$ top $=\& \operatorname{search}=\&$ no $=290$, last accessed on 26 March 2010.

${ }^{21} \mathrm{http}: / /$ www.delfi.lt/jokes/index.php?sdate=\&category=20653\&top=\&search=\&no=60, last accessed on 26 March 2010.

${ }^{22} \mathrm{http} / / / \mathrm{www} \cdot d e l f i . l t / j o k e s / i n d e x \cdot p h p ? \mathrm{sdate}=\&$ category $=20653 \&$ top $=\& \operatorname{search}=\&$ no $=300$, last accessed on 26 March 2010.

${ }^{23} \mathrm{http}: / /$ www.delfi.lt/jokes/index.php?sdate=\&category=20653\&top=\&search=\&no=335, last accessed on 26 March 2010.

${ }^{24} \mathrm{http} / / / \mathrm{www} \cdot d e l f i .1 t / j o k e s / i n d e x \cdot p h p ? \mathrm{sdate}=\&$ category $=20653 \&$ top $=\& \operatorname{search}=\& n o=460$, last accessed on 26 March 2010.

${ }^{25} \mathrm{http} / / / \mathrm{www} \cdot d e l f i . l t / j o k e s / i n d e x . p h p ? \mathrm{sdate}=\&$ category $=20653 \&$ top $=\& \operatorname{search}=\&$ no $=45$, last accessed on 26 March 2010.

${ }^{26} \mathrm{http}: / /$ www.delfi.lt/jokes/index.php?sdate $=\&$ category $=20653 \&$ top $=\& \operatorname{search}=\&$ no $=50$, last accessed on 26 March 2010.

${ }^{27} \mathrm{http} / / / \mathrm{www} \cdot$ delfi.lt/jokes/index.php?sdate=\&category=20653\&top=\&search $=\& n o=220$, last accessed on 26 March 2010.

${ }^{28} \mathrm{http}: / /$ www.delfi.lt/jokes/index.php?sdate=\&category=20653\&top=\&search=\&no=305, last accessed on 26 March 2010. 


\section{REFERENCES}

Anglickienè, Laima 2005. Etnonimų vartojimo lietuvių kalboje ir folklore ypatumai. [The Peculiarities of the Usage of Ethnonyms in Lithuanian Language and Folklore.] Vārds un tā pētīšanas aspekti: Rakstu krājums 9. Liepaja: LiePA.

Bakhtin, Mikhail 1990. Tvorchestvo Fransua Rable i narodnaia kul'tura srednevekov'ia $i$ Renessansa. [The Art of Francois Rabelais and Folk Culture of the Middle Ages and Renaissance.] Moscow: Khudozhestvennaia literatura.

Bergson, Henri 1900. Le rire, Essai sur la signification du comique. Paris.

Bončkutè, Monika 2008. Drąsus įvaizdis Lietuvos: nei kalbos, nei klausos. [Brave Image of Lithuanian: neither language nor hearing.] http://www.lrytas.lt/12016690571200894327-p2-dr\%C4\%85sus-\%C4\%AFvaizdis-lietuvos-nei-kalbosnei-klausos.htm, last accessed on 29 February 2012.

Brzozowska, Dorota 2009. Polish Jokelore in the Period of Transition. In: A. Krikmann \& L. Laineste (eds.) Permitted Laughter: Socialist, Post-Socialist and NeverSocialist Humour. Tartu: ELM Scholarly Press.

Butkus, Alvydas 2007. Lietuva ir Latvija: laikas atsisakyti senųjų stereotipų. [Lithuania and Latvia: it is time to reject old stereotypes.] http://www.delfi.lt/news/ringas/ lit/article.php?id=15043656, last accessed on 29 February 2012.

Butkus, Alvydas 2009. Nominacija ir identitetas: habilitacijos procedūrai teikiamų mokslo darbu apžvalga. [Nomination and Identity: a review of scientific articles.] Kaunas: VDU.

Delanty, Gerard 2002. Europos išradimas: idejja, tapatumas, realybė. [Inventing Europe: Idea, Identity, Reality.] Transl. from English by Almantas Samavičius. Vilnius: Lietuvos rašytojų sajungos leidykla.

Hobsbawm, Eric J. 1990. Nations and Nationalism since 1780: Programme, Myth, Reality. Cambridge: Cambridge University.

Image of country 2009. Šalies įvaizdis kuriamas be aiškių gairių. [Image of Country Is Created without Clear Guideline.] http://www.civis.lt/salies-ivaizdis-kuriamasbe-aiskiu-gairiu-9604.html, last accessed on 29 February 2012.

Karaliūnas, Simas 1999. Etnonimo gudai kilmè: Iš baltų-germanų ir baltų-slavų praeities kontaktų. [The Origin of the Ethnonym Gudai: on Some Aspects of the Contacts between Baltic and Germanic as well as Baltic and Slavic in the Past.] Darbai ir dienos [Works and Days], Vol. 10, No. 19. Kaunas: VDU leidykla.

Krikmann, Arvo 2009. Finnic and Baltic Nationalities as Ethnic Targets in Contemporary Russian Jokes. In: A. Krikmann \& L. Laineste (eds.) Permitted Laughter: Socialist, Post-Socialist and Never-Socialist Humour. Tartu: ELM Scholarly Press, pp. 73-98.

Laineste, Liisi 2008. Politics of Joking: Ethnic Jokes and their Targets in Estonia (1890s2007). Folklore: Electronic Journal of Folklore, Vol. 40, pp. 117-146.

Smith, Anthony D. 1994. Nacionalizmas XX amžiuje. [Nationalism in the Twentieth Century.] Transl. from English by Algirdas Degutis. Vilnius: Pradai.

Tismaneanu, Vladimir 2003. Išsivadavimo fantazijos: pokomunistinès Europos mitai, demokratija ir nacionalizmas. [Fantasies of Salvation: Democracy, Nationalism, and Myth in Post-Communist Europe.] Transl. from English by Giedrè Baltrūnienè. Vilnius: Mintis. 
VDU ER - Archive of the Department of Ethnology and Folklore at Vytautas Magnus University, Kaunas, Lithuania.

Zavjalova, Marija \& Anglickienè, Laima 2005. Stereotip poliaka glazami litovtsev. Etnolingwistyka: problemy języka $i$ kultury. [Polish Stereotypes in the Eyes of Lithuanians. Ethno-linguistic Problems of Language and Culture.] Lublin: Wydawnictwo Uniwersytetu Marii Curie-Skłodowskiej.

Zemkauskas, Rytis 2008. Drąsi šalis. [Brave country.] http://www.alfa.lt/ straipsnis/180098/?Drasi.salis=2008-04-17, last accessed on 29 February 2012. 


\title{
"YOU'VE LIVED IN X TOO LONG, WHEN...": A VIEW OF THE WORLD THROUGH COMIC LISTS (EXPATRIATES' HUMOUR ON RU.NET)
}

\author{
Maria Yelenevskaya
}

\begin{abstract}
This article discusses social antecedents, patterns of reproduction and innovation, and the communicative function of the comic lists which use the pattern "You've lived in X too long, when..." Originally borrowed from the English-language web sites, the idea of describing peculiarities of life in different countries has become popular on Ru.net among Russian-speaking expatriates and residents of Russia. The comic list format serves as a convenient template for individual or collaborative portrayal of those features of various countries that seem strange or weird to outsiders. While teasing the ways and habits of the other, writers of the lists reflect about their own culture, revealing ambivalent attitudes and a conflict of allegiances. Collaborative creation of the lists and heated discussions of their content point to the interactive nature of Internet folklore. Moreover, the users' comments indicate that the lists do not only serve for entertainment, but are valued as a source of information about the world outside the country of origin.
\end{abstract}

Key words: computer-mediated communication, humour of expatriates, identity, Ru.net, self-reflection

\section{INTRODUCTION}

Without fearing to sound old-fashioned or "out of paradigm" Arvo Krikmann, a tireless investigator of folk culture, appeals to folklorists to archive and number jokes: joke indices are essential tools for researchers because our knowledge of how individual jokes and joke patterns are born and evolve, how they travel and what factors contribute to their dissemination is still fragmentary (Krikmann 2009). The nature of fieldwork undertaken by collectors of jokelore has undergone considerable changes in the last decade since much of the humour exchange today occurs in computer-mediated communication (CMC) and requires archiving of material posted on humour portals and in live journals, in chat groups and discussion forums. Humour can be also found on the sites of companies and agencies using it as a gimmick (Alekseevskii 2009b: 152), and humourous messages in text, video and audio formats are circulated in viral 
e-mail messages. Like in the pre-Internet era, Internet humour appears in cycles, and the goal of this essay is to present distinctive features of the cycle of Ru.net humour "You have lived in $\mathbf{X}$ too long, when..." tracing its social antecedents, patterns of reproduction and innovation, and the communicative function.

\section{COMIC LISTS AS A SUB-GENRE OF VERBAL HUMOUR}

Comic lists came to be investigated by folklorists on the basis of English-language material in the 1970s as a subgenre of office folklore that became popular thanks to the spread of fax machines and photocopiers (Dundes 1983; Dundes \& Pagter 1987). This subgenre is represented by lists of definitions and instructions, rules and recommendations, specific features of various groups, objects and phenomena, and so on. Its precursors can be found in the literary tradition, one of the better known examples being the Devil's Dictionary by Ambrose Bierce (1967). Alan Dundes and Carl R. Pagter indicate that some of the popular lists currently circulating in the USA have items that were popular back in the 1930s and 1940s (Dundes \& Pagter 1987: 26). Comic lists are topical and cover a vast diversity of subjects. Like jokes, they mirror folk attitudes to such "eternal" issues as gender relations, social hierarchies and cultural conventions (see, e.g., Dundes \& Pagter 1987: 17, 29-31). Some of the lists reflect social conflicts and inter-group struggle for power. In fact, the popularity of office folklore was primarily analysed by American folklorists as an expression of the employees' protest against a depersonalised corporate environment (see, e.g., Preston 1994, and Roemer 1994). Finally, comic lists are compiled in response to political events, as exemplified by "War in Iraq Humour", which includes such lists as "Top 10 Things That Will Get You Kicked out of Iraq", “Top 10 Things Iraq's Information Minister Has to Say about the War", “Top 10 Saddam Hussein's Tips for a Romantic Evening", etc. http://politicalhumor.about.com/ od/iraq/Iraq_Jokes_and_Iraq_War_Humor.htm, 10/02/2010. ${ }^{1}$ The Internet has given comic lists a new lease on life. In her classification of the Internet humour, Limor Shifman found them to be among the four most popular "old" types of humour, whose dissemination has accelerated since it is no longer dependent on the use of office-based equipment (Shifman 2007: 196).

Research into Soviet and post-Soviet humour seldom, if ever, refers to comic lists. And no wonder. Unlike the officially sponsored and "ideologically correct" lore, popular jokelore in the Soviet period was subversive for the system, and was disseminated orally. When photocopiers and fax machines appeared in Soviet offices they were carefully guarded and inaccessible to rank-and-file 
employees for fear the new equipment would be used for disseminating unwanted information. This does not mean that the subgenre of comic lists did not exist at all as these would be compiled and read aloud in skit shows, at birthday parties, student performances and in $K V N^{2}$ contests. Being too long for oral dissemination, many of the lists were familiar only to narrow circles of the intelligentsia and remained in private archives. This subgenre remained on the periphery of Russian jokelore until the advent of the Internet, which gave a boost to the popularity of longer humourous texts, such as amusing personal experience stories (baiki), parodies of poetry and jocular quizzes (Lutovinova 2009; Yelenevskaya 2008). Today a random search on Yandex yields thousands of pages that offer comic lists starting with the following words

- 10 signs of/that ...

- 10 commandments of ...

- 10 characteristic features of...

Since the opening words are neutral, comic lists in the search results alternate with serious ones, including professional advice, business recommendations and religious discussions (for example, "10 signs of a true Christian".) Most comic lists are tagged as prikoly (conversational Russian for 'jokes and pranks') and deal with diverse issues, not differing from those that are covered in internationally popular jokes. Ethnic humour is presented on such lists as "10 characteristic features of an average" American, Russian, Israeli, etc., which reprocess familiar stereotypes. The lists discussed in this article also deal with ethnic, or rather national stereotypes as viewed through the eyes of expatriates.

\section{HUMOUR OF THE RUSSIAN DIASPORA}

The first post-Soviet decade was marked by mass emigration from the countries of the former Soviet Union (FSU). Wherever sizeable numbers of Russian speakers settled they established their own newspapers and magazines. Whether in Australia or Finland, Germany or Greece, Israel or the U.S.A., these editions included humour columns, which reprocessed old Soviet jokes, reprinted humour from the Russian media and translated into Russian popular jokes of the host country. In addition, editors encouraged readers to send their own contributions dealing with amusing experiences in the new countries. With the growing popularity of Ru.net the bulk of émigré humour migrated to the net (Gorny 2009; Yelenevskaya 2009).

Since humour is among the most important mechanisms that help people overcome psychological and social stress confronting us in everyday life (Lefcourt \& Martin 1986: 1) it is particularly important in the life of migrants. Hardly any 
émigrés from the FSU, even those who moved to a new country on a repatriate ticket, were immune to a culture shock. The lack of language proficiency (most Russian speakers among ex-Soviets were monolinguals), confrontation with unfamiliar customs, the loss of social network, and, finally, hostile attitudes to newcomers on the part of some members of the receiving society - these stress factors called for the mobilisation of intra-group solidarity. Humour also proved to be a useful tool in the interpretation of common past and establishment of the group's position vis-á-vis the host society. It simplified cultural adjustment and secondary socialisation (see Protassova 2006; Yelenevskaya 2009; Zilberg 1995).

\section{BETWEEN GLOBALISATION AND GLOCALISATION}

Like many other products of post-Soviet media and mass culture, "You've lived in $\mathbf{X}$ too long, when..." lists were borrowed from the U.S.A. In the pre-Internet period they appeared in American newspapers and magazines presenting ironic and amusing reflections of expatriates on various cultures as viewed by travelling Americans ${ }^{3}$.

Since in the Soviet times foreign travel was restricted, life outside the USSR and images of ethnicities inhabiting other countries appeared mainly in international jokes, displaying ethno-stereotypes shared by many cultures. These were familiar to Soviet people primarily from literature, movies and the media. The choice of characters featuring in these jokes was also limited, primarily confronting traditional Russian values, habits and behavioural patterns with those presumed to be stereotypically American, English, French and German. ${ }^{4}$ Notably, in the Soviet jokes in which representatives of different nations find themselves in unusual situations or compete against each other, Russians do not necessarily emerge as endowed with moral virtues or winners. Rather, their self-image is critical, exposing laziness, indifference to success, excessive drinking, disrespect for law, and unruliness (Shmeleva \& Shmelev 2002: 75-82). In most cases the setting of these jokes was some vague no-man's land or the Soviet territory, where foreigners had to grapple with much-derided peculiarities of Soviet life. Humour about "ours" in alien lands was scarce, and either related to the Jewish emigration, or to the blunders made by those who were trusted by the authorities to travel to the West. Opening of the borders and mass emigration of the 1990s made the theme of "ours abroad" much more visible in the Russian jokelore of the post-Soviet period.

The lists "You've lived in $\mathbf{X}$ too long, when..." provide a convenient template for individuals and groups to create a portrait of a foreign land, its people and customs describing the unfamiliar nature and climate and those features of society that seem strikingly odd, irrational, weird or bizarre to a newcomer. 
My search on Yandex yielded lists about 40 countries on all the continents. ${ }^{5}$ Of these 32 are devoted to the countries of the so called "far abroad" and 8 to the "near abroad" (countries of the FSU). Since the latter group does not deal with the émigré culture, but is driven by the changes in the life of the newly formed states, these lists were not included in the analysed sample. Material for the study of the lists on the "far abroad" was drawn from 150 sites which included humour hubs, such as anekdot.ru, discussion forums, blogs and pages of commercial companies, primarily travel agencies. Content analysis was applied in order to outline dominant themes and motifs, and text analysis was used in order to check stability of the texts and/or their innovation patterns.

On the one hand, the diversity of countries ironically discussed in the format of comic lists gives a glimpse of the vastness of the geography of the Russianspeaking world today; on the other hand, it would be misleading to link the existence or absence of some country on these lists to the activity of Russianspeaking communities. ${ }^{6}$ Thus, there are three lists on Malaysia, which appear on Ru.net primarily on the sites providing information for tourists, but not a single one on New Zealand, although its Russian-speaking residents are active in Internet forums, ${ }^{7}$ and so on. Two lists in my sample, on Australia and Denmark, appear only once, others, like those on Germany, Italy, Norway, Spain, and the USA keep travelling from site to site as single posts or in combination with lists on other countries, with readers' comments or without. The shortest list in the sample is on Sweden: it consists of just six items, and the longest one is on the UK numbering 204 items. Some sites demonstrate collaborative creation of the lists. A case in point is the rubric "Your Opinion" of the humour hub Anekdot. $r u$ in which various participants contributed observations about America and other countries under assumed Internet names (nicknames or simply nicks) (see, discussion about the creation of the lists at http://gb.anekdot.ru/scripts/gb .php? component $=$ gb\&id $=1 \&$ fu $=0 \&$ sort $=0 \&$ date $=2000-03-17,15 / 05 / 2009)$. The peak of circulation of the lists about various countries on $R$ u.net fell during the years 2003-2006, but new posts keep popping up. The latest lists in my sample were uploaded in March 2010.

The authorship of most lists is not acknowledged, nor is the original source mentioned. In fact, because of the instability of many sites, it may not be easy or possible to trace some of them. Some users introduce or conclude their posts with the following: "just found this in the vast space of the net", "borrowed from others", "[I'm] posting a bayan" (bayan is a kind of accordion which in Russian Internet slang is used pejoratively to denote a stale joke ${ }^{9}$ ). Other posters give links to the sites where they found the list they copy, or give the nickname of the blogger who posted it earlier. Mentioning of real names of the authors is exceptional. Thus some items of the American list were contributed by Dmitrii 
Verner, an astrophysicist and the creator of Anekdot.ru. (http://www.vmizm. net/if.html, 15/03/2010), but on most sites posting the American list neither his name, nor the nicknames of other contributors are mentioned. The most frequently posted Israeli list also appears anonymously although it was written by the St. Petersburg writer and playwright, Igor Gindin shortly after immigration (Gindin 2003). ${ }^{10}$ The Serbian list was created by Irina Antanasievich (http:// iraan.livejournal.com/24279.html, posted on 15/07/05, accessed on 16/03/2010) ${ }^{11}$, and Daria Kirienko wrote a list on Malaysia entitling it "Fairytales about Malaysia" and posted it in her blog on 20/04/2007 at http://upita.livejournal. com/27037.html. Two years later she updated it (http://community.livejournal. com/inostranki/793780.html, accessed on 10/03/2010), and this later version was copied to other sites. There is a good chance that like other popular lists it will finally "lose signature" and will continue its Internet journey anonymously. These metamorphoses of Internet humour: authored $\rightarrow$ anonymous $\rightarrow$ appropriated by another author, as well as the shuttling of the humourous texts between the net, the mass media and oral lore occur in different genres as demonstrated in Mikhail Alekseevskii 2009a and 2010.

Some lists overlap. Thus, the Canadian list recycles what was earlier written about America, and the lists on Latvia/Riga and Lithuania are almost identical (see, e.g., http://www.meeting.lv/guides/event.php?id=7B59ss154, posted on 05/11/2001, http://forum.umora.biz/index.php?act=Print\&client=pri nter\&f=35\&t=2006, posted in June-July 2007, http://www.imho.ws/showthread. php?t=50222, posted on 05/02/2004, all three sites accessed on 29/03/2010.) Similar overlaps are characteristic of lists in English, with the Finnish, Norwegian and Swedish lists to a large extent mirroring each other. These overlaps testify once again that cultures in contact may seem similar to more distant others, who tend to generalise and miss the subtleties familiar to the insiders or members of the cultures in contact.

"Copy-paste" versions of the lists alternate with edited or updated texts in which the posters either choose only those items that they consider particularly apt for describing the host country, or change the wording, or add new items. A case in point is the Israeli list which appears on some sites in modified versions with added items mocking economic and social problems confronting émigrés at a later stage of the integration process and reflecting better familiarity of the writers with socio-political and interethnic problems of the host country (http:// opredelitel.narod.ru/israel.htm, http://danisimus.livejournal.com/109412.html, posted on 13/08/2009, both sites accessed on 17/03/2010). The German, Irish, Spanish, Dutch and some other lists also exist in several versions. Random comparisons with lists, posted on various countries in Google, in English show that some of the items on Russian lists may have been merely translated; some 
others borrowed the idea adapting it to the country described. A case in point is twin items about names. On the forum of American expatriates in Moscow we find an item implying how expatriates' social networks change and at the same time teasing about what is seen as addiction to prototypical local names: "You've lived in Russia for too long when... you know more than 60 Olgas" (http://expat.ru/forum/showthread.php?t=9000, posted on 31/05/2004, accessed on 05/03/2010). In the numerous identical posts of the Russian list about Norway the same idea is expressed in an even more exaggerated fashion: "when... you know 50 Mortons, 40 Tronds and 30 Chelgas", see e.g., http://www.averkiev.com/ forum/showthread.php?t=3974, posted by Gulya E' on 21/01/2005, accessed on 01/06/2009). One of the lists on Malaysia gives the borrowed item an additional touch pointing to the multi-ethnic nature of the host society "when ...among your acquaintances there are five Chans (men and women), ten Mohammeds (men) and five Indian girls named Jaeah" (http://community.livejournal.com/ inostranki/793780.html, posted on 08/04/2009, accessed on 10/03/2010). These repetitions and borrowings notwithstanding, most observations on the Russian lists still differ from those made by expatriates from other countries. Even when creators of the list dedicated to a particular country observe the same phenomena often reproducing pervasive internationally known stereotypes, the writers use the norms and customs of their own society and culture as the basis for comparison. ${ }^{12}$ These norms form an implicit antithesis with the items included in comic lists "You've lived in $\mathbf{X}$ too long, when..."

\section{OBSERVING OTHERS, REFLECTING ABOUT THE SELF}

Infatuation with travelling is one of the hallmarks of our time. When tourists come to a new country they search for the unusual and exotic and often end up seeing the attractive façade without getting but a glimpse of the real life of the country they are visiting. By contrast, migrants get into the very midst of reality, so to say, its backyard, where one has to cope with the mundane, be it everyday food habits, sanitary norms, or relations with neighbours. At the same time, the longer and closer the contacts the better one gets to know social conventions, shared values and cultural tastes of the host society, whether they are openly stated and demonstrated or remain obscure to outsiders. To analyse dominant themes and motifs, items that appeared on the lists devoted to at least three different countries were divided into 14 categories: nature and climate, language use, eating and drinking habits, recreational activities, dress code and styles, etiquette and forms of politeness, conventions of social time, interpersonal relations and communication styles, inter-ethnic relations, culture 
maintenance, respect for law and rules, political culture, national pride, and attitudes to the environment. Some of the items can be classified as belonging to more than one category. Thus, items about food consumption can contain observations about eating habits and also maintenance of culture. At the same time, they often give a glimpse of the difference in the conventions of social time at home and in host countries. Items about language use are combined with observations about norms of politeness, communication styles and maintenance of culture. Ironic descriptions of dress codes point to differences in tastes and the etiquette; in addition they are linked to the management of life in different climates, and so on. Due to volume-wise limitation, I'll now focus on three of the listed categories to demonstrate how they are developed and what they reveal about contemporary Russian perception of other cultures.

\section{Eat to live or live to eat?}

Items devoted to food and drink appear on every list, as if to testify again that this feature of material culture is not only among the most accessible ones for observation, but is also meaningful for comparing different life styles. Globalisation has done little to change Russian culinary tastes. The popularity of imported western products, when they entered the Russian market did not last long. In every country with a sizeable Russian-speaking community, food stores selling traditional Russian food and delicacies are among the foremost successful businesses. The comic lists clearly show émigrés' loyalty to familiar tastes:

- Your eating habits no longer cause surprise or trigger exclamations Y-a-a-ack! What's that? (UK)

- You've stopped complaining and finally discovered all the necessary ingredients for pilaf, borsch and herring-in-a-fur coat [a vegetable salad with herring]. (Malaysia)

- You know where to buy leaven, semolina and poppy seeds... and also sprats, buckwheat and good vodka. (France)

Although none of the foods mentioned above speak of luxury, ironic descriptions of favourite local foods are presented as dominated either by those products that are either too tasteless or too spicy, or associated with the menu of the poor in Russia:

- You distinguish 20 sorts of sauerkraut by taste and you can use it in 20 different dishes. (Austria) 
- You know what the "day of the new herring is" and you also know that herring is the only Dutch delicacy worthy of attention. (the Netherlands)

- You stopped referring to "pasta" as "macaroni" [used in everyday Russian as generic for various types of pasta] and you know over ten different types of pasta. (Italy)

The farther apart is the Fatherland and the host country geographically and culturally, the more items about strange and suspiciously looking, tasting and smelling foods we find on the comic lists. Tasting what is considered inedible is akin to breaking a taboo and is viewed as a small act of defiance:

- You eat raw mushrooms in salads and it no longer amazes you. (UK)

- You can eat shewarma without fearing to find a little dog's tail in it. (United Arab Emirates)

- You believe that an egg that was kept in warm temperature for a fortnight is much tastier than a fresh one. (China)

Two other motifs that appear on the analysed lists are worthy of attention because they touch upon two trends characteristic of food consumption of our contemporaries. One is obsession with low-calorie foods that are in vogue in affluent Western countries:

- You do your shopping in fat-free-food stores but you can spend 30 minutes driving all around a parking lot in search of the slot that is one minute closer to the store. (USA)

Émigrés of the 1990s still remember food shortages at home and perceive preoccupation with "healthy foods" as whimsical, in particular when it is not combined with other attributes of a healthy life style, most often viewed as walking long distances on foot. Driving anywhere, including to a fitness room around the corner, is derided in many lists.

Another trend is globalisation of food habits:

- A good Friday is the Friday when you have a good portion of Indian curry, the spicier the better, and drink a couple of pints of beer with it. (UK)

Austrians who consider Hungarian gulash and Italian pizza their national dishes, Germans and Spaniards who do not even try to eat with chopsticks in Chinese restaurants, and the Chinese who have perfected the art of eating bread 
with chopsticks - all these ironic remarks bring up the topic of globalisation which is still perceived as a novelty by émigrés from Russia, although today in big Russian cities one can find restaurants offering ethnic foods from various corners of the world.

In his seminal book, on ethnic humour around the world, Christie Davies remarks that differences in eating habits are an easy target for deriding the other because they mark visible and fundamental differences in everyday behaviour. They serve to express superiority over the group at whose expense people laugh, preserve boundaries between groups and classes, and warn against breaking taboos (Davies 1990: 276-306). All these motifs are found on the studied lists and suggest that humourous observations about eating habits of the other in most cases have social undertones.

\section{All in good time?}

Temporality plays an important part in making sense of a new environment. Since time is a social construct, when immersed in it people experience the influence of a multitude of times permeating their daily life (Adam 1995: 12) in the ways different from what is familiar to them. Depending on the geographic position and the climate, the day is divided differently in various parts of the world, and different hours are allocated to work and leisure. Thus, in the hot Mediterranean climate work starts early, but there is a break in the afternoon and a lull in activities in the hottest afternoon hours, which makes it difficult for newcomers to adjust to opening hours of various institutions:

- You finally managed to learn opening hours of shops, banks, post offices, state institutions and restaurants. (Italy)

In addition, there are no strictly fixed times for meals in Russia, and respect for keeping their schedule in other countries is perceived as an oddity:

- People who call to discuss business issues from 14 to 16 make you furious, as they disturb your digestion. A war may be waged, but lunch is to be eaten as scheduled. (Spain)

Migrants who settle down in the countries that do not live according to the Julian calendar have an additional difficulty of getting used to a different temporality mediating individual lives and most societal interaction (Mills 2000: 104). This motif emerges on the lists compiled by new Israelis and residents of Muslim countries where religious institutions and religious rituals have a major impact on everyday life of all the residents, even if they are secular and belong to other confessions: 
- You've learned that a week starts on Sunday, a day in the evening, and a year in September, but each time on a different date. (Israel)

- Once a year for a month you have to hide when you eat or smoke. (Dubai)

The last item may puzzle those who are unfamiliar with Ramadan, the sacred period for the Muslims. This is the ninth month of the Islamic calendar, when observant people refrain from eating, drinking, smoking and having sex from dawn until sunset. ${ }^{13}$ Like many other items linked to traditions and customs of the host country, this one implies that even when newcomers do not identify with traditions of their hosts, they try not to alienate them, and if they choose to violate them, they do so surreptitiously. In many respects, traditions in Christian countries are closer to those in Russia. Even in the Soviet period of militant atheism many of the Soviet holidays borrowed rites and rituals from the Russian Orthodox tradition. Yet even in Christian countries it is not easy for migrants to get used to local holidays, be they religious or secular. Holidays are landmarks in the calendar and their observance is linked to shared memory. They form an essential element of individual and group identity and for this reason different dates and different rituals associated with them are mentioned on many lists:

- Among your favourite holidays is the Queen's birthday (although you don't know of which one), Labour Day, races in Melbourne and the inglorious death of a quarter of male population of Australia at the walls of some Turkish fortress. (Australia)

- You start preparing for Christmas in October... which, naturally will be BEFORE the New Year. (Germany)

- Your children know what St. Martin's Day is, but your wife is unfamiliar with the 8th of March. (Germany)

- Celebrating the New Year in the middle of summer is as natural for you as having dinner after 10 or whistling in public places. (Argentina)

Authors of several lists ironically observe that holidays, that were much loved and joyfully celebrated back home, are ousted from their lives by new ones that are not properly understood and do not stir up festive feelings. The lists show once again that the New Year still remains the most loved holiday for ex-Soviets (Fialkova \& Yelenevskaya 2007: 276-277), but in the absence of snow, and without the traditional fir-tree and the exchange of gifts, it loses much of its 
charm. Some of the lists also reflect upon the commercialisation of Christmas, and the wave of consumerism preceding it.

Another motif linked to conventions of social time has to do with different communication styles and basic etiquette. It is well known that friendship is one of the key concepts of Russian culture (Shmelev 2005; Wierzbicka 2002). For many Russian speakers, friends are no less important than family. It is considered to be a virtue to give up whatever you are doing in order to help a friend in need, and spontaneity, such as dropping by at a friend's place unannounced is perceived as a token of closeness rather than impoliteness. Confronted with the people who plan their social life and guard specific hours and days for the self and family, Russians experience ambivalent feelings: on the one hand, these conventions seem too regimented; on the other hand their advantages are too obvious not to be admitted:

- You try to fix the date when you come to visit your friends at least a month beforehand, and darn it, you find it convenient. (Denmark)

- You believe calling your friends after 9 p.m. or on Sunday is comparable with working in your garden on Sunday and deserves severe criticism. (Switzerland)

The two examples above illustrate the difference in the handling of time by what can be called in Edward T. Hall's terms monochronic and polychronic cultures. The former is characteristic of low-involvement people, who compartmentalise time, and the latter appeals to those, who are more involved and tend to be engaged in several operations simultaneously (Hall 1981: 153-155). Lynn Visson, who studied mixed Russian-American marriages, noted that Russians are very flexible in their handling of things planned, and that being late seems to be part of the Russian makeup (Visson 2001: 142-145). Many of the analysed lists deal with punctuality, and show that this may be changing in post-Soviet Russia. In the attitude, if not in performance, respect for punctuality prevails. There are only two teasing remarks about precision in time turned into a cult:

- You apologise for being 30 seconds late. (Switzerland)

- You are angry if the bus arrives at 12:39 instead of 12:37. (Norway) On the contrary, a careless attitude to schedules and failure to keep promises to do things or deliver services on time are numerous:

- $\quad$ One cannot be late for an appointment with you, because you will come later than your partner anyway. (Argentina) 
- When told that something will be done on Wednesday, note that you should call on Friday to ask when it is ready. (Ireland)

- When you hear that some business will be finished tomorrow morning, you don't bother checking for at least a week or a month. (Cyprus)

- Leaving for an appointment you say, "I'll be there in five minutes." Arriving one and a half hours later you say, "F*cking traffic!!!" (United Arab Emirates)

The lists examined reveal once again that the practical problems of time management constitute many a dilemma when representatives of different cultures interact in everyday life. Thomas Luckmann observes that the inner time of those who live and act together must be reciprocally adjusted (1991: 156). When participants of these interactions have internalised different conventions of time management such adjustment is problematic and the emerging conflict of betrayed expectations gives grounds for mutual derision.

\section{It takes all sorts to make a world}

Whether they settle in the countries whose policies are guided by ethnic nationalism or in countries proclaiming political ideals of multiculturalism, migrants often experience suspicion and hostility on the part of the host society. Ex-Soviets are no exception, which makes them alert to the attitudes of the receiving societies to members of their own group and other minorities.

- You believe that a Romanian is an occupation. (Spain)

In many countries migrants occupy specific niches in the job market. Although some of them are highly-skilled workers, they do not feature on the lists and rather one gets the impression that the fate of migrants is to be engaged in hard manual labour or to work in service industries. Indeed, the majority of migrants are low-paid, and many of them penetrate affluent Western countries illegally. These people are mercilessly exploited and neglected socially. In common parlance, their ethnonyms come to signify their occupations. A case in point is Spain, where Romanian males are primarily employed in construction; another example is Israel, where a "Filipina" came to denote a female or male nurse taking care of the elderly.

Some lists point to migrants' ghettoisation in cities that appear to be divided into "white" and "coloured" areas. They ironically admit that the desirable neighbourhoods, testifying to socio-economic success of the residents, remain an elusive dream for newcomers, including ex-Soviets: 
- In the back of your mind you note that if there is no white person left in the subway car, you are more than five stops away from the town centre. (Sweden)

- You and your neighbours, Kong, Mansour, Janis, Salem, Noori and Jiao, consider your neighbourhood to be primarily white and European, while all migrants live in some other area of Sydney. (Australia)

Some items imply that immigrant groups are distinguished by various types of deviant behaviour, be it filling residential areas with stinking garbage, endangering others by careless driving, or having an addiction to drinking and drugs. Moreover, they are blamed for any deterioration in the life of the host society:

- You easily distinguish between the odour of Surinamese and Indonesian marijuana. (the Netherlands)

- You believe every drunkard to be Polish. (Italy)

- You put the blame for all your misfortunes on illegal immigrants from Albania ... Having read this text you are convinced it is sabotage on the part of illegal immigrants from Albania. (Greece)

Interethnic conflicts, economic hardships and increased migration in the territory of the FSU have had a significant impact on the mentality of post-Soviet individuals breeding intolerance of ethic others. Some lists reveal scornful attitudes to ideals of multiculturalism and political correctness in interethnic relations viewing them as hypocritical or absurd:

- You are crazy about all Negroes but you hate every single one in particular. You are not a racist, you don't like racists but you are convinced that Negroes cannot rule the country. (South Africa)

- You refuse to watch "War and Peace" because there is not a single Negro in it, and you are against racism. (USA)

- You feel great sympathy for Chechen black-asses and discuss this with everyone but you hate all Arabs and will never spend a cent on them because they are gradually settling all over France. (France)

Note that none of the lists use the words "Afro-Americans" or "blacks" but only "negroes", although the writers in the lists are unlikely to be unaware of its stigmatising connotations. We also come across scornful folklore-related phraseology and pejorative nicknames like "indo-paki" for Indians and Paki- 
stanis and "black asses" which in contemporary Russian labels a wide variety of ethnic groups, ranging from residents of the Caucasus to Central Asians and Palestinians (see Fialkova \& Yelenevskaya 2007: 94-97, 106).

Although rarely, some list writers explicitly reflect about intolerance of one's own group, mocking alienation not only from various others, but even from the co-ethnics:

- You are not surprised that when all of a sudden your wife switches over to Spanish in supermarkados it means that your former compatriots are nearby.

- You curse Czechs for being dumb and Russians for showing off; you hate Germans, Slovaks, Ukrainians... in fact, in terms of hatred and misanthropy you are becoming a true cosmopolitan. (Czech Republic)

\section{AMBIVALENCES OF DIASPORIC LIVES}

Russian lists "You've lived in $\mathbf{X}$ too long, when..." pose the question about their lasting popularity. What makes Internet users create new items on the known lists and add their own? Why are there heated discussions about them in forums and why are they unanimously placed in the rubrics "humour" and "pranks"? Some of the lists are too sketchy; others are excessively long and contain items that are either lexico-semantic doubles or contradict each other. Their compilers seldom use a play on words or exploit the satirical potential of bilingualism and biculturalism that would seem natural for humour juxtaposing cultures. While some contributions are sharp in their perception of host cultures and reflections about the self, others add details that give but a superficial picture of the country portrayed, lacking originality and relying primarily on over-exploited stereotyping. One possible answer lies in that, like other forms of Internet folklore, they a means of self realisation (Kõiva \& Vesik 2009: 100) and help contributors sort out their experiences. Secondly, they foster solidarity among co-ethnics, irrespective of where they live. While piling up details, some of them disparaging their host countries, others teasing members of their own group, compilers of these lists rely on their readers' recognition of those peculiarities of life in their new countries that are different from what they were used to at home. This expectation of shared values and agreement in the perception of the other turns into what Giselinde Kuipers called a "tiny conspiracy" of the joke teller and his audience (Kuipers 2006: 180). This is confirmed by frequent praises that follow lists in forums and blogs: 
- Thanks for a good laugh! This topic is really cool! (http://www.russianparis.com/forum/index.php?topic=3165.0, accessed on 17/04/2010)

- Good girl! You did a great job writing it all up! These things, they also bring me side-splitting laughs or make me angry... (http://blogs. mail.ru/mail/o_dokukova/40EEE0104D05F536.html, accessed on $17 / 04 / 2010)$

- Great! Sounds a bit like Italy too (-) (http://nat--ka.livejournal. com/148057.html, accessed on 17/04/2010)

Readers, living in the country portrayed, offer additions to the lists or contest certain items. Residents of other countries note similarities with their own observations, these being a special source of amusement and seen particularly often in the comments to the lists on Mediterranean countries. Moreover, some "green-horns" and posters unfamiliar with the country described in a particular list ask for explanations, when certain things puzzle them or remain unclear.

The second explanation for the amusement created by these lists is the ambiguity of the insider/outsider position implied by their authors. One of the main dilemmas for immigrants anywhere is preserving or discarding one's identity. And it is precisely this conflict of allegiances within a group as a whole and within individuals that is reflected in the lists. How much do their compilers identify with their host countries and their people? Do they convey the message that adaptation is inevitable, or is it a warning against assimilation? Naturally, this varies from list to list and depends on the degree of the writers' integration, as well as on his/her personal style and tolerance. In some cases, the ambiguity is resolved in the last item of the list which functions like a punch line in jokes:

- You no longer want to go home. (Norway)

- Damn it, despite all of this, you do like this country! (Austria)

- By no means will you go back home! (Czech Republic)

- You curse everyone and everything in France; nevertheless, you don't want to move away anywhere, even to your own historical Motherland. (France)

In the absence of such statements, it is the correlation of statements in which irony is directed at the hosts or at the self that, as well the use of lexemes with positive or negative evaluative sememes, and the use of possessive pronouns "our" or "their" when referring to the host country, that give clues to the writ- 
ers' acceptance of or alienation from the host country. On some lists, however, these indicators are absent and the ambiguity remains unresolved.

Notably, only on two lists in the sample (one version devoted to the USA, and one to the UK) do we find items ridiculing stupidity of the host population as implied by poor knowledge of geography and the habit of following manuals and instructions blindly. It is well known, from the literature on ethnic humour, that the most frequent theme in deriding others is presenting them as stupid, inept and ignorant (see, e.g., Davies 1990: 10-39; Salomon 2007; Zhdanova \& Frukhtmann 2008). The absence of this theme in most lists also suggests blurring of boundaries between the newcomers and the hosts in the perception of the former.

Readers' comments show that they have no trouble resolving identity ambiguities. The positive evaluation of the countries portrayed prevails and is often emphatically expressed: "I also want this...", "Jeez! I also want to live there!!!", "I couldn't tear myself off it....Your life there is so good!"

Heated discussions around the lists show that, besides viewing them as entertainment, many Internet users regard them as a source of information useful for tourists, potential migrants and for those who are just starting their life in a new place:

- We already have a link on the site "You've lived in America too long if", and it is COOL! How much headache, how many embarrassing situations could have been avoided had I read all this simple wisdom BEFORE my first visit to the United Northamerican States! (http:// gb.anekdot.ru/scripts/gb.php?component=gb\&id=1\&page=18\&sort= $0 \&$ date $=2000 \& f u=0$, posted on $17 / 03 / 2000$, accessed on $28 / 06 / 2009$ )

These and similar comments in praise of comic lists confirm that the boundarymarkers between humour and seriousness are not absolute (Billig 2005: 184). The reliance of contemporary globe trotters on what is referred to as "useful advice from all over the world" again proves the persuasive power of humour and its high demand in communication and socialisation.

\section{NOTES}

1 When referring to Internet sources I indicate the dates when I accessed them.

${ }^{2} K V N$ - is the acronym of the Club of the Witty and Resourceful - a popular TV programme that was among the first live shows on Soviet TV.

3 Although I failed to find any references to these lists in scholarly literature, my American informants remembered seeing a variety of these lists, with newspaper readers sending their contributions to the editors. 
4 The vagueness of a Soviet person's image of the world is also reflected in other genres of urban folklore. For example, in his investigation of Russian urban ballads about distant lands, Nekludov shows that while their geographic settings are extremely diverse plots and the characters involved are limited and stereotypical (Nekludov 2008).

5 Some of the lists do not deal with the whole country, but only with one of its provinces or states, e.g., Bavaria in Germany or Texas in the USA. There are also lists on cities, such as New York and Prague, but the items on the "local" lists to a large extent overlap with those on the lists of their corresponding countries. Parallel to this there is a collection on various Russian areas and cities, e.g., "Piter" (diminutive for St. Petersburg), Chukotka, Sakhalin, and so on. There is a popular list on a very special semi-public, semi-private space with a culture of its own - student dorms that made it to the comic lists of this sort. Finally, the same pattern is used on the lists which concentrate on various periods of time trying to capture its characteristic features, e.g., You've lived in the 90-s, or in the 21st century too long, when...

6 This is true about the comic lists dedicated to the FSU, e.g., the only list on Central Asia describes peculiarities of life in Tajikistan, but there is nothing on Kazakhstan, Uzbekistan, or Kyrgyzstan, three other Central Asian countries with large Russianspeaking minority groups.

7 Internet activities of Russian-speaking New Zealanders can be viewed at http://top100. narodnz.co.nz/russian_new_zealand/, 29/03/2010. They include regular news issues, information about immigration and jobs, some business information and the discussion forum "Novyi Zelandets", Russian for a "New Zealander."

8 Unfortunately, I failed to find the dates of these posts, although the thread reconstructing the joint creation of this list appears at http://www.vmizm.net/if.html, 27/03/2010.

9 See the explanation of the possible origins of this slang word at http://lurkmore. $\mathrm{ru} / \% \mathrm{D} 0 \% 91 \% \mathrm{D} 0 \% \mathrm{~B} 0 \% \mathrm{D} 1 \% 8 \mathrm{~F} \% \mathrm{D} 0 \% \mathrm{BD}, 15 / 01 / 2011$. Despite its wide use on the net and in oral communication, the spelling of the word remains unstable: баян, боян, байан.

${ }^{10}$ I. Gindin does not seem to be particularly happy about the swift "folklorisation" of his text (http://igor-gindin.livejournal.com/profile), but he is not the only victim of this pervasive Internet phenomenon, which is not plagiarism, per se, rather careless "copy-paste" anonymity.

${ }^{11}$ First posted in the author's live journal, this list was published in the rubric "Serbia in Russian" of the first periodical in Serbian in Russia in April 2009. See its Internet version at www.balkany.net, 16/03/2009.

12 The only list in the sample which was merely translated from English is on Russia. Although it derides powerlessness of the rank-and file Russian citizen, attachment to drinking and idiosyncrasies of Russian urban life, it remains popular despite the fact that some of its items have become dated (http://netnotes.narod.ru/sbm/text/t34. html, 22/03/2010).

${ }^{13}$ Compare this to the Jewish joke mocking those who violate the rules of Sabbath and the Day of the Atonement: A Christian, employed as a servant by a Jewish family, remarks that on the whole, Jews are nice people despite some funny habits. Once a week they smoke in the toilet, and once a year they even eat there. 


\section{REFERENCES}

Adam, Barbara 1995. Timewatch: The Social Analysis of Time. Cambridge: Polity Press. Alekseevskii, Mikhail 2009a. "Chto mne vodka v letnii znoi...": problemy tekstologii fol'klora v Internete. [What's the Trouble in Drinking Vodka on a Sultry Summer Day...": Textological problems of Investigating Internet Folklore.] Internet and Folklore. Moscow: GRTsF, pp. 71-89.

Alekseevskii, Mikhail 2009b. Internet v fol'klore ili fol'klor v Internete (Sovremennaia fol'kloristika i virtual'naia real'nost') [Internet in Folklore or Folklore on the Internet (Contemporary Folkloristics and Virtual Reality, in Russian).] pp. 151-166, http://mdalekseevsky.narod.ru/alekseevsky-congress.pdf, last accessed on 3 March 2012.

Alekseevskii, Mikhail 2010. Anekdoty ot Zuganova: Fol'klor v politicheskoi bor'be. [Jokes courtesy of Ziuganov: Folklore in Political Struggle.] Antropologicheskii Forum, Vol. 12, pp. 71-89.

Bierce, Ambrose 1967. The Enlarged Devil's Dictionary. Edited by E. J. Hopkins. London: Penguin Books.

Billig, Michael 2005. Laughter and Ridicule: Towards a Social Critique of Humour. London: Sage.

Davies, Christie 1990. Ethnic Humor around the World: A Comparative Analysis. Bloomington \& Indianapolis: Indiana University Press.

Dundes, Alan 1983. Office Folklore. In: Richard M. Dorson (ed.) Handbook of American Folklore. Bloomington: Indiana University Press, pp. 115-120.

Dundes, Alan \& Pagter, Carl R. 1987. When You're up to Your Ass in Alligators: More Urban Folklore from a Paperwork Empire. Detroit: Wayne State University Press.

Fialkova, Larisa \& Yelenevskaya, Maria 2007. Ex-Soviets in Israel: From Personal Narratives to a Collective Portrait. Detroit: Wayne State University Press.

Gindin, Igor 2003. You've Lived in Israel Too Long When... Narod Moi, No. 4 (297), http://www.jew.spb.ru/ami/A297/A297-092.html, last accessed on 3 March 2012.

Gorny, Eugene 2009. More than Humor: Jokes from Russia as a Mirror of Russian Life. In: Gerard Goggin \& Mark McLelland (eds.) Internationalizing Internet Studies: Beyond Anglophone Paradigms. New York \& London: Routledge, pp. 9-95.

Hall, Edward Twitchell 1981. The Silent Language. New York: Anchor Press.

Kõiva, Mare \& Vesik, Liisa 2009. Contemporary Folklore, Internet and Communities at the Beginning of the 21st Century. In: Mare Kõiva (ed.) Media and Folklore. Contemporary Folklore IV. Tartu: ELM Scholarly Press, pp. 97-120.

Krikmann, Arvo 2009. Jokes in Soviet Estonia. Folklore: Electronic Journal of Folklore, Vol. 43, pp. 43-66.

Kuipers, Giselinde 2006. Good Humor, Bad Taste: A Sociology of the Joke. Humor Research 7. The Hague: Mouton de Gruyter.

Lefcourt, Herbert M. \& Martin, Rod A. 1986. Humor and Life Stress: Antidote to Adversity. New York \& Berlin \& Heidelberg \& Tokyo: Springer-Verlag.

Luckmann, Thomas 1991. The Constitution of Human Life in Time. In: J. Bender \& D. Wellbery (eds.) Chronotypes: The Construction of Time. Stanford: Stanford University Press, pp. 151-166. 
Lutovinova, Olga 2009. Baika v virtual'nom fol'klore. [Amusing Personal Experience Stories in Virtual Folklore.] Russkii Yazyk za Rubezhom, Vol. 2, pp. 77-78.

Mills, Melinda 2000. Providing Space for Time: The Impact of Temporality on Life Course Research. Time and Society, Vol. 9, No. 1, pp. 91-127.

Nekludov, Sergei 2008. Russkii gorozhanin poet o dalekikh stranakh: "filoekzoticheskii" sloi gorodskoi ballady. [The Russian City-dweller Sings about Distant Lands: Philo-exotic Layer of the Urban Ballad.] Fol'klor i Post-Fol'klor:struktura, tipologia, semiotika, http://www.ruthenia.ru/folklore/neckludov41.htm, last accessed on 3 March 2012.

Preston, Michael J. 1994. Traditional Humor from the Fax Machine: "All of a Kind". Western Folklore, Vol. 53, No. 2, pp. 147-169.

Protassova, Ekaterina 2006. Iumor v russkoiazychnoi presse Finlandii. [Humour in the Russian-Language Press in Finland.] Diasporas, Vol. 4, pp. 53-70.

Roemer, Danielle M. 1994. Photocopy Lore and the Naturalization of the Corporate Body. The Journal of American Folklore, Vol. 107, No. 423, pp. 121-138.

Salomon, Hagar 2007. The Ambivalence over the Levantinization of Israel: "David Levi" jokes. Humor, Vol. 20, No. 4, pp. 415-442.

Shifman, Limor 2007. Humor in the Age of Digital Reproduction: Continuity and Change in Internet-Based Comic Texts. International Journal of Communication, Vol. 1 , pp. 187-209.

Shmelev, Alexey 2005. Druzhba v russkoi iazykovoi kartine mira (Friendship in the Russia Linguistic Picture of the World, in Russian). In: Anna Zalizniak et al. (eds.) Kluchevye idei russkoi iazykovoi kartine mira. Moscow: Languages of the Slavic Culture, pp. 289-306.

Shmeleva, Elena \& Shmelev, Alexey 2002. Russkii anekdot: Tekst i rechevoi zhanr. [Russian anecdote: A Text Type and a Speech Genre.] Moscow: Languages of Slavic Culture.

Visson, Lynn 2001. Wedded Strangers: The Challenges of Russian-American Marriages. New York: Hippocrene Books.

Wierzbicka, Anna 2002. Russian Cultural Scripts: The Theory of Cultural Scripts and Its Applications. Ethos, Vol. 30, No. 4, pp. 401-432.

Yelenevskaya, Maria 2008. Humor in the Russian-Language Media in Israel: Cultural Antecedents, Genres and Themes. Israel Studies in Language and Society, Vol. 1, No. 2, pp. 36-58.

Yelenevskaya, Maria 2009. "Ours abroad” As a Theme of Humor on Ru.net: Changing Values, Competing Loyalties. Russian Journal of Communication. Special Issue, The Russian Anekdot As Cultural Genre, Discourse and Performance, Vol. 2, No. 3/4, pp. 267-287.

Zhdanova, Vladislava \& Frukhtmann, Yakob. 2008. Natsional'nost' - durak: "poluchuzhie" v imperskikh anekdotakh. [Ethnicity: A Fool: "Semi-aliens in Imperial Jokes.] In: A. S. Arkhipova \& M. A. Gister (eds.) Kirpichiki: Folkloristics and Cultural Anthropology Today. Moscow: Russian State University of Humanities, pp. 481-497.

Zilberg, Narspy 1995. In-group Humor of Immigrants from the Former Soviet Union to Israel. Israel Social Science Research, Vol. 1, No. 10, pp. 1-22. 


\title{
THE POPULAR NOBEL PRIZE AWARD BANQUET: DISTANCED PARTICIPATION OF AN INTERACTING TV-AUDIENCE
}

\author{
Marlene Hugoson
}

\begin{abstract}
When chemist, inventor, and businessman Alfred Nobel died in 1896 he left a will establishing the Nobel Prize. Over the years, the Nobel Prize Award Ceremony, and the following Nobel Prize Award Banquet, developed into a spectacular and well-known event that was sometimes broadcast on radio. Then, in the year 1950, it was shown on Swedish television for the first time. In the decades that followed television became part of almost each and every household, and the viewing audience could now follow the festivities as they occurred, almost as if they had been invited themselves. A playful attitude towards the event developed, consisting of banter but also of distanced participation in which people dressed up and staged their own Nobel Prize Award "banquets" in front of their televisionsets. In later years this phenomenon has developed, simultaneously becoming both more elaborate and more common, and today there is a variety of privately arranged Nobel Prize Award "banquets" to be found throughout Sweden, some even including their own Nobel Prize Award Ceremonies and attending royalty. In my paper, I will present this public parallel to the highly exclusive Nobel Prize Award Banquet and touch on international counterparts to it and the humorous language that surrounds these events.
\end{abstract}

Key words: Alfred Nobel, annual festivity, banter, dressing up, national pride, Nobel Prize Banquet, parody, role play

On the eve of December 10, a Swedish couple would sit down to enjoy their dinner while watching the Nobel festivities on television. TV-dinners are ordinarily frowned upon, but on this night it is considered part of the celebration of Alfred Nobel, but there are also more elaborate celebrations to be found, where family and friends are invited to a fancy celebratory meal - many times with the TV present and turned on. Sometimes there is a mix of participants attending this fancy dinner, and at other times the "Nobel Banquet" is for couples only (including homosexual couples), or it is the theme of a girls' night (ULMA 39316, 39319-39322: 1). ${ }^{1}$

These alternative Nobel Banquets represent a new and developing annual festivity in Sweden, and they are often held at the same time as the real Nobel 
Prize Award Banquet takes place in Stockholm, on the eve of December 10 each year. In my paper - previously presented at the SIEF conference The Ritual Year and Ritual Diversity. Second Conference of the SIEF Working Group on the Ritual Year ${ }^{2}$ in Gothenburg 2006 - I will examine this public parallel to the highly exclusive Nobel Prize Award Banquet, and touch on historic and international counterparts to it, and the banter and role-play that surrounds this. ${ }^{3}$

\section{THE NOBEL PRIZE}

Before his death in 1896, chemist, inventor, and businessman Alfred Nobel left instructions in his will for the Nobel Prize. Five years later the Nobel Foundation was created to recognise advances in physics, chemistry, physiology or medicine, literature and peace. Later, in 1969, the Nobel Prize in Economy was established in Alfred Nobel's honour. ${ }^{4}$

Over the years, the Nobel Prize Award Ceremony, and the ensuing Nobel Prize Award Banquet developed into a grand and well-known event that in parts was broadcast over the radio. Then, in the year 1950, it was shown on Swedish television for the first time. The event was among the first to be featured on television, which may have contributed to the special status it came to secure in the public mind (SVT production 2004; http://www.ur.se/television).

In the decades that followed, a television set became part of almost each and every household, and the viewing audience could now follow the festivities as they occurred, almost as if they had been invited themselves. The broadcasts even continued throughout the revolutionary era of the 1960s when class society was largely deconstructed in Sweden. Over time a playful attitude towards the event began to develop, consisting of banter but also of distanced participation during which people dressed up and staged their own Nobel Prize Award Banquets in front of their own television sets.

In later years, this phenomenon has evolved further, simultaneously becoming both more elaborate and more common, and today there is a variety of privately arranged Nobel Prize Award "Banquets" to be found throughout Sweden (ULMA 39316-39322).

\section{ALTERNATIVE NOBEL PRIZE AWARD BANQUETS}

Alternative Nobel Banquets are not only held in private homes; various organisations may also arrange their own celebration, such as local folklore societies, where the members take turn in arranging the banquet and dress up in white 
tie or the folk costume of that area, and also organisations like the Scouts, United Nations Stockholm, Rotary International, the Order of Good Templars, the Swedish Temperance Organisation, and finally prominent Swedish politicians who were not invited to the real thing (ULMA 39322: 3).

The Nobel Banquets staged at the Swedish residence in New York are semiauthentic - the guests include former laureates, as in the case of "The Small Nobel Prize Banquet" arranged by the Nobel Museum for children within the age of 7 to 11 (ULMA 39322: 3).

The students at some of the Swedish colleges and universities also want to partake in the celebration by staging their own Nobel Banquets, for example in the cities of Borås, Umeå and Uppsala (ULMA 39322: 2). In Umeå, the issue of homosexuality raised some questions, as gay couples were welcome to attend the banquet, but were not allowed to sit together, because of the high level of etiquette demanded in the seating arrangements: lady-gentleman, ladygentleman (Kinberg 1999). According to strict etiquette, couples are generally not allowed to sit together anyway as during the Nobel Banquet, for example, the Swedish Queen does not sit next to the King. However, the problem is accentuated when there is an unbalance in the number of men and women attending, as outlined in the example above.

Commercial interests have also picked up on the growing popularity of the Nobel Banquets, as the more exclusive caterers, restaurants, hotels and inns have begun to serve Nobel Banquets in the same price range as the real banquet. Furthermore, professional business operators are organising private tours of the Nobel Museum followed by a Nobel Banquet at Stockholm City Hall - i.e. where the real Nobel Banquet is held (ULMA 39322: 4).

\section{PRACTICE MAKES PERFECT}

What is more interesting is that school kitchens have begun to serve a Nobel Prize Banquet for lunch at both kindergartens and schools. This two or threecourse meal is often based on the menu of the previous year's real Nobel Banquet, but is priced at around 10 Swedish kronor - compared to the approximately 1,400 kronor ticket to the real Nobel festivities, which was the charge in 2005 (ULMA 39316-39318, 39322: 2).

Some schools have embraced the idea and developed it further by arranging workshops and their own evening banquets, with fancy dresses and dancing. In the workshops, the students learn about manners and etiquette, or inventions, or they may research the Peace Prize laureates and make presentations using 
role-play. There are also examples of classes with disabled students organising celebratory Nobel Banquets (ULMA 39322: 2).

For many of the younger boys the banquet is a rare, and sometimes a first, occasion to wear a tie. And for the girls a first real occasion to wear a ball gown, high heels and a tiara, as opposed to playing a princess at home. The evening may thus serve a socialising purpose, giving the children a cultural lesson in etiquette, dancing, manners, and to some extent, work, as students sometimes learn to set and decorate a table, and to prepare the food. The younger students at some schools also help serve the food to the older students. Again examples of the TV's presence at the banquet can be found (ULMA 39322: 2).

As the real Nobel Banquet is sometimes held during the weekend, the schools occasionally move their celebration to a previous or later evening that works better with the school schedule (ULMA 39317-39318, 39322: 2). This is sometimes also the case with the Nobel Banquets held in the homes, where the celebration is sometimes shifted to New Year's Eve (ULMA 39316).

\section{RECIPE FOR A NOBEL PRIZE AWARD BANQUET}

The ambition level and concept of these privately arranged Nobel Banquets run from basic simplicity to an elaborate festivity throughout, ranging from an ordinary dinner in front of the TV to the whole shebang, with formal invitations specifying the dress code, to fancy food, dancing, and even "Hobnobbing in The Blue Hall" - a reference to the Blue Hall of Stockholm City Hall, which is especially amusing if you actually happen to have a blue coloured hallway, even though the Blue Hall of Stockholm City Hall paradoxically is not blue (ULMA 39316-39322).

The banquet food served at these private gatherings may thus run from the ordinary to the exclusive, sometimes inspired by one of the many books or cookbooks on the Nobel Banquet. ${ }^{5}$ Even the table decorations may be copied, as the china and crystal and silver- and gold-ware, from well renowned Swedish artists and manufacturers, is available to the public in the better-stocked shops (ULMA 39316-39322).

In recent years, the Swedish daily newspapers have begun to run articles on the topic of "How to Create Your Own Nobel Banquet" and in the days leading up to the Nobel Award Ceremony and the Nobel Banquet, examples of menus are printed along with tips on where to go for the night, at low cost, dress, hairdo and food (ULMA 39322: 1). One such tip suggested going to a Syrian shop for the dress: an example of how a foreign culture in Sweden may suddenly receive unexpected yet positive attention in an otherwise unlikely context (Forsström 


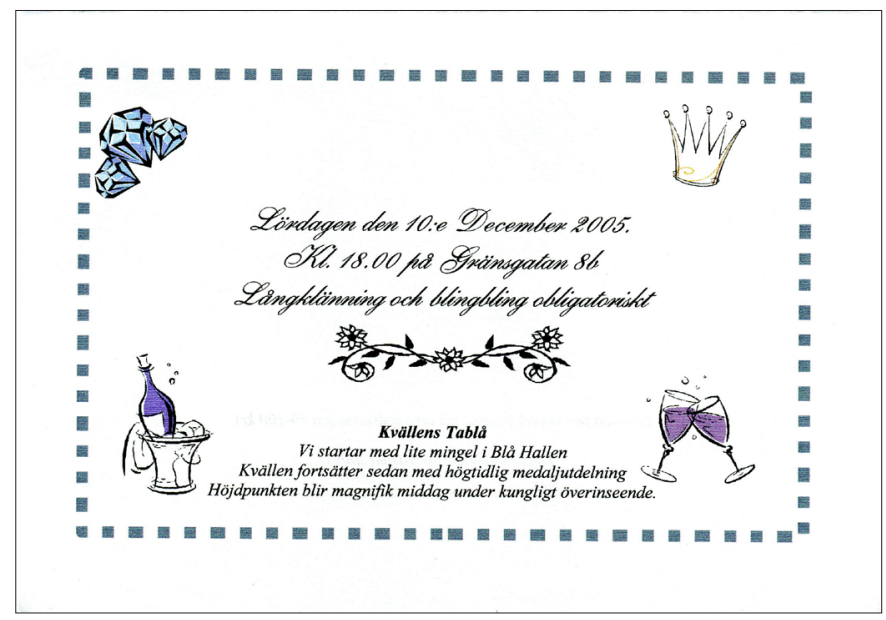

Figure 1. Invitation to a private Nobel Banquet, reading: "Evening gown and bling bling obligatory (...). We will kick off with some hobnobbing in the Blue Hall. The evening will then continue with a grand award ceremony. To top things off, a magnificent dinner under Royal supervision"

i.e. through the media of television. () The Swedish Institute for Language and Folklore

2005). It should be noted that I have found no account of immigrants organising Nobel Banquets; however, this may change as immigrant children participate in the Nobel activities at school, and may want to bring the celebration into their home as well (ULMA 39317, 39322).

Aside from food, the attire plays a major part in the private celebration. Although young Swedes are known for their fashion sense, Swedes in general are not known to be well dressed, rather for wearing more functional clothes. The Nobel Banquet, however, is a rare occasion to put on a show, mimicking the glamour and dress code of the real Nobel Prize Banquet down to the jewellery: often fake tiaras bought at the toy store, and also sashes, rosettes, and medals (ULMA 39319-39322).

Gender is a factor in this context, since it is mainly females who take the initiative to stage these private banquets, maybe because of a "Cinderellasyndrome/complex" where they, if only for a night, get to attend the proverbial ball (ULMA 39316-39322). 


\section{ROLE PLAY AND BANTER}

At the private Nobel Banquets spirits are high and the mood is playful, as people get a kick out of the formal etiquette and the dressing-up. At the same time, the banter surrounding the Nobel festivities is often scented with parody, making fun of class and belonging - as both of these are perceived to be old fashioned notions in today's more democratic Swedish society. Also, any jokes consisting of the word dynamite or referring to explosions are appropriate, as Alfred Nobel was the man who invented this explosive substance, for instance: "The Nobel Prize Award was dynamite this year!"

There are various forms of role-play: children acting more like adults and adults mimicking the higher classes (ULMA 39319-39322). This is especially apparent when the humorous banter is delivered with a simultaneous change in speech pattern, thus impersonating someone from a higher social stratum: "It is so strange, I did not get an invitation this year." Or: "No, I was not nominated this year either, so I didn't bother to go." If preparations are still needed in the kitchen, an excuse can also be made in the form of an explanation that is again a social comment regarding class: "Well, you see the kitchen maid is off this evening, so I have to manage on my own." In reality, of course, there is no maid (ULMA 39319-39321).

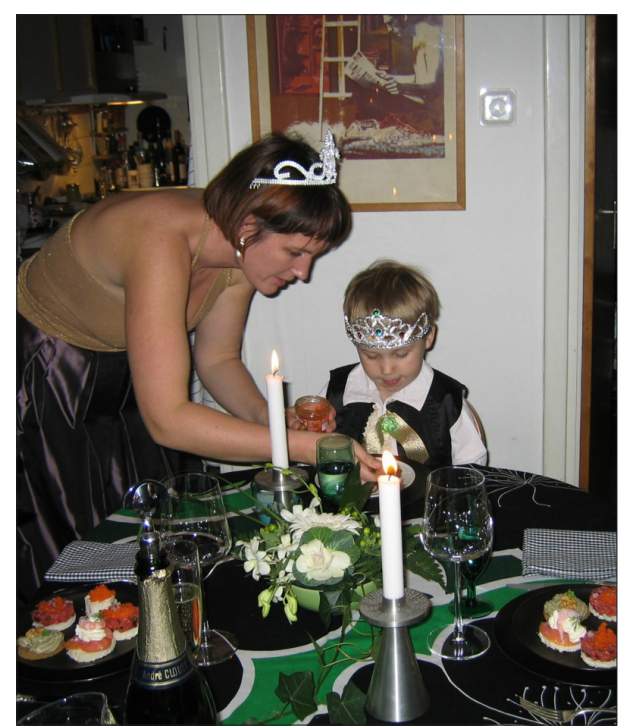

Figure 2. "Nobel Prize Award Banquet" served in a private home in Umeå, Sweden 2004. Photo: Marlene Hugoson. (C) The Swedish Institute for Language and Folklore 
There are also examples of people dressing up and acting the parts of King and Queen, the Crown Princess, or Alfred Nobel himself at these banquets. ${ }^{6}$ In one instance, a hand puppet placed on Queen Silvia's hand was used to represent King Carl XVI Gustaf - yet another example of the humour. These celebrities lend glamour to the evening and present Nobel medallions and diplomas to the "laureates". These prizes are often hand-made or in the shape of a gold-covered chocolate medallion similar to the kind served at the real Nobel Banquet and sold by the Nobel Museum in Stockholm (ULMA 39322: 2-3). ${ }^{7}$

The nominations for the prize are tailored to suit the "laureates". For example, an unspecified Nobel Prize can be given by a countryside folklore society for efforts developing that specific area. A Nobel Prize in chemistry can be given for excellence in the kitchen, and in physics for excellence when handling a vacuum cleaner. Some schools award prizes for academic excellence to all of the best students, and at one school Peace prizes were also given to students who had proved themselves to be good classmates (ULMA 39321, 39322: 2).

\section{HISTORIC COUNTERPARTS AND DEMOCRATIC ASPECTS}

Class snobbery and social division are still all firmly in place, but tempered by the possibility of Everyman gaining admittance. (Strong 2002: 308)

A historic parallel to the TV audience, watching the royals eat during the televised Nobel Banquet, is found in the Renaissance Banquet, and the sixteenth to eighteenth century custom of popes and royalty dining in public; admission to the table was limited and the guests or spectators only had the honour of watching the Pope or royals eat and did not partake themselves (Strong 2002: 134, 202-258). ${ }^{8}$ This effect is achieved now through the medium of television: the present-day television viewer takes on the part of a guest at one of these public banquets.

In today's televised broadcasts, from the Nobel Banquets, the royals set a higher standard to which many viewers would like to strive, in both decorum and appearance. The idea of bettering oneself is also promoted in the televised broadcasts where prominent Swedish authorities on etiquette, such as author Magdalena Ribbing, are called in to explain the "rules" of the occasion, thus giving the viewers a lesson in etiquette (SVT 2005). This knowledge lends a feeling of equality and belonging, while simultaneously marking the difference in class and education between the viewer and the attending guests. 
It is interesting to note that the Nobel Banquet is a rare example of an instance when the Law of Jante is largely set aside. The Law of Jante is a term used to describe the Scandinavian parochial mentality, in which jealousy and striving for equality allows people to mock those who consider themselves above others, and never lets anyone else feel good about their achievements. ${ }^{9}$ During the Nobel Banquet, however, the previously mentioned banter with class and belonging has its limits, showing a boundary for this law; when a provocative author and feminist columnist for one of the two largest evening newspapers in Sweden was sent to cover the Nobel Banquet in 2004, the columnist provoked the other guests at her table, and the viewers at home, by vulgar speech and a total disregard for the "rules" of the occasion. To top things off she gave the Nobel Banquet a very distasteful review in the paper the following day (SVT 2004; ULMA 39316; Skugge 2004a). All of this proved to be a faux pas and a public reaction to her display of bad manners followed (Karlsson 2004; Skugge 2004b).

The Nobel Prize is a matter of national pride for many Swedes, and eager viewers wanted to see and hear only of the glamour and therefore disliked the fact that the columnist had misused a much-coveted invitation to the event. By questioning the event and its rules the columnist inadvertently also questioned the distantly participating viewers - a sore spot since the private Nobel Banquets can be seen as a form of "status-sponging" that undermines the sense of equality and participation in the occasion that the viewers strive for (ULMA 39316).

\section{INTERNATIONAL COUNTERPARTS}

Making an international comparison one will find that other countries have prizes similar to the Nobel Prize. In the United States there is the Laskar Prize for advances made in the field of medicine, in Japan there is the Kyoto Prize for advances in the fields of technology, basic sciences, arts and philosophy, and in Russia the recently established Global Energy Prize is beginning to establish reputability. Closer to home, in Norway, there is of course the Nobel Peace Prize Award Ceremony, including the Peace Prize Concert, but even in Norway counterparts to the privately arranged Nobel Prize Banquets are scarce. There are Nobel Banquets staged at the Nobel Institute in Oslo, by a firm called Meeting Professionals International, but this is a commercial enterprise and not a widespread custom (ULMA 39322: 6). ${ }^{10}$

Also in the United States, a somewhat surprising parallel is to be found in the glamorous Academy Awards. ${ }^{11}$ Some may resent this comparison between 
the prestigious Nobel Prize Awards and the more commercial Academy Awards, but nevertheless the Nobel Prize and the Academy Awards share some defining characteristics. The Nobel Prize Award Ceremony and the Academy Award Ceremony are both televised, and not only in their own countries but all over the world. The two events can also be defined as entertainment, as world-renowned entertainers are hired to perform for the attending guests and TV-viewers. Furthermore, the guests include the glamorous, rich, and famous celebrities that the TV audiences are interested in; the Nobel festivities involve the Swedish Royal family and the occasional celebrity or well-known politician, and the Academy Awards involve movie stars - often referred to as the American equivalence of royalty.

The annual broadcasts from the Nobel Prize Award Ceremony and the Nobel Banquet are one of the most important occasions of the year when it comes to the Royal family's exposure; the same is true of the Academy Awards and the movie stars walking down the red carpet. At both events a lot of attention is therefore made to detail, thus adding to the glamour of the occasion.

Interviewing these famous persons and investigating the clothes and jewellery they wear and the hairdos they show off, the television cameras take the viewers closer to royalty and the stars, than even the invited guests attending these events. This intimacy makes both royalty and movie stars seem more personable, thus also making them easier to identify with and to mimic.

\section{THE PRIVATELY ARRANGED ACADEMY AWARD PARTIES}

Swedes stage their own Nobel Prize banquets, and Americans throw private Oscar bashes - from casual get-togethers, where they watch television, criticise the stars, and predict the Oscar winners, to professionally organised parties where they dress up as fabulous or favourite movie stars (ULMA 39322: 6).

If you want to organise your own party, Fox News homepage gives tips on what to eat and the Washington Post tells online what the best party themes are - ideas inspired by the nominated movies. ABC's homepage advises what to eat and how to pick the winners. Tips are also given at oprah.com, the HGTV homepage and the about.com site.

Not only is there humorous chatter about the Nobel Banquet, but also about the Academy Awards, and not just made by the TV host. On LA Weekly's blog the lost invitation joke is expressed by lifestyle editor Linda Immediato (2006): "I wasn't invited to the Oscars, an oversight on somebody's part I'm sure."

Like the privately arranged Nobel Prize Awards, the guests at the more elaborate private Academy Award parties may take home a prize of their own - 
in the form of a gilded plastic Oscar or one made out of gold wrapped chocolate (ULMA 39322: 6). Again it is mainly women who organise the parties, and the Oscar ceremonies are even referred to as the "Super Bowl for women" (http:// www.cbsnews.com).

While researching the alternative parties, I found a second degree of the distanced participation: Jen Chaney (2006), movie editor at the Washington Post, organises web-parties where a group of people who do not know each other get together online to discuss the show they are all viewing... collectively, but not together. The "guests" were asked to "bring the wine, cheese and snarky comments":

Welcome to our Web version of an Oscar party. This is my third year hosting one of these discussions and, thanks to the wonders of technology, I'm typing from my couch this time, watching the red carpet action on my high-definition TV. So it's almost as good as being at the Kodak Theatre, plus I don't have to wear a gown and uncomfortable shoes. (http://www. washingtonpost.com)

Besides the American Academy Awards there is also another European parallel to be found in the UK, where there take place Eurovision Song Contest parties and people dress up in front of the television set during the final contest. ${ }^{12}$ The same thing happens in Iceland, sometimes with people singing along, similar to karaoke. ${ }^{13}$

\section{CONCLUSION}

The privately arranged Nobel Prize Banquets constitute a developing annual festivity in Sweden, involving banter and role play, and with parallels to both historic customs and current day international events. The alternative Nobel Prize Award Banquets are arranged in private homes, by various organisations, at kindergartens, schools, colleges and universities, by the more exclusive caterers, restaurants, inns and hotels, and by business event organisers, etc.

Maybe the increase in privately arranged Nobel Banquets is connected with the rising popularity of the Swedish monarchy and a surge for the exclusive expressed, for example, in the turn from sex to luxury in commercial advertising in Sweden. But on a deeper level the distanced participation of the national Swedish viewer can be seen as holding an important democratic aspect; for citizens to connect and identify with a national function and as an expression of national pride and a developing sense of nationality in an ever more inter- 
national society, where national identity and uniqueness can easily be felt to be fading.

An earlier version of this paper has previously been published in both Swedish an English: "Den alternativa nobelfesten. En tv-publiks festdeltagande", in Bodil lajv. Festskrift till Bodil Nildin-Wall den 18 januari 2007. Marlene Hugoson (ed.), Uppsala 2007, and under the English title in The Ritual Year and Ritual Diversity. Proceedings of the Second International Conference of the SIEF Working Group on the Ritual Year, Gothenburg June 7-11 2006. Lina Midholm, Annika Nordström and Maria Teresa agozzino (eds.), Göteborg 2007. In addition you can read Professor Christina Fjellström's (2006) article “Vad är väl en bal på slottet...' Nobelfest i slott och koja” ['What's a Royal Ball...' Nobel Banquets in Castle and Cabin] in $\mathrm{Nu}$ gör vi jul igen.

\section{ARCHIVAL SOURCES}

ULMA: The Uppsala Archive of Dialectology (Uppsala landsmålsarkiv), Sweden. This was formerly a separate archive, but is now incorporated with the Institute for Language and Folklore in Uppsala (Institutet för språk och folkminnen, Uppsala).

\section{NOTES}

1 I thank Kersti Wikström, curator at the Nordic Museum in Stockholm, for the parenthetical information.

2 The abbreviation SIEF stands for Société Internationale d'Ethologie et de Folklore. The Ritual Year is one of SIEF's working groups.

3 The study on the privately arranged Nobel Banquets is part of the project Förändring av sedvänjor (Changing Customs), a documentation of current Swedish customs and the extensive changes they are undergoing, initiated in 2003 by the Folklore Department at the former Institute for Dialectology, Onomastics and Folklore Research, in Uppsala. Now reorganised and named the Swedish Institute for Language and Folklore. The project has focused on the more constant among Swedish folk customs - such as annual festivals and celebrations and life cycle celebrations.

${ }^{4}$ When Alfred Nobel drew up his will - stipulating, among other things, that the Nobel Peace Prize Award Ceremony was to be held in Norway and not Sweden - the two countries were still a union. When the union came to an end in 1905 this arrangement continued. For more information, see http://nobelprize.org/ and http://www.nobel.no/.

5 See, e.g., Pawel Flato's and Niklas Lindblad's (2000) Nobelfesten and Hélène Bodin's (1998) Nobelfesten. Moderna recept från klassiska menyer. 
6 The idolisation and mimicking of royals can be found around Queen Elizabeth II of the United Kingdom, and whenever there is a grand royal wedding.

7 I thank Laura Aronovici, supervisor at the Nobel Museum Shop in Stockholm for the information about the chocolate.

8 Over a long period of time Publik spisning (Dining in public) could be found in courts around Europe, for example in the court of Swedish queen Christina in the 17th century, and Swedish king Gustavius III in the 18th century (Strong 2002: 134, 202-258).

9 The term Jantelagen was coined in 1933 by Norwegian-Danish author Aksel Sandemose in his book En flykting korsar sitt spår [A Refugee Crosses His Tracks], in which he listed the ten commandments of Jante.

${ }^{10}$ I thank Professor Anders Gustavsson and Professor Arne Bugge-Amundsen, at the Department of Culture Studies and Oriental Languages (IKOS) at the University of Oslo, Norway, for the (negative) information.

11 The Emmy, Grammy, Golden Globes, or Tony Awards could also have been used as a comparison, as there are private parties of the same kind in connection with them. However, these prize awards are not as old, nor as widely known as the Academy Awards, making them less of an example in the comparison (ULMA 39322:6).

${ }^{12}$ I thank Kate Smith, a doctoral student at the University of Sheffield, England, for the information.

${ }^{13}$ I thank Terry Gunnell, Associate Professor in Folkloristics at the University of Iceland, for the information.

\section{REFERENCES}

Bodin, Hélène (ed.) 1998. Nobelfesten. Moderna recept från klassiska menyer. [The Nobel Banquet. Modern Recipies from Classical Menus.] Stockholm: Mixoft.

Chaney, Jen 2006. Oscar Night Party. Live Coverage of the 78th Academy Awards. (Published on 5 March 2006, collected on 24 July 2006), not found in the webpage's search engine, instead see Google (www.google.com), search words "oscar night party" and "live coverage of the 78th academy awards". http://business. highbeam.com/437235/article-1G1-142855183/oscar-night-party-live-coverage78th-academy-awards, last accessed on 15 March 2012.

Fjellström, Christina 2006. 'Vad är väl en bal på slottet...' Nobelfest i slott och koja. ['What's a Royal Ball...' Nobel Banquets in Castle and Cabin.] In: C. Hagström \& M. Hugoson \& A. Nordström (eds.) Nu gör vi jul igen. [Re-creating Christmas Again.] Gothenburg: Institutet för språk och folkminnen, University of Gothenburg.

Flato, Pawel \& Lindblad, Niklas 2000. Nobelfesten. [The Nobel Banquet.] Stockholm: Prisma. 
Forsström, Maria 2005. Budgetfira kungligt hemma: Metro tipsar: Rätt kläder, hår och mat för Nobelfesten. [Royal Low-Cost Celebration at Home. Metro Gives Tips on the Right Clothes, Hair, and Food for the Nobel Banquet.] Metro, December 9.

http://www.cbsnews.com/. Throw a Last-Minute Oscars Bash! (Published on 26 February 2005, collected on 15 September 2006), search words = throw a last-minute oscar bash, last accessed 15 March 2012.

http://www.ur.se/television. 1950-talet. [The 1950s.] (Collected 24 July 2006), menu choice $=$ TV-historia/1950-talet, last accessed 15 March 2012.

Hugoson, Marlene 2007. Den alternative nobelfesten. En tv-publiks festdeltagande. [The Popular Nobel Prize Award Banquet. The Distanced Participation of an Interacting TV-Audience.] In: M. Hugoson (ed.) Bodil lajv. Festskrift till Bodil Nildin-Wall den 18 januari 2007. Uppsala: University of Uppsala.

Immediato, Linda 2006. The Problem With Oscar. (Published on 6 March 2006, collected on 18 July 2006). http://blogs.laweekly.com/arts/2006/03/index.php?page=4, last accessed on 15 March 2012.

Karlsson, Mia 2004. Tittarstorm mot Linda Skugge. [Viewers Storm Against Linda Skugge.] Expressen December 11. http://www.expressen.se/nyheter/tittarstormmot-linda-skugge/, last accessed on 15 March 2012.

Kinberg, Linda 1999. Festlig nobelbal för ett fåtal. [Festive Nobel Ball for Select Few.] Vertex. Norrlands största studenttidning [Vertex. The District of Norrland's Largest Student Paper], No. 9.

Skugge, Linda 2004a. Linda sätter betyg på festen alla talar om. [Linda Grades the Feast Everyone is Talking About.] Expressen, December 11. http://www.expressen.se/nyheter/linda-satter-betyg-pa-festen-alla-talar-om/, last accessed on 15 March 2012.

Skugge, Linda 2004b. Sluta hata mig så mycket, tänk på era hjärtan. [Stop Hating Me So, Consider Your Hearts.] Expressen, December 25. http://www.expressen. se/kronikorer/linda-skugge-sluta-hata-mig-sa-mycket-tank-pa-era-hjartan/, last accessed on 15 March 2012.

Strong, Roy 2002. Feast. A History of Grand Eating. London: Jonathan Cape.

SVT production 2004. DVD, Guldkorn från 1948-1950. Åren var 1948-1950. [Olden Goldies from 1948-1959. The Year Was 1948-1950.] SVT produktion 2004. [A Production from Swedish Television 2004].

SVT 2004. Televised broadcasting, SVT [Swedish Television], December 10. Nobelfesten [The Nobel Banquet].

SVT 2005. Televised broadcasting, SVT [Swedish Television], December 10. Nobelfesten [The Nobel Banquet]. 


\section{Internet sources}

Google search engine for "Nobel", "Nobelfest" [Nobel Banquet], "Nobelmiddag" [Nobel Dinner], "Nobellunch" [Nobel Lunch], "Fredspriskonsert" [Peace Prize Concert], "Nobel Peace Prize Award Ceremony", "Peace Prize Concert", "Academy Awards", "Oscars", "Oscar bash", Oscar party", "Emmys", "Tonys", “Golden Globes”. The research material collected is too extensive to be presented as a whole, but can be found in the Research Archive of the Institute for Language and Folklore, in Uppsala, Sweden (ULMA accession number 39322, see archival sources above). 


\title{
HUMOUR THEORIES AND THE ARCHETYPE OF THE TRICKSTER IN FOLKLORE: AN ANALYTICAL PSYCHOLOGY POINT OF VIEW
}

\author{
Ana Stefanova
}

\begin{abstract}
Humour theories describe different parts of humour as a phenomenon, obtained on the personal and community level, so difficult to be explained. The analytical psychology of Carl Gustav Jung may help in the explanation of why the search for the "Holy Grail of Humour" is as if trying to catch a shadow. The archetype of the trickster in folklore may help us describe some common and different parts of the universal phenomenon of humour and the specific ethnopsychological traits.

The paper presents an overview of basic humour theories, supported by analytical psychology comments, the archetype of the trickster in Bulgarian and Russian folklore, in the folklore of Native American tribes, Kalevala and Edda (Snorri Sturluson) with an attempt to explain how the traits of this "hero" provide a list of the components making something humorous for different people and what are the common traits that can be described as universal.

This overview could help trace the humour phenomenon from the universal, through the community, to the individual level trying to find how important this is in searching for its characteristics.
\end{abstract}

Key words: analytical psychology, archetype, folklore, Holy Grail of humour, humour, humour theories, incongruity, play, profane, relief, sacred, superiority, trickster

For the explanation of the phenomenon of humour we need to involve different approaches, and different sciences. In order to understand the approach of analytical psychology, it is necessary first to review humour theories, created until recently, mostly on the basis of philosophy. In the Internet Encyclopedia of Philosophy, Aaron Smuts (2006) writes about 4 theories:

1. Incongruity Theory is the dominant approach and includes historical figures such as Kant, Kierkegaard, and perhaps has its origins in comments made by Aristotle in Rhetoric. Focusing primarily on the object of humour, this school sees humour as a response to an incongruity, a term broadly used to include ambiguity, logical impossibility, irrelevance, and inappropriateness. 
2. Superiority Theory - according to Thomas Hobbes, humour arises from a "sudden glory" felt when we recognise our supremacy over others. Plato and Aristotle are generally considered superiority theorists, who emphasise the aggressive feelings that fuel humour.

3. Relief Theory is typically associated with Sigmund Freud and Herbert Spencer, who saw humour as fundamentally a way to release or save energy generated by repression.

4. Play Theories attempt to classify humour as a species of play. In this general categorisation effort, the play theorists are not so much listing necessary conditions, as they are asking us to look at humour as an extension of animal play. They try to call our attention to the structural similarities between play contexts and humorous context, suggesting that what might be true of play, might be true of humour as well.

To create a proper definition of humour, different fields of science must be united: philosophy, psychology, sociology, anthropology - social sciences, cognitive science, physiology and medicine, arts, literature, advertisement (management, marketing, commercials) etc. Humour is a phenomenon that we may observe every day in so many different forms, looking so simple and easily cognisable; at the same time it has connections with possibly all aspects of human personality, structures (somatic and mental) and activities which make us humans. The very fact that even the children and, according to some authors, the animals may recognise humour, yet at the same time the difficulty for us, to give an elegant explanation and definition of it, is phenomenal.

When we try to describe humour, it is visible that there are three sides:

1. Character of our response.

2. Properties of the humorous object.

3. What will be sufficient for an object to be found funny - the Holy Grail of humour.

Aaron Smuts writes: "The Holy Grail is often confused with a question regarding the sufficient conditions for our response to count as humorous amusement, but a crucial distinction needs to be made: identifying the conditions of a response is different from the isolating the features something must possess in order to provoke such a response. The first task is much different from suggesting what features are sufficient to provoke a response of humorous amusement. What amounts to a humor response is different from what makes something humorous. The noun (humor) and adjectival (humorous) senses of the term are difficult to keep distinct due to the imprecision of our language in this area." (Smuts 2006) 
But there appears the question - can something be humorous "by itself" what makes something humorous is the question that suggests something to be apart from the human's estimation. However, it cannot exist away from this estimation, living in nature as "humorous" by itself. The human is the one who gives this "label", according to personal and/or collective criteria. The archetype of the trickster is something that best integrates the opposites, being above Good and Evil; something that best fits the idea of "something humorous by itself", because it is universal. According to Paul Radin (1956: x), "Laughter, humour and irony permeate everything Trickster does." The trickster is universal: "Are we dealing here with the workings of the mythopoeic imagination, common to all mankind", the speculum mentis?" (Radin 1956: x).

All humour theories describe different traits and have their meaning.

\section{The concept of C. G. Jung about the psychic structure}

To review humour theories through the standpoint of analytical psychology there are specific concepts that must be defined. According to Jung the psychic structure has conscious and unconscious parts; there is also personal and collective unconscious.

The personal unconscious is about matter that is connected with nationality substances, interjected in early childhood, family, tribe, motherland. Its visualisation in the activities reflects the specific vision and characteristics of the native culture, the spirit of contemporary times, the Shadows. (All that the defensive mechanisms are "hiding" from us but still are ours, our "dark side").

The collective unconscious is the deepest one, "below" the personal, as the deepest "layer" in the structure of the personality, the same in all and everyone, as a pattern. That is why it is universal, because it is identical for all the people (may be in animals, too). The collective unconscious is not dependent on culture, it has its own structure - the archetypes (Jung calls them "organs of the soul"). Its matter has never been in the conscious as it is inherited structure, primordial, that we all are born with. We cannot observe the unconscious directly, but it has a great impact on our personal activities, way of thinking, this is the deep and dark place, where the impulses, instincts, with their imperative way come from.

The archetypes are the tissue, the structure of the unconscious. The interactions among them define the dynamic of the unconscious. They have specific traits and characteristics of interaction among them and the conscious, which actually is the psychic dynamics. They have manifestations in our visible activities, in our thoughts, in the art, folklore, dreams, even in symptoms of diseases. The 
archetypes could be described as different personalities, who lived in our Self, but until the conscious holds the control, the person is psychically healthy. The connection and interactions among the archetypes have a kind of a pattern, framed by our instinctive nature; they are instincts by nature (“...the archetype could be extracted by abstractions of a class of experienced images or objects" (Corsini 1998: 81)).They are "imprints" of the experience of the forbears, not the experience itself, not facts or images, but their mainframe, their essence. The archetypes are connected to the instincts, being numinous, unconscious, autonomic and compulsive. The archetype is a psychosomatic idea that connects the soul and the body, the instinct and the image (Samuels et al. 1995: 38).

We inherit archetypes, they have their own life and personality, but they are also a part of our personality. If they get more energy, they could have the control over the person. The huge variety in material culture is due to the variety of models of creativity of the spirit, having their roots in the archetypal nature. "There are as many archetypes, as typical situations there are in life," writes Jung (1999: 56).

According to Jung, Freud's theory about the libido is partial and unbalanced. In spite of that the concept of the energy has its place in Jung's work. "The neutral nature of the psychic energy means that it may be used everywhere including for searching instruments for reducing the energy tension." (Samuels et al. 1995: 79) These "instruments" could vary a lot - including arts, humour, sport, every kind of activity. "The unconscious is older than the conscious, it is primordial, from it the conscious arises constantly" (Jacobi 2000: 138), thus the conscious "dresses" and guides our actions, but it is impossible for something to appear in the conscious without having roots in the unconscious. The unconscious is the basis; nothing can be developed if it does not have any precursor in the structures before; we cannot really see or understand something if we do not have a primordial archetype or instinct for it as "images" and models for action.

Whatever phenomenon we observe, we must know that there is nothing in the conscious that has not been in the unconscious before. The phenomenon of humour is not an exception in this regard. It is about an instinct, an archetype. Coming from the unconscious, it has an emotional, instinctive nature, the "deepest" layers in our psyche, reducing the energy tension. The conscious may guide and "dress" this instinct, but it could be compulsive if the conscious, the I (Ego) loses control or goes on to "lower" levels (these are the conditions in cases of abusing different substances, stress, mental illness, little children, immature people - all kinds of situations with low control or weakness of the Ego. The conscious is "the connection of psychic content with the Ego, when 
the Ego knows about this", it supports the connection between the unconscious matters and Ego (I, Self) (Samuels et al. 1995: 171).

With regard to its anatomy, the conscious has 4 main structures:

1. Cognitive.

2. Existential-affective.

3. Intentions and will.

4. Reflexive structures.

The cognitive structures act when we first see something, asking the question "what is this?" The existential effectiveness is immediately after them: this is the question "what is the meaning of this object to me?" Everything we get through our senses has emotional estimation for us. There is nothing that we observe, think or have, that has no emotional "colour" for the personality. This is the way our personality works.

Jung's concept describes a universal psychic "layer" and the personal one, dependent on the culture (the group) and the individual, according to his classification of psychological types (a combination among the four functions of conscious, plus intra- and extra-version). This is the way the universal and individual co-exist.

Having these explanations in mind, we can try to reach the very heart of the appearance of the phenomenon of humour.

\section{Humour}

- Always brings pleasure; there is no humour without pleasure for the person, who accepts it as such, bringing quick and easy enjoyment. Not everything about pleasure, fun and entertainment is humorous. Humour can be all of these. Arvo Krikmann (2009) quotes Arthur Graesser, arguing that "recent psychological observations appear to confirm that items of disparaging humour tend to get the highest ratings for funniness."

- It is a form of communication - could be positive (for example "breaking the ice" in a difficult and very serious situation, relaxing the atmosphere) or negative (involuntary or intended sarcasm, mockery, demonstration of superiority). Humour has the potential to bring peace or declare war. According to the linguist Steven Pinker: "The act of communication is based on mutual collaboration between the one who talks and the one who listens. The one who talks sends statement to the listener and implicitly guarantees that the information, which he gives, is relative: it does not repeat the things already known and is connected enough with what the 
listener thinks and may be used for new conclusions with minimum mental effort." (Pinker 2007: 269) From this description we may trace the way humour is dependent on "outer" conditions as an act of communication: 1) the audience - the more prepared it is, the bigger is the effect. Important is the group-effect, the effect of "infection"; 2) the cultural context; 3) the satisfaction of the understanding and the conclusions, to "catch", to get the joke. It should be short, informative, prompt, relative, clear, unambiguous (in cases of incongruity the ambiguity of the communicational act and expression is the "core" of humour, but the understanding should be clear) - these are the traits that the listener expects. Thus, the traits of humour can be described as an act of communication. "The metaphor and humour provide a comfortable way to generalise the two mental actions, which participate in the understanding of a sentence. The ideas are objects, the sentences packing, the communication - sending and receiving." (Pinker 2007: 271)

- As an act of creation (Arthur Koestler's concept about humour, discovery and art): comic collision or oscillation between two frames of reference/worlds of discourse/codes and associative contexts (Krikmann 2009). To demonstrate "good taste" and intelligence - "sophisticated" humour. Aaron Smuts (2006) defines the comic as a professionally produced source of humour, a generic element of various art-forms.

- There can be found similarity within the structures of wits, jokes and dreams. According to Freud, these are products of the primary process, expression of Id. The multiplication and compression are characteristics of the visualisation of the psychic dynamics in dream images. They are also recognisable in jokes, fairy tales and witticisms (in the products of psyche, having unconscious roots).

- Depends on the person's individual traits - such as temperament and psychological type. However, people of different temperament or psychological type obtain humour with different expression, the expression is personally dependent, but its existence is universal.

- Has specific cultural traits, yet there is no culture without humorous traditions or products.

- Could have physiological expression. Humour is somehow connected with laughter - but we can find examples of humour without laughing only bringing positive emotion. At the same time, the reason for laughter could be something very different from humour - jokes, tickling, irony, chemical substances, sometimes as an abnormal reaction - in cases of fear (regres- 
sion as a defending mechanism), sex (in some cultures), even pain (these instances are culturally dependent and of great relevance if we want to go to the very roots of this phenomenon). If we search for an honest scientific approach, the point of view should not be of the "average, white European, with normal intelligence and education". According to Robert Provine, laughter is "a physiological process that results in a limited range of characteristic vocal patterns that are only physiologically possible for bi-pedal creatures with breath control." Laughter because of humour is secondary because it is in response to it.

- There is another important trait - saturation: one joke could not be funny twice or more times; in humour there exists a kind of surprise. If we hear or see something more than twice, it loses "its humorous power". The reaction cannot be so strong any more.

- What is the purpose of the play, we may see in the contribution of observing and learning about the world and ourselves; this is the natural impulse to learn with pleasure that we start feeling at a very early age, as a compulsive need. Humour is very similar to playing. Just like playing, humour is all about observing and exploring the environment. If we search for the purpose, the meaning of humour in life and adaptation, here we may find any basis and similarities. It could be considered as a reaction (active, if it is an act of creation, or passive, if we are only respondents) to the changes in the usual order in the environment that brings us information, quick pleasure and releases energy. Cognition is being involved just as much as emotions (they are inseparable). Krikmann explains the cognitive similarity between metaphor and humour: "Both of these are embodied in texts with dual planes of meaning, both involve a semantic contradiction or incompatibility that the recipient has to disambiguate, using his/her linguistic competence and encyclopaedic knowledge to find some analogy or other "common link" to relate the involved planes of meaning." (Krikmann 2009) This describes the cognitive mechanism for finding "news" and decisions. That is why, connected with "solving problems", humour has a lot in common with riddles, puzzles, wits and also with the language. Because of the emotions involved, humour is estimative. In the process of comparison and disambiguation there is a moment of surprise, observable in riddles, wits, jokes, and in comedies that are funny and "for play". What is needed here is an "intellectual training", a level of cultural integration and education - little children cannot understand thoroughly every act or create cultural products with the purpose to be humorous (it could happen incidentally, but the appreciation comes from adults), but they find other things humor- 
ous, funny. Krikmann quotes Tony Veale about the "the listener as a social agent" and the fact that "the humorous effect arises not because jokes, thanks to their structural properties, force their resolutions on listeners, but because the listener as a social being is predisposed" (Krikmann 2009). This is an extreme "social" and rational position and may not explain if someone finds humorous a product of another culture, being not "prepared" in it or why the children obtain it, too. It does not explain the humour in cases of weakness of the conscious (the conscious is a culture-dependent psyche). This approach puts humour only in the conscious, as an education, in cognitions, not considering its emotional tissue. The psyche cannot act without this component. Yet it is without doubt that personal expectations, connected with the social background, also have their role (often humour arises in exactly such cases of broken expectations). Krikmann quotes Rachel Giora, that "the figurative and humorous items are most enjoyable, if they convey a balanced share of salient and innovative marked information" (Krikmann 2009).

- Has universal basis, i.e. unconscious, archetypal nature. The proof for this is also the common origin of humour along with dreams and creative or cultural products, something expressed in the plots of myths themselves (as it is well known, the mythology is the basis of a way of thinking and belief of the collective kinds of cultures and has its expressions in the individual culture, too). Everything in the behaviour "passes" through the personal traits and culture, but is "powered" by the instincts. All the archetypes as instincts help us adapt better to the environment, they all have evolutionary meaning - for learning (the play), breeding (Anima/Animus), defending (Hero, Wisdom Ghost) etc. According to Radin (1956: x) "as an attempt by man to solve his problems inward and outward, does the figure of Trickster become intelligible and meaningful".

The irrationality, the unconscious, is the worst enemy for the cognitive science in the attempts of making artificial intelligence. The mechanism "if...then" does not make sense. In "humour" we may find the entire palette of emotions: sexual, aggressive, sarcastic, hatred...all these could be humour. Arvo Krikmann writes about political, social, ethnic and obscene (erotic or scatological) themes prevalent in contemporary jokes (Krikmann 2009). He is of the opinion that punch-lines are the basic form of contemporary humour, having functions as social weapon (sounding Marxist) and taboo-breaker (sounding Freudian). This is the way Krikmann explains the "golden era of joke-making" in the former USSR, and he concludes: "despite 
the proliferating cult of sex, joke tradition in contemporary welfare societies is undergoing rapid degeneration" (Krikmann 2009).

The universality is a basis for colourful forms. There is no person or nationality, no culture - contemporary or primitive that has not an attitude to humour. Humour is of compulsive nature, searching ways for expression - a characteristic of the unconscious. The same could be said about music and aesthetics. Creativity and the unconscious origin are the things that they have in common. Even in the simplest object we may see the child or "the savage" making efforts to make it look aesthetic. There is no person who does not have favourite music or who does not like listening to music, even on rare occasions. There is no culture, even primitive, without any kind of music. There are no sufficient conditions to be met in order for something to be "aesthetic" or "music". These phenomena are not directly connected with breeding or surviving. Why do we like them? Yet we are not able to describe what is aesthetic and why. We discharge energy when we communicate with or create any kind of art. Whether we like it or not, depends on the personal and collective level, on universal and specific individual traits. The same goes for "what is humorous". Where to put the borderline, i.e. what makes an "aesthetic" object "a piece of art"? A white ring on black background - is it art? Where does the line exist between tribal drumming and a sophisticated percussion concert (may be the wearing apparel of the listeners and the performance of the "orchestra" in a hall?).

Humour is about vision and hearing and it has no connection to the other senses - olfaction, touch, taste. Nothing that is perceived by way of these three senses could be described as "funny" or humorous. Instead, humour may be found in visual forms, sounds, "intellect" and language, with certain meanings and emotions (coming through the "eyes, ears and mind"). To tickling we may respond with laughter, hence the question - where to put the line between humour and physiological feelings that bring us fun, pleasure and discharge energy with laughter? What amount of something must appear in a situation or in us, or in the environment, to be humorous? According to this review, there is no such a line; the transition from the physiological to intellectual humour is very invisible. The trickster holds both of them and the entire diapason in between. The concept "humour" in Greek means 'juice', 'taste' - in this concept we may find how "fluid" and slippery it is and how much it depends on personal or cultural estimation. It varies in one person in different situations: using substances, creating atmosphere. When we hear laughter, this makes the things funnier; this is a psychological effect - James-Lange theory ${ }^{1}$; humour is contagious. The 
Rizzolatti theory about the mirror-neuron system ${ }^{2}$ also provides explanations in this regard.

- With humour we mark something harmless, but about the "responder". It might not be humorous for the other people. That is why the question about the minimum traits for something to be humorous "by itself" is inappropriate. Someone's grief could be funny for someone else. This is its connection with survival.

Only the trickster's image may "skip" these poles and contradictions, obtaining the characteristics of the numen and the sacral.

- As "responders", there is nothing dangerous or painful about the things we accept as humorous. If the borderline of the situation goes "up", the object is no more humorous, and the fun could be replaced by irritation, fear, anger, aggression - a range of other emotions may appear. It depends on the individual traits of acceptance of the situation and on the permanency of the conditions. The time for reaction is individual, too. For example, if we find someone stupid (superiority) or peculiar, it might seem funny at first, however, if it continues we may feel irritation against this person or situation; other persons or cultures may find it humorous always, etc. Humour and the other possible emotions make a "line" and could "switch" from one to another. In most of its forms humour could be considered as a socially acceptable way for reaction, showing personal maturity, an easy, harmless, cultural way to solve problems, a way to get a "prize" and to "win", taking advantage of a situation, without "going too far". It is also a way to minimise the problem and the importance of a situation, or to manage with a problem. It could also be a form of regression to lower stages of growth and maturity. We may reverse the emotions, after cognitive information, for "retreat": in cases of fear and frightening, when we feel relief and safety, we may react with laughter and/or humour, discharging energy. The situations with "hidden camera" are an example of this: after seeing that it is "unreal" and harmless, the scale of emotions "turns back" and we start laughing. On the other hand, humour may be a reaction of immaturity, rudeness, incorrectness or low control. But there are no sufficient criteria in the object, in the person or in the situation, which help us mark the conditions, in which one "switches" to another. Having in mind the dynamics of emotions, the "level" of humour, once "passed", turns into other emotions - irritation or aggression and it is often hard to be "turned back". A parallel with the physiology of tactile receptors in the skin may be given as an example. One and same agent may cause tickling (itching) (and discharging energy with laughter in many cases), irritation, or pain (discharging with 
scream in some situations). The reaction and the feeling depend on the forces of pressure and the personal threshold for pain. We may clearly see how through the emotions, the quantity turns into quality and the dynamic is between the two contrary poles. The strength of the pressure and the "time amount" of our "exposure" to a humorous act may vary in the scale from pleasure to displeasure (from humour/fun to another emotion). The cultural background, age, temperament, the situation before, and many other factors could be important for the reaction. There are universal and individual components.

Having this in mind, we may conclude that humour (as a psychological dynamic) is both regression and progression: it frames both maturity and immaturity; rational and irrational, emotions and cognitions; it could range from neglecting to overestimation, showing different kinds of expressions (as a reaction to estimation).

In conclusion we may say that humour is based on the anatomy of the conscious, it arises from the unconscious that empowers the actions. Behaviour and activities are visualisation of the human psyche.

If we want to create a humorous product, first we need to consider a "target group" - depending on nation, age, class, sex. Even in this case it would not be funny for all of the audience. A reason-consequence law about something to be humorous cannot be dismissed, as it is to do with something irrational and depends on many factors. The same situation is observable with the concept of "aesthetic". If we observe cultural evolution from the tribal level to nowadays, we will see how the sacred and the profane have changed in their expressions. In the tribal cultures the role of humour is very important for the community and its healing power is embedded in the human psyche. Being sacred has many aspects; it is multidimensional, having the characteristics of numen. This proves the archetypal, instinctive nature of humour. In other products of human activity (e.g. in folklore), humour is also embedded in stories with a moral, to teach the youth. As a way for revenge, for example, the small and the poor outwit the big and rich - this is a way for discharging negative emotions, envy and a way to take advantage over someone, in front of whom one feels helpless. It has integrative, educative, entertaining, therapeutic, estimative, communicative, self-expressive roles.

The collective unconscious is universal, probably also including the animals, writes Jolande Jacoby (2000). Play theories often take an ethological approach to studying humour, tracing it back through evolutionary development. These theories and the situations of conscious suppression (weakness) give information about the roots of some phenomena (humour in this case) and the interaction 
between the conscious and unconscious. Aaron Smuts writes: "They look at laughter triggers like tickling, that are found in other species, to suggest that in humour ontogeny recapitulates phylogeny. In The Enjoyment of Laughter, Max Eastman develops a play theory of humour with an adaptive story. He thinks we can find analogies of humour in the behaviour of animals, especially in the proto-laughter of chimps to tickling. He goes so far as to argue that the wagging tail of a happy dog is a form of humorous laughter." (Smuts 2006) By definition, the conscious is a culturally created and determined kind of psyche. It means that only mature, psychically healthy persons obtain the conscious. But the preposition for humour lays in the unconscious. Do retarded people or people with mental diseases enjoy humour? Yes, because it is empowered by the unconscious, the conscious only gives a "form". What is perceived to be humorous in a normal situation differs from that under the effect of different substances. In the latter case even an apple may seem to be funny, whereas in a "normal" situation, the same person would not think it to be humorous at all. However, humour cannot be explained by way of biochemistry regarding the metabolism of the used substances (e.g. when using LSD), because in the same situation, under the same conditions, the reaction of this person may vary from laughter to fear or panic attack, while under the effect of one and same substance (moreover, the emotions in such a condition could move from one extreme to another). Likewise, the "background" is important, too. When the person is suppressed, in stress, tired, in a dark mood, or not interested, the threshold for something to appear to be humorous is higher, so there are stronger stimuli needed to activate the relevant reaction. In such cases the emotions are suppressed. When consciousness is weakened, emotions arise more easily and powerfully.

The "holding back impulse" of immediately discharging, according to Freud, ensures longer and bigger pleasure - the sophisticated and intellectual kind of humour could be observed in the situations of a good control and "higher" conditions of the conscious, when cognitive functions work well. Such humour is a product of conscious awareness and creativity, and is a kind of art.

All these facts support the thesis that humour has roots in the instinct, in the deepest "layers" of our psychic structure. The archetype expresses the attempt to find a way to release energy in the behaviour, in the activities. How much it "takes" from the conscious depends on many factors, at personal and collective level, and the border is conditional and conventional. Yet all these factors are rooted in the universal unconscious; they originate from this one ubiquitous source, equal for all. "Touching" the conscious and the outer environment, it "meets" conditions that form its face and traits. 
In The Language Instinct Steven Pinker defines the "d-structures - everything, which is hidden, universal, deep or meaningful - they are about the visual perceptions, like narratives, myths, poems, pictures, musical compositions etc. (Noam Chomsky defines this in the sixties of the 20th century). D-structures are the interface between the mental dictionary and typesetting (compositor's) structure." (Pinker 2007: 136) The nature and the structure of the language are in deep connection with the psyche. It is a life form of the psyche and also a construction material for different psychical phenomena, which "are dressed" in the language.

Pinker explains that we do not think in words, arguing that the language does not come from the conscious. He uses the term mindlect when referring to the d-structures. These intuitive structures are on the level of the primal process (Freud's concept) and if we "translate" the product to the level of the secondary process, we have a logical and tidy explanation, but the humorous part disappears (only cognitions play a role in this "translation", escaping the emotions). On the secondary process level, the humour is dead. Very often we may find something humorous, when just seeing it, and if we try to put it in words, the "magic" disappears. In humour, as in language, there is a deep, irrational part which comes from the unconscious and fills the product with these phenomena, giving them life and power.

According to Pinker the mindlect helps us, giving "labels when we see something and guess about its characteristics, which are not immediately visible. In this case we use the traits that we can see as a basis" (Pinker 2007: 179). When we have a "humorous experience", we see traits that the culture and/ or our background experience and personal characteristics "recognise" as humorous. It is compulsive, but in most cases there is a moment of "education" about what is funny. Once "labelled", on a cultural, community level, we are already prepared on a personal level to act in a specific way. The child from early age, subject to a certain culture, begins with more "physiological" samples of humour (cartoons, jokes, etc.), and passing through the process of becoming familiar with the cultural patterns, he/she gets to a certain level, depending on his/her personality, education, experience and cultural background. Pinker (2007: 180) describes experimental testing on babies evidencing that they can recognise objects and activities, even before they know the words which denote these objects. This is another supportive argument underlying that the drive for humour is away from words and activities. The "labelling" has yet another function - it helps "holding back" the release of energy for a shorter or longer period of time, according to Freud, thus causing additional and longer pleasure. (The process of thinking, evolving with the age, is also connected with holding 
the impulse for immediate discharging. This delay develops in thinking, according to Rapaport (Brenner 1993: 44)).

Pinker argues that the deliberated violation of the unwritten norms of communication activates some forms of non-literal language, such as irony, humour, metaphor, sarcasm, wits, rhetoric, biting remarks, persuasion and poetry (Pinker 2007: 270). So, the conditions cannot be placed only in person, in the environment or in the object. They are in variable combination, but the main is the instinct, the congenital need for making and accepting humour - what is "seen" and what is "heard" as humorous is in the language of the primal process, connected with the experiencing of a symbol (according to Jung, the symbol always says more than we see, it is unlimited). Humour may be found in and created by the language.

Arvo Krikmann discusses the relationship between verbal humour and figurative speech, describing cognitive similarity. He finds it difficult to devise clear-cut theoretical criteria to distinguish between the two. Reviewing the concepts of other scholars, he outlines the metaphor as a violation of certain rules, schemas, frames, isotopes, involved in both metaphor and punch-line jokes; the perception of both funniness and figurativeness. Krikmann argues that the "awakening" of metaphors, idioms and "decomposing" of compound word (via translating or otherwise) are largely exploited techniques of humour making, similarly to the parodying of proverbs, and also the blends thereof, which "quite obviously appear to have a strong natural capacity to feed fantasy and produce humour"; "jokes can be based on the literalising, extending, twisting or mixing of metaphors" (Krikmann 2009). Also, nonsensical words could be divided into simply nonsense and funny nonsense. According to Krikmann (2009) "it does not allow us to distinguish more precisely which violations of maxims will simply result as communicative errors, which ones as units of figurative speech, and which ones as humorous items." The analyses so far, according to Krikmann, "do not aim to tell us more exactly which blends do result in humour and which ones do not" (Krikmann 2009). Once again, it is visible that sufficient conditions are not easy to be brought out. The sufficient conditions cannot be found even in the character of the trickster: "Yet it is difficult to say whether the audience is laughing at him, at the tricks he plays on others, or at the implications his behaviour and activities have for them." (Radin 1956: x) 


\section{The sacred and the profane}

According to Jung the primary readiness to believe in transcendental forces, is a premise for the experience of the numinous. The definition that Samuels et al. give about "numinous" is: "A characteristic of a tangible object or impact of intangible presence, which causes a specific change of the conscious. It is unexplainable, but it seems it transfers a kind of individual message, which is mysterious, secret and deeply impressive." (Samuels et al. 1995: 11-112) The numinous cannot be overcome; one can only open himself for it. The archetype has numinous and sacred traits. Mircea Eliade (2000) states that the Sacred is universal and the beginnings in cultures originate from religious experiences and beliefs. He also argues that the dialectics in the Sacred precedes and is a pattern for every dialectic movement, discovered by the mind later. The experience of the Sacred by unveiling the being, the meaning and the truth in an unknown, chaotic and frightening world prepares the way for systematic thinking. The Sacral is an element of the structure of mind; it is not a stage in its history (Eliade 2000). Bearing in mind these conclusions we may review the trickster's images and their "evolution" in different cultures and in time. Eliade describes how very important it is to review a fact not only with regard to its historical, socio-cultural, linguistic, context, but also in its "spiritual" essence and meaning, i.e. "the dimension creates the phenomenon". That is why the description of archetypes is so important - to reach the deep, unconscious, universal matrix and its dynamic, always connected with the conscious and outer conditions, which gives the "community" vision in folklore. Humour which is an option of the mind has sacred and profane traits in a certain balance, changeable in time and space.

Jung describes the archetypes, the traits and dynamics of which are observable in myths, folklore, products of creation, dreams, and can be symptoms of disease.

The archetype of the trickster is the one, opposing the traits of the funny/ humorous/bad/tricky hero with all the sacred and controversial traits in unity. The trickster is a part of almost all the cultures in the world, he is universal. The trickster could be not only male but female, too. This character is the "interface", leading from the universal unconscious to the specific "outer" expression - the products of humour. "He wills nothing consciously" writes Radin, describing the trickster's origin and dynamics. The trickster keeps us from being too confident in ourselves, in our point of view, argues Susan Wyatt (2005). According to her, it is an advantage to be a trickster. He is an inventor of many cultural achievements (fire-making, the lyre, the www, railways (communication), etc. - that proves the creative aspects of humour). However, he is also a de-constructor, 
breaking the rules is his way to find new horizons (the same aspect of "breaking rules" is visible in humour-making methods); finding and bringing knowledge is yet another aspect of humour. The trickster gives us the possibility to experience the paradox; he delights in the "auspicious bewilderment" (Anderson 1998: 84). He refuses the oppression of the spirit - a thing that humour does. Susan Wyatt (2005) describes him as a charmer and enchanter, transformer of reality searching for multiple of possibilities of meaning - these are the traits used by people to describe those who obtain and react with humour. The trickster is skilful with language - the connection between humour and language is undeniable. He provokes insight and awakens energy (Wyatt 2005) - exactly as humour does. The image of the "funny" hero in folklore is very representative of humour (with its own specific psychological traits) in the regions and countries, where the trickster "gets his outer form".

This archetype is about the carnival, about the turning upside down, associated with many rituals (Jung 1956). This is Heyoka from the Native American folklore, the medicine man, the shaman who heals the tribe, always behaves on the contrary to the situation, yet obtains the biggest power compared to all other kinds of shamans. The awakening of his powers is summoned by lightning, by the Thunderbirds in his dreams. In the image of this archetype we could find the grotesque, the chaos, the lie, the demonic, the ugly, revenge, damage, harm and mischief. The character is ambiguous, obtaining also Wisdom, the Sacred in Unity. The trickster (the jester) is the only one allowed to tell the truth to the King, he is the best singer and poet, but often neglected and contemptible. The jester is intuitive, intelligent and clever. He combines prompt truth and the grotesque expression. Trickster stories reveal in "gleeful insubordination" (McNeely 1996: 87). This is closely connected with his divine function, to mediate the worlds.

Diabolic vision is also related to the trickster. The contemporary man likes to keep away from the trickster in ordinary life. But not one of the archetypes can be cut away from the soul. The archetype is "an everlasting presence and the question is only in that: do the conscious accept it or not" (Jacobi 2000: 62).

This archetype is the closest idea to what the Holy Grail of Humour searches for. Being above Good and Evil, ambiguous and whole, this image excludes the pros and cons and is a complete idea. "He has no control. He knows neither good nor evil yet he is responsible for both" (Radin 1956: ix).

The trickster in the culture of Native American tribes is widely spread. In this culture he is presented in his "earliest and most archaic form" (Radin 1956: ix). The Zuni have sacred clowns Koshare (Pueblo clowns), performing during the spring and summer fertility rites. Among the Hopi there are five figures who serve as clowns: the Payakyamu, the Koshare (or Koyaala or Hano 
clown), the Tsuku, the Tatsiqto (or Koyemshi or Mudhead) and the Kwikwilyak. With the exception of the Koshare, each is a kachinam or personification of a spirit. It is believed that when a member of a kiva wears the mask of a kachinam, he abandons his personality and becomes possessed by the spirit. Each figure performs a set role within the religious ceremonies; often their behaviour is comic, lewd, scatological, eccentric and alarming. They dance between the different parts of serious sacred ceremonies, saying funny, ridiculous, rude jokes to some people of the audience. Their behaviour is ridiculous copying of the solemnity. This is a responsible and sacred occupation, not an antithesis of the official ceremony, but an important part thereof. The Mica (Coyote) and Iktomi (the spider-trickster spirit in Lakota mythology) are other trickster-heroes. There is a lot of sexuality, cunning, tricky ways of acting and solving situations. The sacredness connects these traits with a "higher" principal - fertility, wellness, joy, a certain order in the Cosmos, above the profane. In trickster's actions we may observe clear examples of all the basic humour theories: superiority, incongruity, play and relief. The sacred and the profane are closely connected, the character is ambiguous.

Particularly in the "primitive" cultures can we find the essential role of this phenomenon, and the sacred aspect that comes from this archetype proves the irrational nature of humour, originating in the collective unconscious (along with creativity, dreams and symptoms). All other attributes come "in addition", specific for space, time and individual.

The mythological description of Iktomi, the spider-trickster spirit, unveils some important traits that may show how humour is connected with life, what do people accept and how do they do this, what is its meaning and importance. Iktomi is the son of the rock, the creator god. His brother is a destructive and powerful spirit. Once Iktomi was Wisdom, but was stripped of the title because of his troublemaking ways. His malicious plans very often failed, so these tales were usually told as a way to teach lessons to Lakota youth. Iktomi gives the dream-catcher to people. Folk tales unveil how he is respected, feared and mocked. A lot of traits entangle in this hero and all the aspects describe the attitude to the sacred phenomenon of humour in tribal cultures. In collective cultures, in the mythological way of thinking, it is better visible. The opposites are reconciled, this is one of the relevant traits - here we see how evil and good, funny and wise are one, having a supreme power and being servant at the same time. Iktomi is a shape-shifter. He can use strings to control humans like puppets. He also has the power to make potions that change gods, gain control over people and trick gods and mortals. According to a prophecy Iktomi would spread his web over the land. Today, this has been interpreted by some contemporary Native Americans to mean the telephone network, and then the 
Internet - the world-wide web. Iktomi has been considered by Lakota from time immemorial to be the patron of new technology, from his invention of language he gave to the people, to today's modern inventions, such as the computer or robots. The myth is a way for the psyche to talk about itself, according to Jung. These models and ideas, that the folklore narratives give, point to the roots of humour from the unconscious, accompanied by creativity/inventions, language, communication and dreams (dream-catcher) as gifts from one and same character. In the phenomenon of humour we may see its manifestation and similarity in all these, proving the unconscious origin of all (language, humour, dreams). Iktomi is also connected with games and playing, with music and pleasure, just like humour. This is how the mythological basis may give information for the components and the traits of the archetypes. Many Lakota today consider Iktomi to be the god of the Europeans, who (they claim) seem to readily follow his (to them) bizarre behaviour and self-entrapping tricks. This is a kind of projection of unassimilated psychic substances over something "foreign", experiencing them as an "outer" part. This shows the process of splitting in the unity of the character, marking a process of transformation from collective into an individual kind of culture.

Coyote is Iktomi's great accomplice in all of this, though there are times when he behaves seriously and comes to the aid of the Lakota people, there are instances where he gives the people ways to protect from evil, live a better life with technology, or warn them of danger. The European equivalent is the Fox. He rises against the restrictions (just like the Id, according to the psychoanalytical theory), against the authority, he is everything that the "descent" and conform person secretly wants to be: mischief and hero and the one who brings progress as clown and maker. In most of the stories and interpretation he is immortal. There are some tales, in which he made people from wood or clay, invoking life with his breath; he is a Demiurge. He behaves as a normal person, too; there are funny stories with a sexual kind of humour, where he acts as a normal man, in profane situations. The sacred accompanies all tribal life. In one and same story he appears as greedy and lusty, but also as a grateful and heeling medicine man (healing the blind for example) and is "the one who always lives at the shore" (Erdoes \& Ortiz 2005: 548). The Great Secret Power created Coyote; in some stories this Power is very wise and likes joking and fun. The Great Secret Power protects him, because of his funny behaviour. The same way as the Ego appreciates humour and Superego makes restrictions (according to the psychoanalytical theory).

The thin line between fun and stupidity, between harmless and dangerous is described with the four lives that the Power gives to Coyote ("Coyote dances with a star" in Erdoes \& Ortiz 2005: 584) to protect him from his own stupidity. 
By nature the Power is generous, with a sense of humour, wise, but appreciates entertainment and diversity. The trickster is a part of that Power (the Self, according to the analytical psychology concept), an integrated subject thereof.

It is very important to mark the meaning of and the attitude towards these characters. The community gave them the name Wisdom. In peoples' expectations Iktomi created a huge amazing invention as the dream-catcher, and the world-wide-web could be considered to be the most recent "equivalent" of this, as mentioned above. Iktomi is creative, wise, but at the same time bad, envious, greedy and ambiguous. All this makes him sacred, because in such societies (collective cultures), the concepts are closer to their archetypal meaning.

The Algonquin story, "Gluskap Fulfils Three Wishes" (Erdoes \& Ortiz 2005: $553)$, is about the tribe from the "savage" times, searching to find the funny sounds from the body. Yet there is an indication that recently this has changed. In the same story the young man, with the help of Gluskap, obtains the possibility for making such sounds, because he wants to be funny for the others. At first the tribe finds this very amusing, but quite soon no one wants to listen to the sounds any more. This folklore tale allows for diachronic observations and enables to see the sequence of emotional changes - how irritation replaces humour, when it lasts too long. It also tells how something, funny for some, could be disgusting for others; how, in the course of time, the criteria for humour change - in the community and in a single individual. Folklore facilitates the research in time, space, and of us ourselves.

There are other trickster images in Native American folklore - different animals - the Rabbit, the Raven, who possess magical powers and are extremely cunning. However, "basically he possesses no well-defined and fixed form" (Radin 1956: x). Being a shape-shifter, the trickster is just like "humour" (liquid), escapable.

Richard Erdoes is a co-author of a biographic book about the famous shaman from Sioux Lakota, Lame Deer (Erdoes \& Lame Deer 1999). This was not only about his shamanic "career", but his personal life as a trickster, full of adventure and ambiguity (as "morality" according to the wide-spread belief in the collective conscious principles), but not contradictory. Lame Deer is an example of successful unity and harmony. This is how the close connection with the archetype works, giving the opportunity for integration and reaching the Self.

The trickster, as an archetype, lives in every one of us, he is a universal image and rises against the archetype of Persona. His sacred creativity is better visible in ancient stories, where the moral is less important. He brings the vital powers of Chaos, introducing the new, not understandable, the wired, and the progress. 
The completeness of the character may be seen only if searching for its different expressions on the basis of the universal archetype. For instance, the connection with death and unity, that frame the traits of continuation and immortality, is especially well developed in the voodoo culture (Metro 2004). There the trickster images, loa Guédé (Baron Samedi etc.), spirits of the dead, reveal another side of the archetype, giving an idea for its multi-dimensional nature that explains well the feeling for numinous, sacred and mystery. Loa Guédé being promiscuous, their language is full of blasphemy, and their behaviour is scatological and erotic. These are characteristics of humour, but in a generalised line they lead to the sacred concept of fertility. In the same character Fertility is united with the Death - two opposites, which make the trickster ambiguous, but are whole and why this brings the experience of numinous.

In Snorra-Edda there is also a trickster image in the pantheon of gods: this is Loki. He helps the gods, but sometimes makes trouble. He is a shape-shifter, and has a role to play in Balder's death.

We may also find the trickster's traits not only in mythology but also in the "Story of Shuttle-Halli", "Story of Hreidar", etc. Here the trickster loses his "holiness", but is respected, adaptive and survives. The trickster-hero is a legendary character. He may turn every situation to his own advantage and win even in the most severe circumstances. There is no assessment of good or bad, the hero is above them. This is because the ambiguity, which only brings the person to reach the Self, obtaining the Manna-traits (giving possibilities for individuation, opportunity for connection between the worlds, between the sacred and profane). The story gives the feeling that all people, even the enemy, admire him; irrespective of the deeds, the winner is always right. These traits are about the integrative, adaptive aspects of the trickster archetype.

In Kalevala Lemminkäinen is a shamanistic figure. He is an epic hero, but also a trickster's trait bearer. He is a kind of a super-human person; his body is recovered (according to Eliade - a shamanistic skill for initiation) thanks to his mother's prayers and magic. He is not a god, but has supernatural skills. He makes mistakes; very often he shows disobedience in a very funny way, frivolous and rushing, with great self-confidence. Singing loudly and out of tune, not at the right time and place, he becomes the reason for ruining the mission of his friends, but is also good company and a brave hero. Here we see this image still in the group of mythical and sacral.

In the age of Christianity humour is not God's attribute anymore. We may see a clear division in the trickster's image, becoming a Devil's or Satan's characteristic. This marks the beginning of splitting the unity, because in late Christian culture Satan and Christ are not equal members in the Heavenly Pantheon. The ambiguity is apart, in divergence. The trickster's traits are 
reduced and shown with a small range: stupidity, chaos, cruelty, anger, cunning, trouble-making, mischief or misunderstanding, but without the opposite traits (wisdom, healing opportunities, creativeness etc.) in one and the same character. According to Susan Wyatt (2005), it is difficult for the trickster to thrive in a monotheistic world. He could be found in contemporary mythology, too (for example the character of Jack Sparrow in the "Pirates of the Caribbean").

There are some animals in European Christian cultures, bearers of trickster's traits; they are close to the Devil, his familiars or bearing a similar appearance: the Wolf, the Fox, the Raven. Christianity separates the symbols, creates dualism in folklore, in ideas in general. There is a certain negative attitude to those "dark" fellows, the ambiguity and sacral moments, well visible in pagan cultures, are missing. Some pagan traits or plots are imprinted in folklore expression, but the sign and modification of Christianity is very clear.

The national hero-tricksters in Bulgarian and Russian folklore are peasants and the sacral traits are missing. All their activity is aimed at better adaptation, to win an advantage, very often - material acquisitions and prosperity. The character is mostly rational. This is the image of Hitar Petar (The Cunning Petar) in Bulgarian folklore tales. The Devil and the Wolf are also tricksters, having very similar traits in Bulgarian folklore (non-symmetrical, belonging "here" and beyond, ambiguous). They could be either "light-bearers" or "light-eaters".

In Russian folklore this is the image of Ivan the Fool. The profanity of the sacral is visible, but there exists also another element: a kind of a destiny involvement, supernatural luck, Guiding Force, blessing and protective (like the Native American story "Coyote Dances with a Star"). Yet here, this Force is nameless; not explained as a God's will or any other kind of Power. It is helping, forgiving stupidity, appreciating good heart and funny acting. Ivan the Fool is not cunning, like the trickster in Bulgarian folklore. Very often his deeds are just the contrary, putting him into trouble. This nameless Force in the plot takes part in the moral of the story, it is like a conclusion, that this Power exists, protecting the good and funny, and is the "bridge" that welds together the split opposites, bringing back the unity. The sacral feeling is missing, the numen is gone; these stories, being just tales are either entertaining or have an "educational" meaning to the youth (in both ways "do just like Him if you want to win", or "don't fool yourself like Him"). But they are never a subject to healing performance for the community in the way the myth-based narratives were performed in other cultures and times. The sacral experience of the community, the mystery and the ritual are away. The power, the meaning and the importance of the tales and their connection to the myth (through the archetype) is not a subject of this paper. 
The specific traits on a community level put an imprint on personal experience and performing of humour, and on other community phenomena. It is well observable how the instinctive, personal impulses took shape; they form under the pressure of the collective factors and find specific expressions, certain symbolic forms and plots in the folklore. We can see how the meaning changes in time, altering the sacral traits as much as it comes away from the "pattern" of the archetype, forming a part of the individual kinds of culture.

The question about the traits and minimum conditions for something to be humorous should not be asked partially and only from the "outer", descriptive side, without considering the universal phenomenon of the driving instincts, the archetypal nature as a powered impulse. The question should not be asked about a typical average person, culture, time or community.

Exactly as in the myth, the Holy Grail is an archetype - literally. The archetype of the trickster obtains the idea of the unity of opposites, the experience for humour above Good and Evil, on a high, or more exactly "low", basic level. That is why this experience has numinous traits - because of the multidimensional nature of Unity (in the ambiguity) that the archetype obtains. It really exists, but has different vision, appearing "through" the conscious; we cannot push it in one form or definition, but we experience its heavenly sacred and/or desacralised substance (depending on the personal and collective level and difference in time). As everywhere in science, when we ask a question, the answer always begins with "It depends on..." 


\section{NOTES}

1 "The more I cry, the sadder I become." The physiological impulses from the body are reason for psychic reaction and condition.

${ }^{2}$ Giacomo Rizzolatti and Laila Craighero (2004). The mirror-neurons help us understand the behaviour of the others and also "do" the same we see or hear, on a "virtual", subliminal level.

\section{REFERENCES}

Anderson, Rosemarie. 1998. Intuitive Inquiry: A Transpersonal Approach. In: W. Braud \& R. Anderson (eds.) Transpersonal Research Methods for the Social Sciences: Honoring Human Experience. Thousand Oaks, CA: Sage.

Brenner, Charles 1993. Psikhoanaliza. Osnoven kurs. [An Elementary Textbook of Psychoanalysis.] Sofia: Fondatsiia "Otvoreno obshchestvo".

Corsini, Raymond 1998. Entsiklopediia psikhologiia. [Encyclopaedia of Psychology.] Sofia: Nauka i izkustvo.

Eliade, Mircea 2000. Tarseneto. Istoriia $i$ smisal v religiiata. [A History of Religious Ideas] Sofia: Izdatelstvo Lik.

Erdoes, Richard \& Ortiz, Alfonso 2005. Mitove i legendi na severnoamerikanskite indiantsi. [American Indian Myths and Legends.] Sofia: Iztok-Zapad.

Erdoes, Richard \& Lame Deer, John (Fire) 1999. Kutsiia Elen. Tarsach na videniia. [Lame Deer, Seeker of Visions.] Sofia: Shambala.

Jacobi, Jolande 2000. Psikhologiiata na K. G. Jung. [The Psychology of C. G. Jung.] Pleven: Lege Artis, pp. 18, 62, 138.

Jung, Carl Gustav 1956. On the Psychology of the Trickster Figure. In: P. Radin The Trickster: A Study in American Indian Mythology. New York: Schocken.

Jung, Carl Gustav 1999. Arkhetipite i kolektivnoto nesaznavano. [Archetypes of Collective Unconscious.] Pleven: EA, p. 56.

Krikmann, Arvo. 2009: On the Similarity and Distinguishability of Humour and Figurative Speech. Trames: A Journal of the Humanities and Social Sciences, Vol. 13 (63/58), No. 1, pp. 14-40. Also available at http://www.kirj.ee/public/trames_ pdf/2009/issue_1/trames-2009-1-14-40.pdf, last accessed on 30 March 2012.

McNeely, Deldon Anne 1996. Mercury Rising: Women, Evil and the Trickster Gods. Woodstock, CT: Spring.

Metro, Alfred 2004. Kultat vudu v Khaiti. [Voodoo Cult in Haiti.] Sofia: Lik.

Pinker, Steven 2007. Ezikoviiat instinkt. [The Language Instinct.] Sofia: Iztok-Zapad, pp. 136, 175, 179, 269-277.

Radin, Paul 1956. The Trickster: A Study in American Indian Mythology. New York: Schocken.

Rizzolatti, Giacomo \& Craighero, Laila 2004. The Mirror-Neuron System. Annual Review of Neuroscience, Vol. 27, pp. 169-192. 
Samuels, Andrew \& Shorter, Bani \& Plaut, Fred 1995. Kriticheski rechnik na analitichnata psikhologiia na K. G. Jung. [A Critical Dictionary of Jungian Analysis.] Pleven: EA, pp. 38, 79, 171.

Smuts, Aaron 2006. Humor. Internet Encyclopedia of Philosophy, http://www.iep.utm. edu/h/humor.htm, last accessed on 30 March 2012.

Wyatt, Susan 2005. Awakening the Trickster. The First International Congress of Qualitative Inquiry, May 5-7, http://www.iiqi.org/C4QI/httpdocs/qi2005/papers/wyatt3. pdf, last accessed on 30 March 2012. 


\title{
ETHNIC HUMOUR: WHAT DO PORTUGUESE PEOPLE LAUGH AT?
}

\author{
Pedro Martins
}

\begin{abstract}
The concept of ethnic humour may be defined as a type of humour in which fun is made of different traits (especially personality, behaviour and customs) of a group and/or its members thanks to their social, political, cultural and economic background.

Within Portuguese society we may find numerous jokes, riddles and puns about several nations and countries with which Portugal, by virtue of its historical past, had some kind of connection. From an anthropological perspective it is then particularly interesting to try to identify the reasons hidden behind each and every nation's selection. By recalling the three major humour theories we are sure that the jokes, riddles and puns were especially generated either to release tension regarding a tragic situation or to reveal the incongruity of certain behaviour, thus showing Portuguese superiority over the other nations.

It is therefore the aim of the article not only to introduce and share with you a part of Portuguese humour but also to analyse what may be the particular cause of its original creation and today's usage.
\end{abstract}

Key words: ethnic humour, humour, Portuguese culture, Portuguese humour

\section{PART I}

\section{On the concept of humour}

In order to better approach the concept of humour we shall try to answer three main questions regarding our topic: 1) what is humour; 2) why do we laugh; and 3) what do we laugh at?

\section{1) What is humour?}

There is unfortunately no direct answer to this query.

Despite the efforts of many researchers, from different fields of expertise (philosophy, anthropology, psychology), there is no univocal or consensual definition for the word humour. 
It may be interpreted as a biological and instinctive action and reaction to social and communicative behaviour, as a joyful state of mind or simply as something we are able to identify but not define (cf. Darwin 1965; Dearborn 1900; Oring 2003; Sully 1902).

If we were to present our own explanation, we would probably say humour is the ability someone has to amuse him/herself, or others, according to a cognitive stimulus-response mechanism.

Laughing (or at least smiling) is also naturally related to this framework but it is not its standpoint. In other words, since we laugh in many other situations, laughter rather than the essence of humour should be considered as its physiological consequence and its external manifestation.

\section{2) Why do we laugh?}

Based on our previous statement laughter, together with other traits as language and tool making, is usually seen as a characteristic unique to human beings (cf. Apte 1985).

The complex facial expression associated with laughter is a result of a natural coordination between eyes, cheeks, mouth and vocalisation and may occur for many and different reasons. Whether part of the socialisation process or not, laughter may be observed as a reaction to tickling, laughing gas, to someone else's laugh, etc.; as an expression of joy, anxiety and/or irony; and, particularly important to our subject of course, as a response to humour (cf. Goldstein \& McGhee 1976).

According to the three major humour theories as developed by David Hector Monro (1988) people laugh either to release tension and accumulated energy (Relief Theory), to reveal the absurd of certain behaviours and situations (Incongruity Theory), or to show superiority over others (Superiority Theory).

The Relief Theory was firstly presented by Herbert Spencer in 1860 (cf. Spencer 1881). According to this author, in one way or another, during our daily life we accumulate energy from several sources that in the end must be somehow released. This excitation tends to stimulate muscular motion which is usually expressed through its easiest channel - laughter.

At the beginning of the 20th century Sigmund Freud (1928) approaches this same idea claiming, however, that laughter as a consequence of humour has its own source in energy which otherwise would have been employed to repress sexual and hostile feelings.

In this manner, and in both cases, laughter acts as an escape valve for our negative compressed energy. 
The Incongruity Theory is probably the most famous one since it is related to the most typical laughing factors: non-sense and absurdity.

In fact, in accordance with this theory first introduced by Aristotle (1996) and later developed, among others, by Immanuel Kant (1951) and Arthur Schopenhauer (1969), laughter results of a reaction to an unexpected outcome. The surprise element, that suddenly transforms an apparently normal situation or behaviour into something absurd, usually makes us laugh.

From a social perspective, laughter due to incongruity may also act as a very strong social corrective. On one hand it helps community members to recognise the faults and undesired actions of their peers and, on the other hand, by discriminating against those who do not live by the established rules, contributes to the creation of a constant pattern within the entire society.

The Superiority Theory is based on the fact that people laugh in order to reveal their triumph over other people or circumstances.

Whenever we feel less foolish, ugly, unfortunate or less weak than our peers, a sense of euphoria is generated inducing us to laugh.

Thomas Hobbes (2005), probably the best known superiority theorist, talks of laughter as a sudden glory arising from the conception of some superiority in ourselves by comparison with the inferiority of others or with our own former situation. This is what we could also call the joy of victory, the typical "Ha, ha!" response after defeating someone's idea, thought or argument.

These three perspectives, however, do not represent the entire theoretical framework. As a matter of fact, they should not even be considered as rivals; on the contrary, they are to be seen as truly complementary to each other.

\section{3) What do we laugh at?}

The answer to this question is very subjective. Humour is a personal feeling and follows no logical thoughts.

In a single and general sentence we could, however, borrow Henri Bergson's perspective and state that the comic element does not exist outside of what is strictly human (Bergson 1980). In other words, everything can be humorous as long as it may be humanly and intellectually analysed. What we are trying to express is that we may laugh at everything because we (human beings) are able to judge everything that surrounds us in a funny way. If we laugh at an animal, or even at an object, it happens only because we are giving to it a human and humorous use and interpretation.

Nevertheless we could also definitely point out some other factors which normally would make us laugh, namely: 1) repeated actions, 2) snowball effects, 3) deformations, 4) absurdity, 5) exaggeration and 6) language itself. ${ }^{1}$ 


\section{On the concept of ethnic humour}

Ethnic humour may be defined as a type of humour in which fun is made of different traits of a group and/or its members thanks to their social, political, cultural, religious and economic background (cf. Apte 1985).

According to Christie Davies "the term "ethnic" tends to be used in a broad way about a group that sees itself and is seen by others as a people with a common cultural tradition, a real or imagined common descent, and a distinctive identity" (Davies 1990: 1). The most frequently mentioned topics, within ethnic humour, are therefore geographic origin, ancestors, customs, religion, race, language and physical attributes (Apte 1985).

Despite its apparently inappropriate use - it is in fact easily accepted that besides discriminatory feelings, "ethnic humour may conceal malice and allow expression of aggression without the consequence of other overt behaviours" (Apte 1985: 140) - it is simultaneously true that ethnic humour gathers many other social and psychological functions: 1) it may substitute physical aggression, 2) express social criticism, 3) help the preserving, defending or enhancing of the ego of a certain community, and at the same time 4) it may also simply entertain.

Whenever we tell a (ethnic) joke making use of commonly used techniques such as over-generalisation, stereotypes, exaggeration of gestures, accents, deformations and so on we present a "misleading tale that begins as a plausible account of a real people and then switches to an absurd script based on a wellknown, established convention" (Davies 1990: 320). ${ }^{2}$

We have therefore a precise and identified mock target that, even if replaced according to the speaker's will and necessity, will always play an exact and determined humorous role; we mean that as long as the contextual determinants subsist - nature of the considered society, type of contact and interaction between addressed and addressees, historical motivations, etc. - ethnic jokes will always persist.

\section{PART II}

\section{On Portuguese humour}

In this second part we would like not only to introduce some Portuguese jokes, riddles and their respective mock targets but also to understand why the Portuguese people tend to laugh at them. 
These are the results of personal choices and interpretations, we confess, but only within the scope of better illustrated part of Portuguese humour and culture. They do not represent the author's way of thinking.

The following jokes were divided into six different groups according to the targeted origin or nationality (Chinese, Russian, Brazilian, African, Spanish and Portuguese).

Their vehicular language is naturally Portuguese and even though many translation theorists say it is impossible to translate a joke, we have done our best trying to render them into English - all the translations are therefore our responsibility. All jokes may be easily found on the World Wide Web in sites dedicated to Portuguese Humour ${ }^{3}$.

\section{1-2) Chinese and Russian people}

There are actually not so many jokes on these nationalities as the contacts Portuguese people had with the citizens of those countries are rather few. Still, Portuguese nationals take advantage of phonetic similarities between all three languages in order to stimulate the sense of humour among their peers.

Since their contents mostly regard linguistic and phonetic aspects we may classify it as ethnic humour based on language attributes, however, we should also affirm there are no malice or offensive thoughts in either case. As we may see, Portuguese people try to amuse their audience answering all questions in an apparently correct form by mixing and playing with Portuguese words that may sound Russian or Chinese, at least to a Portuguese speaker.

Their goal is therefore simply entertaining:

- Do you know how you say "mother-in-law” in Russian? [No]

- Sóstorva!

[In Portuguese: Só estorva - 'she only disturbs']

- Do you know what the name in Russian is for "someone who is about to die"? [No]

- Pépakova!

[In Portuguese: (Com os) pés para a cova - 'to have his/her feet towards/ near the grave']

- Do you know how do you say "vacuum-cleaner" in Chinese? [No]

- Limpópó!

[In Portuguese: Limpa o pó - 'it cleans the dust'] 
- Do you know how to say "your hair is dirty" in Chinese? [No]

- Sen Chan Pô.

[In Portuguese: Sem champô - 'without shampoo']

\section{3) Brazilian people}

According to the jokes we are about to consider, Brazilian people, on the contrary, are regarded with malice. As in most cases of ethnic humour, based on physical and psychological attributes, Brazilians are here criticised and discriminated against for their lack of intelligence. It represents therefore a clear example of the Superiority Theory which, in this case, may also be linked to the historical relations between both countries. If previously Portugal used to dominate and subjugate the Southern American territory, as well as its people, for almost four hundred years (16th-19th centuries), lately (especially in the last decade) Brazil's economic and political role became everyday more and more important. This new and unexpected reality stung Portugal and its national pride and status so that Portuguese people had to create different ways to claim their (pseudo) superiority over their former colony:

Two Brazilian people were admiring the Colosseum in Rome...

- My God! Isn't that amazing?

- Oh yeah! Now just imagine when it will be finished!

A Brazilian citizen was catching a plane to go back to Brazil. He had a second class ticket but he was trying to travel first class. The hostess noticed his deception and approached him saying more than once he would have to go back to his assigned place. But the man was stubborn and replied he wouldn't go anywhere. He wanted to travel first class no matter what. Without knowing what else to do, the hostess called the captain. When he came next to the Brazilian, he whispered something to his ear and the man immediately ran back to his place in second class. Watching this situation the hostess was very surprised and asked the captain:

- Excuse me, captain, what did you say to him?

- Oh well, I simply told him first class was not going to Brazil! 


\section{4) African people}

The following two ethnic (racial) jokes were particularly common during the Portuguese Colonial War in Africa (Angola, Guinea and Mozambique) in the 1960s and the 1970s. Thanks to both examples we may observe, firstly, the use of the Superiority Theory in order to disgrace the poor and badly nourished nationals of the Portuguese ex-colonies in Africa who could not easily have access to meat and, secondly, the need to enhance awareness and relieve Portuguese people and soldiers about typical and tragic war situations such as stepping on a landmine. By making use of this kind of humour Portuguese nationals were trying not only to sustain their spirit and morale but also to convince themselves that they were stronger and more powerful than Africans:

- Do you know when a nigger eats meat? [No]

- When he bites his own tongue!

- Do you know when a nigger reaches a higher level in his life? [No]

- After stepping on a landmine!

\section{5) Spanish people}

In the next two examples we may observe malice is once again present in Portuguese jokes. If we consider rivalry has always been part of the PortugueseSpanish relations, it is not surprising that Portuguese nationals use humour to criticise the neighbouring country either to stimulate and/or enhance the Portuguese ego. Despite the geographical, historical and language proximity between both countries, the previewed jokes show that Portuguese people may be very hard on their Iberian "brothers"/neighbours and, as in the second example, even launching them out of an airplane. Within the second situation an extra cultural explanation regarding Aljubarrota is due: at the end of the 14th century Portugal was facing a serious succession problem as after King D. Fernando's death his only female child was married to the King of Castile. If on one hand there were people interested in the unification of both kingdoms, on the other hand the majority of the Portuguese nationals desired that Portugal remain independent. Thus, being in such a situation and in order to mark his position, the King of Castile decided to invade Portugal but he was completely defeated by the Portuguese soldiers in the famous battle of Aljubarrota. Therefore, Aljubarrota stands as a sign not only of Portuguese independence but also of Portuguese superiority over Spanish people. 
Before the visit of the Spanish Prime Minister to a Portuguese school, the teacher decided to prepare his students for the welcoming ceremony for his distinctive guest.

- OK children, you have to be very polite with the Spanish Prime Minister, do you understand?

- Yes, sir...

- And when I'll ask you what do you think about Spain, you'll say Spain is a very good friend of ours, OK?

- Yes, sir...

But Joãozinho stood up and replied:

- No teacher, we should say Spain is like a brother to us.

- I see, but you don't have to exaggerate. Just say it is like a friend to us.

- No, no, like a brother!

- But Joãozinho, why do you insist we should say Spain is like a brother and not like a friend to us?

- Teacher, it is simple, because friends we can choose!

An Englishman, a Frenchman, a Portuguese and a Spaniard are on a plane. Due to an engine breakdown and after getting rid of all the cargo, the captain tells the four passengers that only one can remain onboard and that the other three would have to put their parachutes and jump out of the plane.

After a moment of silence, the Englishman steps to the door and before launching himself off the aircraft screams: "Long live the Queen!"

After him comes the Frenchman and just before launching himself off the plane says: "Long live Jeanne D'Arc!"

And then comes the Portuguese and screams: "Long live Aljubarrota!" throwing the Spaniard through the open airplane door.

\section{6) Portuguese people}

Portuguese people can also be very critical about themselves.

According to the Relief Theory and Incongruity Theory, we may naturally argue the next three jokes are no more than ironical but it is also defendable that they rather reveal a very strong social critique with two main interpretations: on one hand, they represent an opportunity to point out different faults, incongruities and defects of the Portuguese society as well as that of its members and, on the other hand, they work as a social reaction so that the negative aspects of the Portuguese community may be minimised and eventually 
accepted. Laughter is thus supposed to stand as the true remedy towards the enhancement of society:

An Englishman, a Frenchman, and a Portuguese travel together throughout Europe...

The Englishman:

- Oh, I think we are in London...

- Why do you say that? (ask the other two)

- There is Big Ben!

A couple of days later the Frenchman says:

- Oh, I think we are in Paris...

- Why do you say that?

- There is the Eiffel Tower!

A week later the Portuguese also has his say:

- Oh, I think we are now in Lisbon...

- And why do you say that?

- Someone has stolen my wallet!

The Heads of State of Portugal and Switzerland meet each other at a European summit...

The Portuguese Head of State introduces his team to the Swiss colleague:

- These are my Health, Education, Culture and Justice Ministers.

- Nice to meet you all. (replied the Swiss delegate)

And then he introduced his own team:

- And these are my Health, Agriculture, Education and Navy Ministers.

The Portuguese suddenly laughs at him and asks surprised:

- I am sorry to interrupt you but... well... if Switzerland has no sea, why do you have a Navy Minister?

- What do you mean!? (replied the Swiss Head of State) When you have introduced your Health, Education, Culture and Justice Ministers, I haven't laughed, have I?

After being captured, a Frenchman, an Englishman, an American and a Portuguese face a firing squad...

The French prisoner takes his place before the soldiers and thinks of a way to avoid his death. When he heard the word of command "Reaaaaaaaadyyyyyy..." he decided to scream "Earthquake!" and everybody ran away... 
When the English prisoner's turn came, he was ready to use a similar trick. And when the general said "Reaaaaaaaadyyyyyy..." the Englishman screamed "Tsunami!" and everybody left the place...

By the time the American prisoner reached the shooting mark and heard the command "Reaaaaaaaadyyyyyy..." he screamed "Hurricane!" and everybody went away...

At this point it was time for the Portuguese prisoner to face the firing squad. "Reaaaaaaaadyyyyyy..." - "Oh my God... What shall I say..." (thought the Portuguese) "Let's see: Earth, Water, Wind... Hummm... Oh, I know: Fire!” (he screamed)

Last but not least we would like to show that Portuguese people are also very proud of themselves as well as of their capabilities.

As a matter of fact, the Portuguese consider themselves to be particularly successful at getting out of trouble and/or at inventing unexpected solutions, therefore national humour could not ignore this. Our next and final joke points out another clear example of the Superiority Theory in which it is not even important to bring out other nationalities. In this specific case Portuguese humour and competence subsist independently and erga omnes without any need of direct confrontation or opponent. Although this joke could naturally be also related to the theories of absurdity and incongruity, its main goal is definitely to stress Portuguese people's (sometimes involuntary) superior and outstanding abilities:

In a Portuguese elementary school the teacher asks, out of the blue, a pupil who was not paying attention to the lesson:

- You there, tell me two pronouns, quickly!

The boy, very frightened, stands up and says:

- Who? Me?

- Oh, ok... Very good, I thought you were distracted. You can now sit down again, thank you.

\section{CONCLUSION}

In conclusion, and as previously stated, it was our goal not only to introduce and present part of Portuguese humour but also to analyse as to what may be the particular causes for its original creation and today's evocation. 
After having presented the principle humour theories, respective Portuguese jokes and riddles on this subject and the analysis of the major questions regarding humour and laughter, we would hope that Portuguese humour and culture is now much closer and clearer to us all.

\section{NOTES}

1 In order to obtain a full perspective on this specific topic allow us to suggest you six Monty Python sketches that perfectly illustrate the respective given examples: 1 ) "Falling from building"; 2) "Dirty fork"; 3) "Ministry of silly walks"; 4) "Silly Olympics"; 5) "Killer rabbit"; 6) "Argument clinic".

2 Cf. Monty Python sketches, endnote No. 1.

3 Cf. http://anedotas.numsitedejeito.com/, last accessed on 30 March 2012.

\section{REFERENCES}

Apte, Mahadev 1985. Humour and Laughter: An Anthropological Approach. London: Cornell University Press.

Aristotle 1996. Poetics. London: Penguin.

Bergson, Henri 1980. Laughter. Baltimore: John Hopkins University Press.

Darwin, Charles 1965. The Expressions of the Emotions in Man and Animals. Chicago: University Press.

Davies, Christie 1990. Ethnic Humour around the World: A Comparative Analysis. Bloomington: Indiana University Press.

Dearborn, George V. N. 1900. The Nature of the Smile and Laugh. Science, Vol. 11, No. 283, pp. 851-856.

Freud, Sigmund 1928. Humour. International Journal of Psychoanalysis, Vol. 9, pp. 1-6.

Goldstein, Jeffrey H. \& McGhee, Paul E. 1976. La psicologia dello humour: prospettive teoriche e questioni empiriche. Milano: Angeli.

Hobbes, Thomas 2005. Human Nature. In: The English Works of Thomas Hobbes of Malmesbury. Vol. 4. Yarmouth: Elibron Classics, pp. 1-76.

Kant, Immanuel 1951. Critique of Judgment. New York: Hafner.

Monro, David Hector 1988. Theories of Humor. In: L. Behrens \& L. J. Rosen (eds.) Writing and Reading Across the Curriculum. Glenview, IL: Scott, Foresman \& Company, pp. 349-355.

Oring, Elliot 2003. Engaging Humour. Chicago: University of Illinois Press.

Schopenhauer, Arthur 1969. The World as Will and Representation. New York: Dover Publications. 
Spencer, Herbert 1881. The Physiology of Laughter. In: Humboldt Library of Popular Science Literature. Vol. 17. New York: J. Fitzgerald, pp. 253-258.

Sully, James 1902. An Essay on Laughter: Its Forms, Its Causes, Its Development and Its Value. New York: Longmans, Green \& Co. 


\title{
THE JOKE CYCLE ISLAND OF CANNIBALS: STRUCTURE, FUNCTIONS, MESSAGES
}

\author{
Grigor Haralampiev Grigorov
}

\begin{abstract}
The author argues that the fundamental interdependence between structure and meaning in the joke can be outlined only if the joke cycle is chosen as a main research topic. As an example, the joke cycle Island of cannibals is analysed. The specific features of the cycle are: people from three emblematic communities and the cannibals as characters; an initial frame and their successive episodes; the trial; the gradation.

The analysis uncovers the hidden meaning of every specific feature, posing questions about their function. Why is it that the joke must include three successive episodes? The behaviour of the first two characters creates an expectation of a normal reaction of the third character, destroyed at the point of the joke. What is the function of the trial? The trial is a specific rite of passage, etc. These steps help to uncover the hidden meaning of the joke cycle: the "Our" (here - the Bulgarian) character succeeds in proving that he has the cultural competence to become a member of the cannibal society because we are uncivilised, aggressive, "cannibals"... The conclusion is that these jokes release masochistic impulses and they are aimed not at the "Others", but at "Us", or, this is a specific type of auto-racism.
\end{abstract}

Key words: auto-racism, cannibals, folklore, genre, humour, joke, jokelore

Arvo Krikmann (2006) has reviewed contemporary humour theories and classified them in 3 groups:

1. Theories of incongruity, or inconsistency, or contradiction, or bisociation.

2. Theories of superiority, disparagement, criticism, or hostility.

3. Theories of release, relief, or relaxation.

With all respect to Prof. Krikmann I would prefer to re-arrange his generalisation. Thus, the first category may be extended to a more general formulation - these are theories (logical and linguistic), which explain how laughter is produced and what kind of mechanism makes the joke possible. On the other hand, categories 2 and 3 can be integrated as theories regarding the social contribution of the joke. Thereby, we have two conclusions: 
1. Theories of the semiotic game (linguistic or logical) mechanism producing laughter.

2. Theories of cultural functions of laughter as a specific human reaction. This reformulation leads to an explicit research function that must follow simultaneously two directions. On the one hand, the joke-producing game mechanisms should be investigated, i.e. the humour instruments - these questions exist in the field of semiotics. On the other hand, the very human ability of laughing must be analysed; in this direction we should try to answer the questions "why are we laughing?" and "what makes us laugh?" - and these questions lie in the field of semantics. The goal of this operative function is to prove the fundamental interdependence between game mechanisms and the plot. For this purpose two methodological frames can be applied: the mature non-enigmatic structuralism, developed in Tartu and Paris (regarding questions of semiotics), and the reception theory, formulated in Constance, referring to the reception and the contribution of the work (on the question of semantics) ${ }^{1}$, from which the results will be expressed in psychological terms.

The chosen methodology requires a specific approach to the material, mainly regarding the choice of the joke cycle as a research project. Two reasons motivate this decision. Firstly, there is no strictly drawn border between the joke and the "neighbouring" texts. Thus, collections of jokes share a lot of non-joke forms (play upon words, puns, bon mots, inversed wellerisms, etc.). It is enough to take a pun, to put it in the frame of Radio Erevan was asked..., to place it in a situation of joke speech and we will have a joke, or, a quasi-joke. It is specific for the most part of undisputed jokes that they generate cycles - this is the second difference between schwank and joke, the first one being the point of the joke, as Arvo Krikmann (2009) argues.

Secondly, the joke cycle is the field where semiotic and semantic issues can be observed simultaneously. This is due to the fact that every joke cycle is focused on certain social phenomena and carries a constant message. On the other hand, many jokes from a cycle and, as a rule, have largely a common structure. So, we can conclude that to a not too inconsiderable degree each joke cycle is characterised by the unity of structure and message ${ }^{2}$. Actually, there are two types of joke cycles: subjective, i.e. focused on a concrete character (blondes, cops, Scotsmen, Stirlitz, etc.), and predicative, organised by a specific situation (Man caught the golden fish, Man returned home from a business trip, People caught on an island by cannibals). The last plot will occupy our attention in the following pages - following the outlined plan firstly, we will define the semiotic game, which organises the joke cycle (structure), then, we will reveal its cultural function (semantics). 


\section{STRUCTURE}

All variants of this joke cycle, which I found in the Bulgarian Internet, are included in the appendix to the paper. It is not impossible that some other examples can be added too, but they would scarcely change the picture. The narratives have a stable plot structure: after an accident (a plane or a shipwreck) three men of different communities (nationalities) find themselves on an island of cannibals. After the natives' hostile reception they get a chance to save their lives by passing a trial process. One of them reacts in an untypical way (far from our notions of normality), and usually saves his life. From a formal point of view the jokes of this cycle are composed of an initial frame and three successive episodes: two of them are quite similar, and the third one is completely different. This third episode is the point of the joke, or, the moment of the "narrative transformation" (Todorov 1980), i.e. this is the moment when the initial situation is transformed to the final scene. It is not a coincidence that characters are exactly three: the reactions of the first two men are necessary to create an expectation of a normal reaction by the third one (the "horizon of expectations"), which the outcome will virtually destroy.

Burlesque variants of this joke cycle also exist - then the different reaction of the third character does not save him (see examples Nos. 15-17). However, even in this case the point or the transformation is not omitted, so it is an example of zero transformation - "when the effort for change of the previous situation is ruined" (Todorov 1980: 130, see also Todorov 1978). Moreover, zero transformation is typical for the jokes because the stabilisation of a plot creates the opportunity for the emergence of its burlesque doubles, which provoke laughter on the basis of the "misleading expectations". A long time ago Henry Bergson (1924: 41) reminded us of two classical definitions of laughter: "Laughter could be a symptom of an effort which suddenly turns out useless" (Herbert Spencer) and "Laughter is the effect of a sudden transformation of a tense expectation of nothing" (Immanuel Kant) ${ }^{3}$.

The joke cycle Island of cannibals is a part of a bigger group of exaggeration jokes which can also be named gradational. The role of exaggeration as a source of humour is well-known - there is no need to look for many authoritative opinions; it is enough to once again quote Bergson: "Exaggeration is comic when it is continuous and mostly when it is systematic". This formulation needs to be supplemented: although it is used as constructive technique, the systematic exaggeration is not comic taken alone - to provoke laughter, even the strongest exaggeration must be expressed by a signal which is alien to the established logic, by opening of another plan. This opinion can be illustrated by the following political joke: 
The presidents of the great nations asked God:

Reagan: How many years will pass to the moment when my nation will become absolutely happy? - 50 years. Reagan left crying.

Mitterrand: The same question. - 100 years. Mitterrand left crying.

Gorbachev: The same question. - God left crying.

It is clear that, if in the point of the joke, some immense number (as 10000 ) was mentioned, the exaggeration would not be funny. This leads to the assumption that laughter is provoked not by the exaggeration itself but by the invasion of a signal which is alien to established expectations. Thus, the constructive mechanism acts in the following way: a gradation is set up which ends with a leap, foreign to the current logic of gradation. In other words, we have an opening of a second plan, which results in pushing of gradation logic beyond its natural border (from a formal point of view), or in exaggeration which cannot be exceeded (from a semantic point of view). Another example will illustrate this mechanism:

Three trappers were boasting while sitting by the fire. The first one said: "Once I was sleeping on my horse and when I woke up I saw a bison herd running against me. I took my gun, started shooting and killed 100 bisons to make a path among them!"

The second: "Once I entered an Indian village and the men of the tribe attacked me. I killed them all with my gun - there were over 200 warriors!"

Then the third trapper calmly stirred the coals with his penis.

It is obvious even from these few examples that a radical transformation occurs in the point of the joke: either the action is changing, or the statute, or the roles. If we go back to the cycle Island of cannibals, we shall see that the third character does not just do something more than the others; he does it in a totally different way. The turnover is manifested also by the change of the roles - the knowledgeable becomes unaware. Principally, the exaggeration jokes have a 3-episode structure, but this is not the rule - they can be reduced to the structure question - answer. In this case the notion of "normal" appears in the minds of the listeners in the time gap between the question and the answer, as in this joke:

How did the Grand Canyon appear? A Scotsman lost a penny in a ditch...

Nevertheless, all joke variants of the "cannibal" cycle contain the first two reactions, and it seems that they cannot be omitted. This fact is meaningful too $^{4}$, and on this basis a supplementary meaning can be extracted: the first two reactions are necessary to stabilise the image of the cannibals which is not 
altogether stereotypical - the cannibals are aggressive, but not uncultured and this, as we shall see, is meaningful. This is the next bridge between structure and semantics: the 3-episode structure is necessary for the shaping of the cannibals' image.

\section{SEMANTICS}

The plot of the "cannibal" joke cycle comprises a story of a competition between people from different nations (the gradation is a figure of the competition - this is the next link between structure and meaning), and the rules of the game are set by unprejudiced arbiters who are not influenced by nation's prestige. The competition winner is the "Our" character (here - the Bulgarian, or the Russian) who is more resourceful than the representatives of the great nations. Thus, the reception contribution of the cycle and the reason for its telling is that the narrator and his/her listeners enjoy, in a compensatory manner, the game situation where the "Our" character defeats those who usually outmatch "Us". This is the infantile delight in accepting a dream as reality. Indeed, some of the jokes do not contain any other reception contribution (as Nos. 1-4, which we define as narcissistic).

But this statement is nothing but a simplification and it does not reveal the potentials of others examples. If we carefully look at the images of representatives of different nations we shall find that the jokes do not give reason to conclude that the "Others" (the American, the Frenchman or the Englishman) are less flexible; they are just more cultured while the Bulgarian is obviously more primitive. Thus, the big difference between characters follows the dichotomy nature - culture. Moreover, the first two characters act rationally while the third one does so irrationally. Then isn't it the message of the joke: we are less cultured but this situation has some advantages?

This conclusion does not reveal all the meanings that the jokes contain. We must further provide an answer to some more questions: why such a long initial frame is necessary, why the jokes persistently return to the island of cannibals (next minus-device). According to the rules of speech economy, if the frame is not a part of the message, the jokes could begin with the utterance: An American, Frenchman and Bulgarian took a decision to compete under the following conditions... But in this case the joke will disappear. Why?

The island of cannibals is necessary to underline the competition's peculiarity - it is not a simple competition, but an initiation, a rite of passage, as it was defined by Arnold van Gennep (2004). It is well known that the initiation trials in archaic societies are rituals which permit the adolescent to become a 
full member of the community. From this point of view, the representatives of different nations cannot pass the trial - not because they do not possess personal abilities, but because they lack necessary cultural competences. In contrast, the "Our" character succeeds because he is familiar with the cannibal's cultural codes and norms, because he feels himself at home among them. Furthermore, he succeeds even to surprise the cannibals because the norms in his own country are even more cannibalistic that in the cannibals' society.

What does this mean? Though the "Our" character wins the competition, the jokes emphasise that the victory is not due to his personal skills but to the fact that he is living in a society, similar to the cannibals' one; the Bulgarian succeeds, because the Bulgarians are uncivilised, aggressive, cannibals... In these cases the jokes release masochistic impulses, which are aimed not at everyone else, but at us - because we find in ourselves the same features, which we hate in the "Others". This is the opposite side of national narcissism, which does have nothing in common with rational self-criticism: this is the reason to name these jokes masochistic.

From this analysis we can extract a more fundamental conclusion: the jokes with characters representative of different nations are compensatory - they are a cultural mechanism to redeem our low national spirit.

The compensation can be manifested in two ways: narcissistic (when without good reasons we consider ourselves identical with civilised nations); or masochistic (when, again without solid grounds, we assume that we are uncivilised). That is why through one character there can be expressed such contradictory messages at one and the same time that: we are and we are not civilised.

Yet, we have not extracted all messages that the analysed cycle contains. A joke with similar structure, but with a different frame, gives a hint for the discovery of another important element:

The devil caught the American, the Frenchman, and the Russian, and gave them two tests: to drink 10 bottles of alcohol and to sleep with 10 women.

The American confessed that he is able to drink 3 bottles and he is able to sleep with 3 women.

The Frenchman announced that he is able to drink 5 bottles and to sleep with 5 women.

The Russian declared that he will drink 11 bottles because he always has a bottle in his pocket. Then he suggested sleeping with 11 people, because the devil looked sexy too. 
In this case the cannibals are replaced by the devil but this does not confuse the message, which can be understood in two ways: narcissistic (the "Our" character transcends the devil's wile), or masochistic (the "Our" character is more amoral than the devil). Thus, the cannibals and the devil are counterparts and the choice between two initial frames is one between violations of two taboos: blasphemy and racism. This fact reveals another blind spot - the joke cycle Island of cannibals contains arrogant attitudes toward primitive and non-European cultures, and it is straightforwardly racist. In order to make sure that we are correct we should speculate on the question: why the initial frame is "men are caught on an island by cannibals", and not "men are caught by an aggressive cannibal tribe"? There are two possible answers: firstly, because the cycle is stabilised following the pattern of texts like "Robinson Crusoe"; secondly, because the image of the island is necessary to underline that the scenery is not in Europe, i.e., to produce the racist message.

But the racism of this joke cycle is unusual as it is not directed against the "Others" but against "Us"; this is auto-racism, because in "Us" we discover features that we hate in the "Others". This statement might look as an overinterpretation, but actually it is not: in Bulgaria, where the joke cycle is wellknown, the contextual background being idioms such as "we joined the African countries", "if only we could feel as the white people", "we are like Indians"; in Bulgaria the clichés "Bulgarian work" and "Gipsy work" are synonymous and have the meaning of 'incomplete, poorly done work'. It is clear - at least after the pioneer work of George Lakoff and Mark Johnson (1980) - that "the metaphors we live by" influenced our notions and even our everyday activities. The presence of the joke cycle in a concrete culture is a symptom, in which its bearers develop masochistic auto-racism, which, of course, gives the comfort of thinking of themselves as innocent victims.

A similar hypothesis has been presented in Bulgarian scientific research by Aleksandar Kyosev (1998: 9f.). He proposed the concept of self-colonisation to describe the policy of Bulgarian intellectuals after the liberation from Ottoman rule (1878), orientated towards the overcoming of the feeling of backwardness and on the creation of cultural standards, similar to European ones. He speculates that self-colonisation is a peculiar situation where a culture finds itself uncivilised because it sees itself from the perspective of civilised foreigners. This policy persisted in Bulgaria until World War I, after which the appeal "back to the roots" replaced the call for "Europeanisation". It is symptomatic that this line exactly coincides with the public attitude towards the Bulgarian joke character Bay Ganyu.

Its origin is literary - the name is borrowed from Aleko Konstantinov's book "Bay Ganyu" (1895), the first part of which consists of stories - funny and sad at 
the same time, - about the inadequate reactions of a Bulgarian during his trips in civilised Europe. So far there is nothing unexpected - a lot of joke characters are based on literary characters (Natasha Rostova and Lt. Rzhevskii, Stirlitz, etc.), and some of them become joke personifications of national characters (as Tartarin of Tarascon in France, Švejk in the Czech Republic). There is another interesting point - when Konstantinov's book was published the Bulgarians recognised Bay Ganyu as an anti-hero and were shocked at the idea that he could be thought as a personification of the Bulgarian national character. But during World War I the Bulgarians started to sympathise with Bay Ganyu and recognised him as a typical representative of the nation. Later the fluctuations of the attitude to him became more balanced and nowadays we are inclined to accept Bay Ganyu simultaneously with a sympathetic and ironic identification (Jauss 1978b: 150-153), i.e. we accept and reject him at one and the same time ${ }^{5}$.

Probably the evolution of the joke cycle Island of cannibals followed the same pattern. The masochistic jokes appeared first (otherwise, the initial frame would be unnecessary), and later as a replica - the narcissistic and burlesque variants. Nowadays they exist simultaneously, and depending on the context, we laugh in a compensatory way, giving vent to our narcissistic or masochistic impulses. As the structure poses the problem of negative and positive features of our national character, but does not resolve it so - the final judgment depends on stereotypes incorporated in the joke.

$$
* * *
$$

And eventually, two conclusions must be outlined. The first one is the successful decision to choose the cycle as the main element of analysis. If we have interpreted a single joke or the full thematic group of jokes about national character, we would miss determining that these jokes function as being political (when they are narrated in a totalitarian state) and the fact that, in their depth, they are racist.

The second conclusion is that the joke cycle is a narrative matrix, which enables the realisation of certain compensations whose type depends on stereotypes used in the joke. Thus, the joke cycle Island of cannibals poses the issue of the national character in the same way as the cycle Man caught a golden fish calls on the story of the missed chance - but this article has not been written yet. 


\section{APPENDIX}

\section{Narcissistic}
A. Characters
B. Trial
C. Result
D. Point

1 Englishman, To wash their The Englishman German, Bulgarian. socks, to sleep with a native woman and to write their autobiography in 5 minutes. washed his socks, the German wrote his autobiography, the Bulgarian succeeded in doing everything.

How did he do that? He made the woman stand on all four, penetrated her from the back, wrote his autobiography on her back, and made her wash his socks. "If we had tied a frame-saw to my ass, I would cut wood too!"

2 American, Frenchman, To make natives laugh and then Bulgarian. shock them with the totem animal of the tribe - a horse.

The cannibals will cut the penises of the victims depending on their professions.

4 American, Frenchman, Bulgarian.
To suggest an insoluble riddle.
The American and the Frenchman failed completely on the first stage. The Bulgarian succeeded in both.

"How did you manage it?" - "First I said to the horse that my penis is bigger than his and then I showed it to him".

The American woodcutter (with frame-saw), the Frenchman - butcher (with chopper).

The American: "100 penises - 1 rope?" -"100 men are pulling a ship". The Frenchman: "100 ropes - 1 penis?" "Parachutist". The riddles were solved.
The Bulgarian: "9 wings - 5 penises?" - "No idea". - "Ninewingy fivepenis". 


\section{Masochistic}
A. Characters
B. Trial
C. Result
D. Point

American, To have good

The American:

The Bulgarian:

Frenchman, recommenda-

"Let me go! I am a

Bulgarian. tions (hidden trial).

friend of Bill Clin-

ton!" The Frenchman: "I am a

"Such people did not impress you, how can I - an friend of General De Gaulle!" The cannibals were not impressed and ate them.

engineer from Sofia University?" - "When did you graduate?" "Which courses did you take?"

6 George Bush, To find the Bush and Putin Vladimir unique male failed, Petar StoyPutin, Petar Stoyanov. mosquito among millions of females.

succeeded.

How? "I entered and introduced myself: I am Petar Stoyanov, the president of Bulgaria!" And one of the mosquitos replied: "Fuck my cock"! ${ }^{6}$

7 American, Frenchman, To teach a dog (the totem animal) to speak. The cannibals gave food and instructed the victims to take care of the animals.

8 American, To make someFrenchman, thing unseen Bulgarian. with two small balls.

The American and the Frenchman did not succeed in making the dog speak.

The dog given to the Bulgarian was exhausted of starvation. "Did you feed the dog?" asked the chieftain. "Of course!" - "He is lying" - replied the dog.

The American juggled with them, the Frenchman did conjuring tricks, but the Indians were not impressed. The Bulgarian took the balls and ran, they caught him.

9 American, To say an unFrenchman, heard word Bulgarian.

The American: "Atomic bomb", the Frenchman: "French love" - the cannibals started a discussion: huggermugger and decided to put them in the boiler.
"He made something unseen: lost one of the balls and broke the other one".

The Bulgarian said: "Plenum". "What is plenum?" - "Just like your discussion: huggermugger and a man is put in the boiler". 
10 American, Frenchman, Bulgarian.

11 Frenchman, German, Russian.

12 American, Frenchman, Russian.

13 University students from: the Sofia University (mostly humanitarian), the Architectural and the Engineering Universities in Sofia.

14 American, Englishman, Bulgarian.
To say what is the biggest pleasure.

To hit a hawk with a rifle.
The Frenchman: "Women, wine, Moulin Rouge", the Englishman: "Golf, castle, RollRoyce". The cannibals were not convinced. The Bulgarian asked the chieftain to drink beer with him. After 10 beers the chieftain wanted to go to the toilet. "Hold on" - replied the Bulgarian.

The Frenchman and the German failed and requested one final drink as a last wish. In contrast, the Russian first requested some drinks, drank them, shot and hit.
To produce not less than 5 minutes echo.

The American: "O-key-ey-ey-ey!" - 2 minutes. The Frenchman: "Merci-i-i-i-i-i!" - 3 minutes.

To count how The first and the many sheep second failed. The there are in a third told the corhuge flock. rect number (e.g.: $4389524)$.
When the situation became unsupportable, they went to the toilet and started to urinate. The chieftain was convinced: "This is the biggest pleasure!"

"How did you succeed?" - "With ten guns it is not difficult to hit one of the twenty hawks!"

The Russian: "Vodka!" - "Whe-e-e-e-ee-ere?" -2 hours.

- "How did you do it?" - "It was easy! I counted their legs and divided into 4".

Get on the guillotine and survive if it fails to work.
The Bulgarian
was pushed to go first. The guillotine failed.
He said: "Give me a screwdriver and machine oil to repair this guillotine!" 


\section{Burlesque}
A. Characters
B. Trial
C. Result
D. Point

15 First, Second, Third.

16 First, Second, Third.

\section{First,} Second, Third.
Choice between "fucky-fucky" and "yummyyummy".

Choice between "fucky-fucky" and death.

To bring 10 pieces of a certain fruit, necessary for a second, unknown trial.
The first and the second chose "fucky-fucky". They were raped by the cannibals and then eaten. The third chose "yummyyummy".

The first and the second chose "fucky-fucky". They were raped by the cannibals and then eaten. The third chose the death.

The first brought 10 pieces of avocado, the second 10 blueberries. The second trial was to put them in their ass without a sound. The first failed, the second reached almost to the end and started to laugh.
OK! But first "fucky-fucky"!

OK! "Fucky-fucky to death"!

Why? Because he saw that the third is coming with watermelons. ${ }^{8}$

\section{NOTES}

1 From the theoretical school (Jauss 1978a) I have borrowed the term horizon of expectation and the policy of reconstructing the recipient's reaction.

2 This approach is also not typical for the Bulgarian scholarly tradition, represented by the books of Stanoy Stanoev (2005) and Ana Dimova (2006). The orientation towards joke cycles as an object of research seems to be a new tendency, see, for example, Stanoev 2010.

3 We must again mark the symmetry between structure and semantics: the zero transformation is connected with another source of laughter - the misled expectations. This change also influences the characters - they are no more representatives of different nations, but are simply the first, the second and the third. 
${ }^{4}$ Following Yuri Lotman's idea that the lack of a signal is a signal too - to describe it, the scholar has introduced the concept of the "minus-device" (Lotman 1998: 59-60).

5 The fluctuations in the attitudes to Bay Ganyu, the overuse of his image in arts and the shaping of his figure as a joke character are described and analysed by Inna Peleva (2002: 265-286).

6 Variant: George Bush, Vladimir Putin and Georgi Parvanov, i.e. American, Russian and Bulgarian.

7 Plenum - a session of the Central Committee of the Communist Party.

8 Another variant: each must choose a weapon (and then put it in his ass). The first comes with a tommy-gun and failed, the second - with a pistol and almost succeeded, but he laughed because he saw the third coming with a tank.

\section{REFERENCES}

Bergson, Henry 1924 (1900). Le rire. Essai sur la signification du comique. Paris: Éditions Alcan.

Dimova, Ana 2006. Vitsat kato ezikov i kulturen fenomen. Nemsko-balgarski paraleli. Prevodimost. Veliko Tarnovo: Faber.

Gennep, Arnold van 2004. Arnold Van Gennep. The Rites of Passage. London, Routledge, 2004.

Jauss, Hans Robert 1978a. L'histoire de la littérature: un defi à la théorie littéraire. In: Pour une esthétique de la réception. Paris: Gallimard, pp. 21-80.

Jauss, Hans Robert 1978b. Petite apologie de l'expérience esthétique. In: Pour une esthétique de la réception. Paris: Gallimard, pp. 123-157.

Krikmann, Arvo 2006. Contemporary Linguistic Theories of Humour. Folklore: Electronic Journal of Folklore. Vol. 33, pp. 27-58.

Krikmann, Arvo 2009. "Kontsovka" - mezhevoi stolb v istoricheskom razvitii zhanra folklornoi shutki? Ot shvanka ATU k sovremennomu anekdotu. www.ruthenia. ru/folklore/krikmann2.pdf, last accessed on 25 March 2012.

Kyosev, Aleksandar 1998. Spisatsi na otsastvashchoto. In: A. Kyosev. Balgarskiiat kanon? Krizata na literaturnoto nasledstvo. [Bulgarian Canon? The Crisis of Literary Heritage.] Sofia: NBU, pp. 5-49.

Lakoff, George \& Johnson, Mark 1980. Metaphors We Live By. Chicago: University of Chicago Press.

Lotman, Yuri 1998. Struktura khudozhestvennogo teksta. In: J. Lotman Ob iskusstve. St. Petersburg: Iskusstvo, pp. 14-285.

Peleva, Inna 2002. Aleko Konstantinov. Biografiia na cheteneto. Sofia: Prosveta.

Stanoev, Stanoy 2005. Vitsat i negovite poslaniia. [Jokes and Their Messages.] Sofia: Akademichno izdatelstvo "Marin Drinov".

Stanoev, Stanoy 2010. Dumb Blondes and Democracy. Folklore: Electronic Journal of Folklore, Vol. 46, pp. 43-60. 
Todorov, Tzvetan 1978. Les deux principes du récit. In: Les Genres Du Discours. Paris: Seuil, pp. 63-77.

Todorov, Tzvetan 1980. Poétique de la prose (choix) suivi de Nouvelles recherches sur le récit. Paris: Seuil. 


\title{
VISUAL JOKES ABOUT CHRISTMAS AND SANTA CLAUS ON THE INTERNET - WHY AND WHY NOT?
}

\author{
Guntis Pakalns
}

\begin{abstract}
This article analyses a collection of Christmas-related images and video clips found on the Internet. The author started collecting this material in 2005, since that time the material in the form of a PowerPoint presentation has been shown to diverse audiences discussing the context (mainly from the perspective of a folklore researcher) while observing the reaction of the audience.

The central part of the article is devoted to a brief overview of the most characteristic groups of the jokes (with links to the images, video and descriptions of the traditions): Santa Claus as the bringer of presents, his trip from the northland and his friend Rudolph the Red-Nosed Reindeer, arrival through the chimney, different other persons wearing Santa's hat (politicians, terrorists, women, animals, etc.), Santa's sexuality, drunken Santa, Santa murdered/killed, etc. In addition, the regional version - Ded Moroz and Snegurochka (Father Frost and the Snowgirl) - is discussed here. Parodies related to the topic - the Christmas tree, snowmen and figures made of snow, elves, angels, Chinese horoscope's "animals of the year".

Some hypotheses regarding the differences, functions, selection and perception of the worldwide available jokes in different social situations (western and post-Soviet world) are put forward, also considering social groups and situations, the time before and after Christmas. Why would people need such jokes? An attempt is made to explain it by different "levels of joking" - starting with "simply jokes" with their specific context in the tradition of the particular subject matter and the carnival-like sense of the reversed world (also used by the traders, making the originally rather eerie Santa Claus look like a friendly joker in the "shopping mythology") and jokes as a kind of psychological self-defence - trying to compensate, by way of irony and black humour, for the rapidly changing and excessive tediousness, seriousness, sacralisation, or right the opposite - secularisation, commercialisation of the mass media imposed Christmas traditions and the holiday stress.
\end{abstract}

Key words: Christmas, Ded Moroz, Internet folklore, Internet humour, modern myths, parodies, Santa Claus

At the end of 2005 The Club of Emeritus Scholars of the Latvian Academy of Sciences invited me to lecture about Christmas. A year earlier they had heard a lecture by an outstanding professor on the Latvian traditional Yuletide. I did 
not want to sound repetitive, besides I was not confident that I would be able to maintain a serious facial expression while talking about how clever the "ancient Latvian" was while beautifully celebrating this festivity in the historically nondifferentiated distant past - I assumed that this was expected on the level of stereotypes from a folklorist. But I chose to view the topic from the "other end" - how this festivity continues its life in modern culture, while simultaneously taking the opportunity to inform colleagues from other branches of science and scholarship about the changes in folklore study in modern days. ${ }^{1}$

I arranged a bulk of funny and comic images, video clips and PowerPoint presentations that I (just the same as many others) had collected, over time on my computer's hard disk drive, by theme. Supplemented them with similar materials from the Internet - all I could find with little effort. I arranged this material by topics and chapters, placing variants side by side and following the sequence of activities by placement of the aforementioned chapters, thus creating some "plot" within reasonable limits - similarly to the practice found in folklore publications, including also the academic edition of Latvian folksongs. I went there and presented the audience with the result of my efforts, briefly commenting on the images within the limits of my understanding.

When I finished my lecture the audience consisting of some 100 scientists of honourable age was strangely silent... They asked me no questions and did not discuss the subject matter, neither did they object nor rebuke my approach. It seemed that many of them were thinking something like this: "When we were young the world had much better morals!" In any case, what I presented was not the romantic "Christmas story"" that probably was expected (Figs. 1-2).

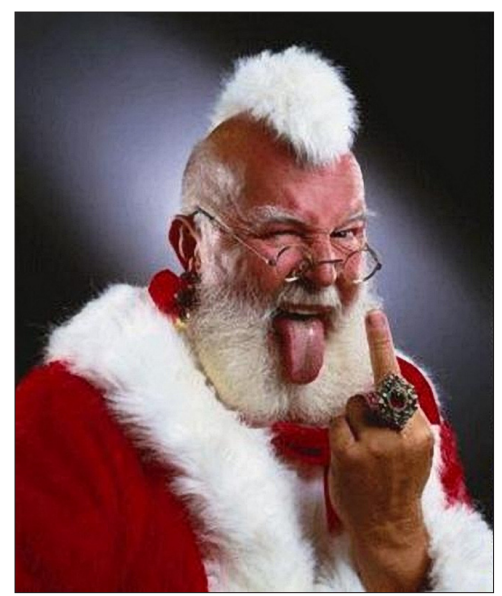

Figure 1. Santa Claus - a punk. (Source: http: / / www.fotolog.com/alantijca/37189946/)

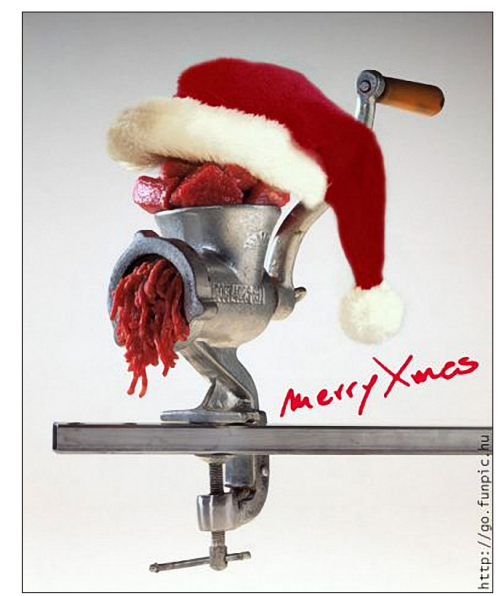

Figure 2. Merry Xmas! (Source: http: / /www. funpic.hu/en/categories / santa-x-mas/25024_ merry-xmas?142) 
I have later updated the presentation adding new and current material, including more "positive" and "beautiful" examples, which still seemed rather flat and boring in comparison to jokes and humour. But the basic structure of that PowerPoint presentation was preserved. Mostly around the turn of the year I have presented it to different audiences, e. g. older and younger folklore enthusiasts, leaders of folklore groups, students of vocational schools, anthropology students and lecturers, my colleagues at the Archives of Latvian Folklore, etc. The most extensive version contains more than 830 slides ( $c a$ 1,100 still images, some 20 video clips and 9 included PowerPoint presentations) with a nearly 3-hour-long lecture, while the shortest - ca 207 slides (318 still images, 8 video clips) and a duration of slightly more than 20 minutes. ${ }^{3}$ During these presentations I not only demonstrate the jokes, but also, depending upon the overall planned length and the interests of the audience, provide some insight into different cultural, historical, social and functional contexts of the images, telling the history of Christmas traditions and symbols - people are surprised at finding many traditions considered age-old being actually rather recent and significantly changed over the last decades.

I have recorded nearly all of these lectures, and the recordings provide material for analysis showing: 1) how very different my comments and topics of conversation can be though dealing with generally the same sequence of images - and this does not only depend on the composition and knowledge of the particular audience (dealing more with either the history of Christmas traditions or the Internet, humour, folklore or mythology - depending on the extent to which these notions need explanation in every particular setting), but also the time of the year (the closer to Christmas, the more carefully one has to be with such jokes); 2) that the reaction of different audiences is also different - laughter, or the very opposite - silence, protests and questions. Although I have tried to be scholarly considerate in my choice of material and comments, I still have a feeling that there is "something wrong" with this collection and its comments - that the critical attitude of the audiences is soundly based. Notwithstanding this general feeling I cannot find anything particular triggering the attitude - is it the material itself, the selection criteria, maybe even the Internet as such, or some problems of personal experience and attitude (I am one of those who "do not love Christmas"; why? - look for some hints at the end of this article). This is also one of the reasons why I had not yet prepared a published version of this presentation. The second such reason is the visual material, which is easier shown than described verbally. Though publication is generally considered the main outcome in scholarship, in this case it appears to be just a secondary one - the primary being the very collection and its different performances as author's (lecturer's and scholar's) communication with every 
particular audience. One more hindrance - the huge amount of material, difficult to be kept in any perspective, and still dynamically growing; also - there are many Christmas-related topics, thus only touched upon, while many are developing into an object of separate study.

It is possible that the cause for the perplexity and indignation of the audience was a particular group of Internet folklore ${ }^{4}$ that could be characterised as ironic, parodying, "dark" and/or aggressive, even destructive. My study deals with this particular group (and not Christmas in general!).

I usually begin by showing several rather typical and popular video clips, the context of which is tried to be found and understood during my performance. Four examples:

1. Santa is sitting in a toilet, (the activities are illustrated by impressive background noises); he notices that he is out of toilet paper. With his pants still down he jumps to the next room, where a huge pile of letters to Santa can be found. He chooses one and returns to the seat reading it. There is constant loud laughter in the background. The clip ends with an advertisement of a clothing store urging to go shopping and not write to Santa. ${ }^{5}$

2. Christmas evening in a family - a candle is lit on the tree, the Grandpa opens a song book, children dressed in stylised national costumes start playing "Silent Night..." on a recorder, guitar and a keyboard; it sounds somewhat awkward, with false notes. Mother listens to it with concern but also proudly, Grandpa falls asleep, father picks up his beer... At this moment the children turn to some wild rock'n'roll music, and just like at some concerts the guitar is smashed, the girl jumps up the Christmas tree and tumbles it with a shriek. Grandpa wakes up and looks at all the activities quite approving. The clip ends with a short ad, apparently music industry related. ${ }^{6}$

3. Seemingly, a home video, filmed with a hand-held camera: a child unpacks his gift - a light-sabre resembling that seen in "Star Wars"; he sways it around and inadvertently cuts Grandma in half, then the lamp comes down, after which the screen is filled with noise - the camera has been hit... ${ }^{7}$

4. On a football field there are 11 women, seen from behind. A simple animation moves their buttocks, so that they appear to be "playing" the Christmas song "Jingle bells" in this way. ${ }^{8}$ 
The problem remains: people laugh at these jokes, forward them to others, but become infuriated seeing them collected in larger numbers and in a public environment. Should a researcher of folklore and culture ignore them or still study? Is folkloristics capable of providing any explanation? What are the jokes about? What do these jokes say about social processes and Christmas traditions?

In order to understand (or interpret), let us view several contexts including the following: 1) the Internet as a "natural" communication environment (similar to oral storytelling two or three centuries ago, or a newspaper a hundred years) and the Internet lore; 2) Santa as an important image of modern mythology - becoming more and more international, but still with national or local features; 3 ) commercialisation of Christmas, that has possibly made some modern Christmas traditions "aggressive" towards people, creating more stress situations (growing volumes of shopping, adaptation to mass media stereotypes) and obtrusively offering in the public space trivialised and secularised symbols of this festivity.

Some information regarding the collected material: my collection consists of approximately 3,000 files, mainly still images (though including some animated), PowerPoint presentations and video clips. The method of collection: received by e-mail (I asked acquaintances and students to send them to me, some of the most diligent were those working in state institutions) or found on the Internet. Many of the files were received several times, found on numerous sites (frequently only the logo of the site had been added, with no indication of origin), thus it is becoming increasingly difficult to find anything thematically new or any new content - this might attest to the collection being representative.

Initially I was interested exclusively in the material to be found in the Latvian environment and Latvian websites, but soon I became aware that it is a fragment from a much larger multinational tradition. (Some small national features can be found, but, omitting the few local jokes and particular wordplay, there are regional traits, such as "to the west" or "to the east" of the Baltic States, i.e. jokes in Western Europe and the USA, and jokes in the former USSR territory. And a second aspect - what is considered funny, interesting and agreeable by people of different groups, nations). There are sites that have images related to Christmas, Santa or the New Year placed separately. ${ }^{9}$ But a great many images can be found within other collections - while collecting the material I spent days and weeks sitting still and browsing different archives of jokes and images, copying from those what I found useful, making sure that my "field-work" on the Internet is no less physically demanding than visiting informants by dirt roads in faraway, secluded places. At the time, I was not yet aware of such search tools as Google Images; however, several of the largest sites have accumulated archives from the last 5-10 and more years, 
facilitating search. I used not only the anonymous images, but also caricatures by known authors that were freely available on the Internet and "played" with the traditional topics. ${ }^{10}$

Placing the images in particular chapters and positions of my presentation I created my own "Christmas story" which, in a way, is also a tradition, although usually, such sequences do not exceed 10-30 images. For the context I also collected texts (anecdotes, funny stories, proverbs and quotes, etc.). Quite frequently such texts are combined with audiovisual material (PowerPoint presentations with music, images and some aphorism, chain letters, visualisations of written texts, etc.), so there are no strict limits. One can observe a tendency "from the text to the visual" - the latter can be more readily and conveniently perceived, requires less effort. Thus, unlike during the early days of the Internet when only small data amounts could be sent, the images and videos have become much more popular nowadays. Yet as with all things in folklore only a small part of the "folk creation" has become popular. It was more difficult to document the online games where, e.g., Santa is the hero (or just in the function of the ball), as well as earlier only online viewable flash videos (e.g. "the dancing reindeer"11), or personalised greeting cards ${ }^{12}$. Naturally, it is not possible to cover all of these joke genres, therefore I have focused on images. Each of this genres covers a range of topics that is either partially common or overlapping, but each of those has more or less pronounced specifics determined by both their history and technology.

Not delving into theory and avoiding quoting particular authors I shall briefly remind the reader of some issues regarding this material from the folklorist's perspective.

Naturally, this is not pure folklore and nothing else but folklore, still it is an object of interest to the researchers of folklore and other culture research spheres. They possess the characteristics of traditional folklore: 1) tradition (in form, content, function, genre, images, performance situation, etc.); 2) variation of the traditional themes; 3) collectivism, anonymity, popularity (no authors known, people readily "retell" - forward, "quote" in different situations, create private and public collections); 4) these are used by groups forming common identity; 5) reaction to power, the ruling, the right ideology (alternative culture), etc.

The Internet offers new opportunities to meet the ancient need of the people: 1) communication - to exchange messages, find similarly oriented individuals, form communities with an identity (communication on the Internet is closer to oral tradition than the printed texts, as there is the possibility of feedback - evaluation, comments, forwarding, developing similar material, etc.); 2) fun - watch, compose and retell jokes; 3) listening to stories, watching images and 
events, feeling informed; 4) secretly watching and doing what is considered indecent.

Santa Claus (Father Christmas, Дед Мороз, Weihnachtsmann, etc. - the names in different traditions are not the same but the origins are at least partly common) is an outstanding personage of modern mythology, not only for children. As is known, this image has a lengthy history, but the image still in use was formed in the 19th century, in the mass media environment of the time (press), combining elements from different cultures. It continues to develop dynamically in the 20th century. Many of the elements of this image can be clearly dated, but this is deliberately forgotten. Santa Claus has its own myth of ancient origins, its own image (is it the archetype of the wise old man, father?), he dwells in the mythical and the real space, has his specific attributes (beard, the red coat, bag of presents), helpers and functions. It is the main personification of Christmas in modern times, widely recognised, maintained and publicised by mass media, present in different cultural and traditional structures. ${ }^{13}$

If in earlier times he was frequently pictured as a harsh man with a rod, punishing the disobedient children, then in modern times his main task is bringing gifts (this theme is closely related to industrialisation when gifts became increasingly easier to produce and they had to be sold, thus their religious symbolism was transformed). The closer to the present day, the more pronounced are the features of a trickster, that probably are related to the commercialisation of the image - a jolly and friendly humorous image promotes shopping during the pre-holiday period. (Entering the name Santa Claus, in the Google Images or other image search engines would return results showing him as something comical, but definitely friendly, smiling and clearly joyous.) Santa Claus is an important image in shopping mythology, for instance: 1) as a commercial brand - personification of a gift-shopping-related festival; 2) letters to Santa Claus as lists of gifts; 3) travelling during the festival and to the dwelling place of Santa Claus in Lapland; ${ }^{14} 4$ ) greeting cards, music, films, concerts; 5) jobs for his impersonators. All these trades involve significant financial outlay. Christmas shopping in many countries is the last chance to improve the year's economic figures. Therefore the already folklorised phrase is also true in regard to him: "If there was none such, then he had to be invented."

By the way: what could be the conclusions if some centuries from now a research of the materials on Santa Claus preserved from our day was conducted the way we study ancient Latvian deities - without the knowledge of the cultural context for the texts and images and their situational application? Would it be possible by the images alone, without the aforementioned context to discern which of the character's features are meant "seriously" and which - as comical, ironic, parodying some particular cultural elements or merely insignificant? 
What is this Santa like, judging him by the visual jokes collected on the Internet starting in 2005?

Verbally describing the images (which cannot be shown to the readers of the present article, see previously and further indicated URLs), we can briefly discuss the parodies on several most popular topics regarding Santa and the Christmas "myth" - how these are reflected in the visual part of the Internet folklore. As already known only that can be parodied which is widely, generally known, otherwise the parody will not be recognised and understood. For the sake of simplicity I will ignore the different "national variants" of Santa (Weihnachtsmann, Ziemassvētku vecītis, Ded Moroz, St. Nikolaus, etc.), as the internationally more readily available Internet folklore in most cases allows us to view this character as generally homogeneous, without particularly pronounced and specific "national characteristics".

One or many? Despite the "official myth" (that Santa lives in the North alone or together with his wife, who is the only female in the dwelling - and makes gifts together with his elves), many of the images depict together tens, hundreds and even thousands of similarly dressed performers of the task. They participate in the Christmas race, go skiing and - of course! - go shopping in supermarkets, are seen in store decorations. Video clips show many Santas being trained in an army camp, ${ }^{15}$ etc. In similar costumes, with the difference being the much less amount of cloth used - those are the generally pretty female representatives of the trade. Still, in most jokes Santa is alone.

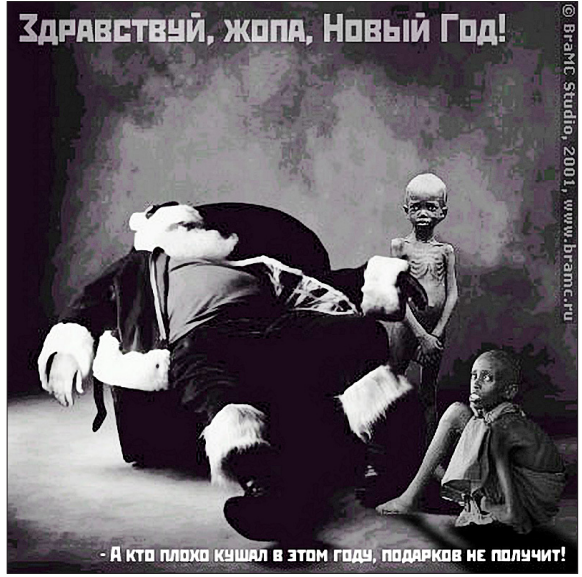

Figure 3. Those who have not eaten properly will receive no presents! (Source: http: / / www. bramc.ru/cgi-bin / page.pl?docid=112)

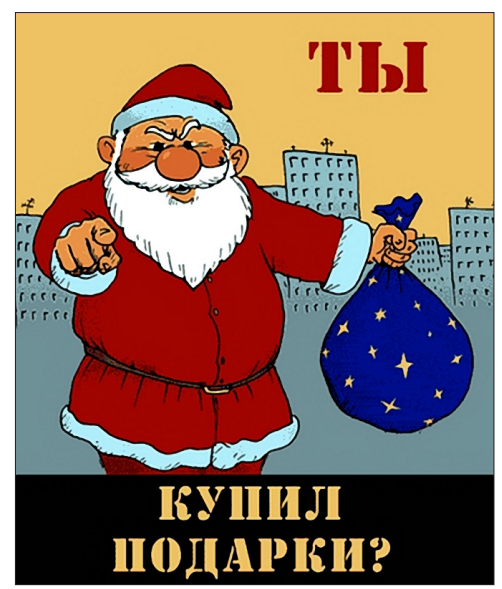

Figure 4. Have you bought the presents? (Source: http:/ /www.cruzo.net/kartinki / novogodnie/a-ty-kupil-podarki.html) 
Santa as bringer of gifts. His too heavy bag of gifts is frequently treated, along with its non-traditional content (weapons - the "toys" for adults), and the way of the bag's delivery. There are jokes related to the over-lengthy list of the required gifts, to the production of those gifts or their purchase, about the idea that every one seeing Santa has the right to demand a gift (even when on the potty...), regarding the phrase that only the children who have eaten all their food will receive those gifts (Figs. 3-4). (Within the framework of this topic it is possible to tell the history of Christmas gifts, which has seen dramatic changes over the course of time, as well as explain the ethnography of gift-giving as such.)

Santa arrives from afar - thus from abroad! The parodies play on the situations that are not included in the fairy-tale or "myth" on the arrival from far away - what happens when Santa Klaus meets border guards (Klaus - obviously a German!), customs officials (confiscating gifts as illegal merchandise), how he is incarcerated for illegal border crossing or unlicensed night flights.

Rudolf the Reindeer is not only show as the puller of Santa's sleigh, but also as a friend of his and a man-like ally. ${ }^{16}$ The parodies deal with the different problems that may result in the modern view from the driving of sleigh pulled by reindeer in general or specifically Rudolf - no safety belts, braking at crossings, technical condition of the road and the vehicle's lights (Rudolf's red nose), speeding, ${ }^{17}$ meeting road police or thieves stealing from the sleigh, etc. A wide range of parodies are related to the flight of the sleigh - it is visible in allegedly documentary photographs taken through an aircraft's window, the sleigh caught by a plane's wing, the sleigh crashing into an UFO or different buildings, including a parody on 11 September in the USA - Santa crashing into Twin Towers (Figs. 5-6). It is said that Rudolf can only fly because of his drug addiction. A proof of the sleigh

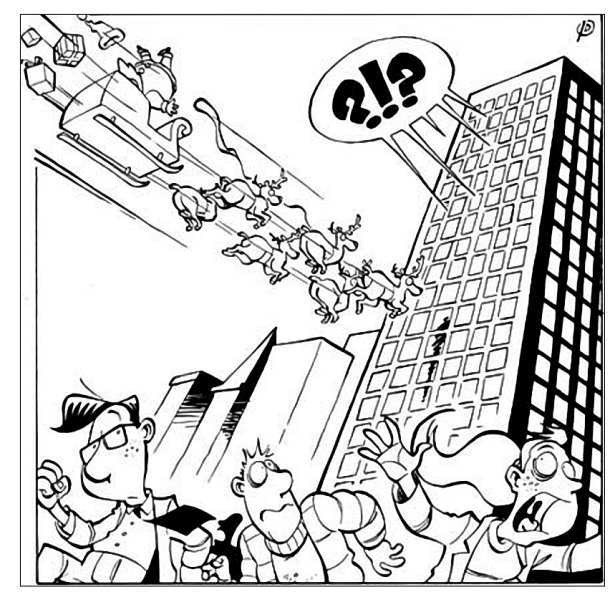

Figure 5. Christmas 2001. (Source: http: / / www.funpic. hu/en / categories / santa- $x$ mas/9678_picture)

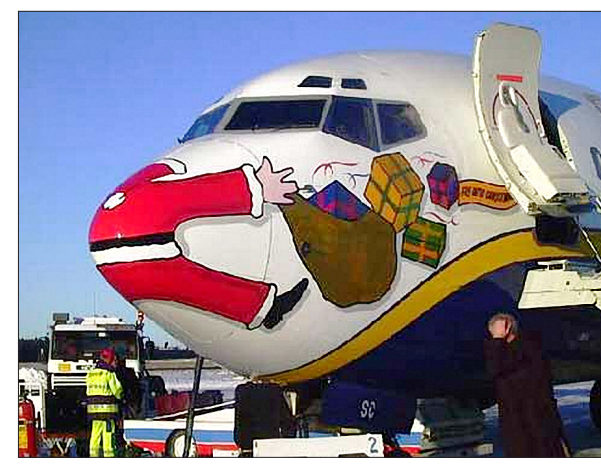

Figure 6. Santa Claus hits a plane? (Source: http: / / www.esche-world.de /lustigebilder / weihnachten/crash-mit-flugzeug-1280.html) 


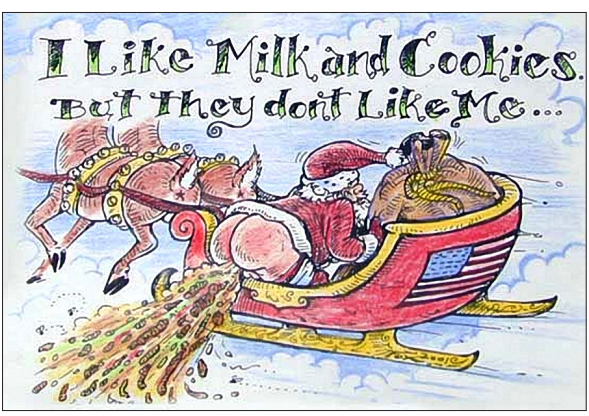

Figure 7. I like milk and cookies, but... (Source: http: / /www.funpic.hu/en / categories / santa-x-mas /9610_picture) having flown over a house is reindeer droppings on its roof. But these can also be a result of Santa overeating milk and cookies left for him in every house (Fig. 7). As they are together most of the time the caricatures also deal with the relationship of Santa and Rudolf as a close one of two men, there is also a clip showing Santa buying a rubber doll from a sex shop - an inflatable reindeer ${ }^{18}$ (Fig. 8). Different animations show reindeer singing and/or dancing happily. Those who feel bored by such happy singing can choose a clip where a reindeer sings "Silent Night" in the voice and appearance of a drunk. ${ }^{19}$ Depending upon the "animal of the year", Santa's sleigh can also be pulled by a dragon, bull, monkey, rooster, etc.

Hereinafter it is obvious that in frequent occasions, the main method of joke-making is desecration of the beautiful and generally known "myth" of Santa - what makes up the very core of the Santa's story both in children's literature (and partly also business mythology) is being ridiculed, trivialised, placed in mundane, unlikely or "worst possible" situations. Another way, more belonging with official culture, is the aestheticising and modernisation of the myth, formally adapting it for the modern world.

An example: Santa's other vehicles. This is dominated by "simply nice pictures" - of Santa with his huge bag on his back riding a motorbike, a motor

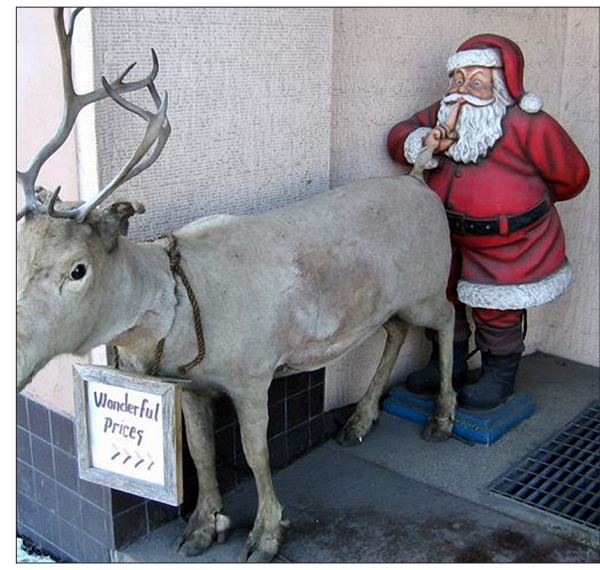

Figure 8. Santa Claus - a too close friend of Rudolph? (Source: http: / / www.cruzo.net / kartinki/novogodnie /xitryj-santa.html)

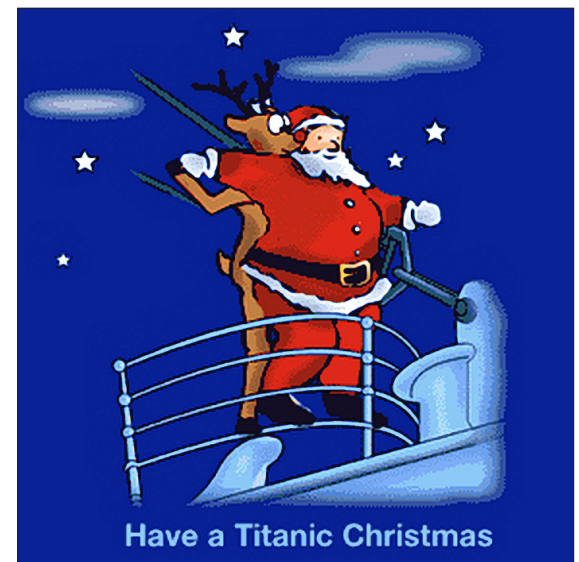

Figure 9. Have a Titanic Christmas! (Source: http: / / www.funpic. hu /en / categories / santa- $x$ mas/9439_on-the-titanic) 
sleigh, driving a jeep, flying a plane, a rocket, on board a ship, arriving with diving equipment or a parachute. At the same time, the alternative cultures feature parodies of this topic of vehicles - Santa and Rudolf on the bow of "Titanic" (Fig. 9), a bike shaped as a reindeer etc.

Did you expect Ded Moroz? Jokes and parodies, of course, are interested in the unusual and unexpected. This is also true regarding the arrival of Santa - those at home are unprepared and taken by surprise, the children would not leave the telly. Santa falls into some trap set by the owner of the house to catch thieves, or even gets shot because he was entering through the chimney and taken for a thief. In the Russian-speaking environment the caricatures also employ the play of meanings: in Russian jargon 'to order' (zakazivatj) also means 'order a murder of...'.

Entrance through fireplace chimney as obviously illogical and incredible is very much employed in this type of material - Santa, of course, is too fat, and therefore gets stuck. The reindeer try to save him or lose all hope and leave without him. Other images of Santa: he sits on the chimney with his pants down, like on a toilet seat. Or how icicles are formed - romantic children faces watch through the window yellowish icicles growing, while they do not see that these grow from Santa and Rudolf urinating. In case Santa manages to get through the chimney all soiled black in soot, it is not a victory for him yet: he inadvertently kills the cat sleeping by the fireplace, is taken for a thief, or he arrives in a hangout of drug addicts, catches a naked couple on a coach, is met by a dangerous dog, etc. The parodies of sexual nature also belong here: a girl or a woman offers herself, instead of milk and cookies, while lying naked by the fireplace.

The story of the chimney is also employed in a very popular animation - a parody of the tale of three piglets. ${ }^{20}$ Accompanied by dynamic and exactly illustrative music the piglets are carrying the Christmas tree, chased by the Big Bad Wolf. They manage to reach their house. The Wolf is trying to break the door, barricaded by the piglets using everything available (while the window is actually left accessible). Then the Wolf leaves. In a moment heavy footsteps are heard, someone is attempting to enter through the chimney. The piglets have a quick solution, taking off the lid of a pot and the intruder falls in and the fire is started in the stove. When the pot is served on the table Santa's hat and a boot along with some gifts are floating on top. The closing scene - in the yard the sleigh with reindeer stands waiting. The fact that many have already seen this film means that it is distributed like folklore - it is "told" (forwarded).

Santa's hat. There is a rich cluster of world wide web-distributed visual parodies showing different characters wearing Santa's hat. (As to my memory, in the Soviet times this hat was the exclusive attribute of Ded Moroz, no-one 
else was allowed to wear it. This tradition changed in the 1990 s, when the supermarkets started offering such hats for a rather low price - I had a difficulty accepting that in the West this hat has a different function and meaning: by wearing it we just participate in the festival, their "carnival". The caricatures depict as Santa (most often marking by the hat alone, seldom - the full costume) both the well-known politicians (sometimes with the bag - as "gift bringers", one's promising "gifts" in the new year) and terrorists - making people remember terrorism as a global modern problem, that can influence the future of the whole world in the next year. Santa can also be transformed as a horrible image of some computer game. Computer technologies allow for simple and quick transformations of images, therefore the result depends more on the taste of the creator (and those forwarding the image), not the technology.

Related to the previous topic - Santa is dead: hanged in a toilet (Fig. 10), caught by the helicopter blades, torn apart by dogs or polar bears, an allegedly documentary photograph showing both Santa and his reindeer shot by a hunter, etc. Wordplay used because of the similarity in Russian: Ded Moroz - Dead Moroz. Crucified - due to a mix up with Jesus or for some reason substituting the latter ${ }^{21}$ (Fig. 11). An image of a crying boy and the tombstone of Santa. ${ }^{22}$ This displays another way of demythologisation - to pronounce someone dead (does therefore the myth die along with the character?). However, this motif is related to the image of Ded Moroz as personification of the old year, better known on the territory of the former USSR. The New Year was personified as a boy turning into an old man in a year's time, then either driven out or "killed" by the next New Year. If there is a will one can trace the so-called transition

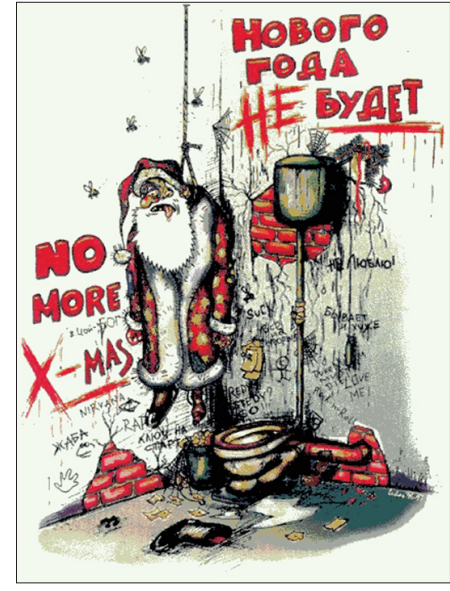

Figure 10. There will be no New Year! (Source: http: / joki.oho.lv/default. php?grupaid $=1 \&$ bid=1923)

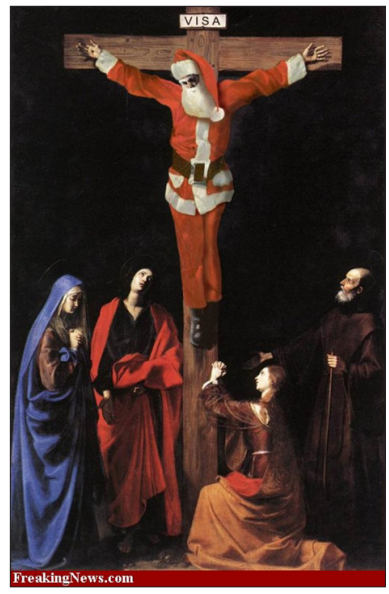

Figure 11. Santa Crucified. (Source: http:// www.freakingnews.com/Santa-Crucified-Pictures-42109.asp) 
ritual as the basis of this - the old must be symbolically killed in order to access the new.

Images of animals wearing Santa's hat are extremely popular, the reindeer horns being seldom employed in this function; one will also find animals around a decorated Christmas tree, mostly cats and dogs. The same hats, horns and angel wings are used as a costume when photographing small children (probably reference to child Jesus, appearing in these parodies nearly unexpectedly seldom). This range is dominated by the "nice", not comic images. Still, the most popular comic image is that of a dog "leaving poo" by the tree and gift boxes.

Unlike children and animals, the adults put on this hat fully consciously. Probably the most numerous images, though only partially related to parodies and jokes, while having more in common with sexual and pornographic images, are the ones depicting half-naked or nearly naked people only covered by some Santa's attribute or showing a decorated tree in the background. The jokes dwell on the issue whether a woman can be a Christmas gift herself, or whether she can get her gift without getting laid (Figs. 12-13). Woman's breasts are compared to tree decorations, "Merry Christmas!" is written on the naked body parts, etc. Photographs taken at Christmas and New Year parties display this approach.

In this context Santa's sexuality is also being discussed (one more aspect of demythologisation and "tough not" for the hypothetical over-serious researchers of the 21st century mythology in the near future). He is paging through sex magazines, pictured with one or more half-naked girls and different indecent situations. Also as an exhibitionist "coat opener" (actually showing a watch

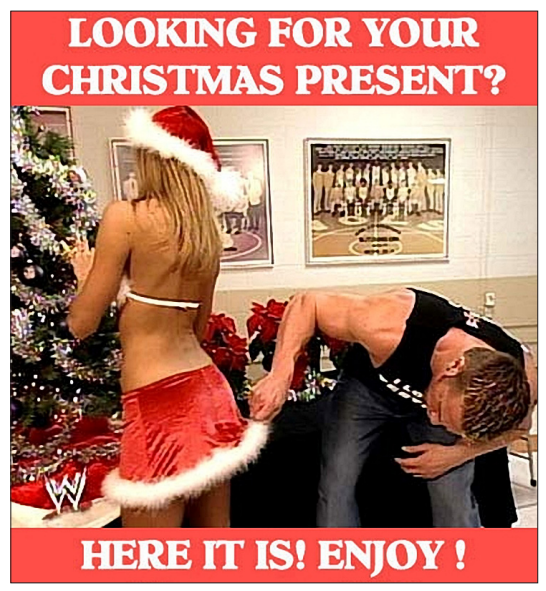

Figure 12. Looking for your Christmas Present? (Source: http:/ / www.funpic.hu/en/categories / santa-x-mas/9703_picture)

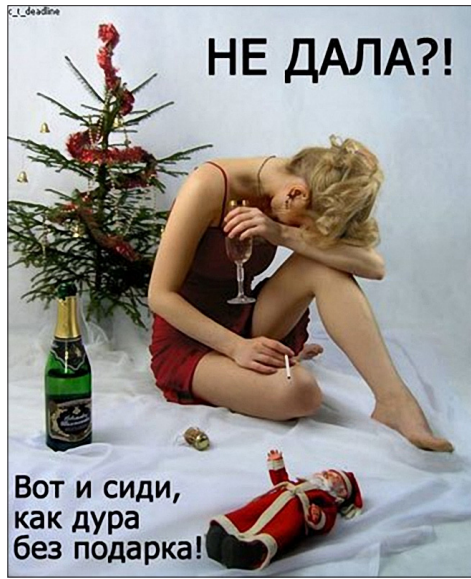

Figure 13. No sex - no gifts! (Source: http: / / www.netlore.ru/novogodnee) 
symbolising the passage of time), a sado-masochist (he himself or his host being extremely pleased by the rods brought), in close relationship with Rudolf, or bringing his wife erotic toys styled in Christmas theme. A popular theme is the one wherein Santa is punishing quite grown-up "naughty girls", as well as variations of the type of anecdotes: unexpectedly the husband returns ("Virginia, Santa really does exist!"23), wordplay with sexual hints: "Santa Claus is coming". (Following the protests of female audiences I have substantially reduced this part of my presentation.)

One more way to "compromise Santa" are photographs showing him with one or more children on his lap, but - unlike the traditional happy festive images - the child is scared, cries, and tries to break free. ${ }^{24}$ In connection with the discussed above, also the images of a "big girl" sitting on Santa's lap or Santa holding a child while sitting on a toilet seat also belong here. These images can be interpreted as a response to the widely distributed pictures of an overly "correct" character (Santa or more generally - a positive mythical hero, a politician - with a happy child on his lap).

There is another popular cycle of images: drunk Santa - with a bottle of booze in his hand, answering the call of nature, asleep half-naked, etc. This cycle still emphasises the differences between the "West" and the "East" - if Santa is shown as a jolly person celebrating (from the mythology view-point this is just an indication of ritual use of alcohol at a festival), images of Ded Moroz displaying the captions in Russian emphasise the "harsh reality" of Ded Moroz's position, practically requiring a healthy dose of alcohol in order to maintain sanity, the only problem being that of knowing the limits.

The characters of both Ded Moroz and Snegurochka are usually connected with alcohol. The joke goes that Ded Moroz is a mythological character - when sober. Snegurochka tends to be shown not as the grand-daughter (as in the "nice" texts), ${ }^{25}$ but as a partner, girlfriend (unlike other Santas who usually having male helpers). Ded Moroz needs her because of drunkenness or some other reason he is unable to perform his duties. This shows some relation to the image of the woman in the culture of Soviet times, where she is shown as being stronger than the man, capable of doing all "men's jobs" when the man is not willing or incapable to do them (Figs. 14-15). Another branch of Snegurochka motifs is her strong sexuality, playing

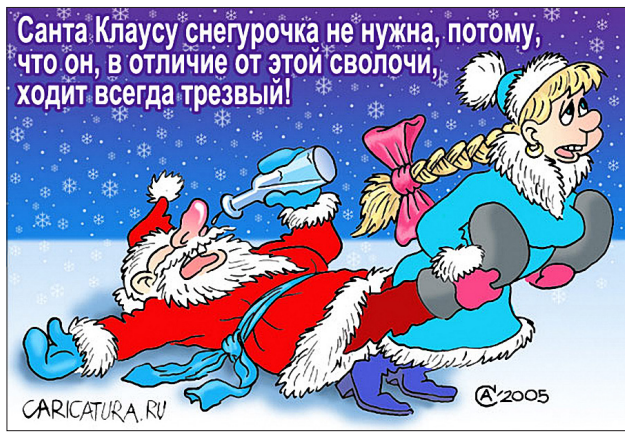

Figure 14. Santa Claus needs no Snegurochka, as he, unlike this bastard, is always sober. (Source: http: / / caricatura.ru/art/Sayenko/url/parad/ Sayenko/6296/) 
with her initial coldness and "melting" in warmth.

Some more characters, objects and images are related to Christmas and turn-of-the-year mythology as well as the corresponding jokes. The Christmas tree. (I have noticed that there is a tendency not to believe that it only became popular in present-day Latvia and the surrounding territories around the end of the 19th century and the first half of the 20th - childhood experience tends to take precedence over any facts established by scholars $)^{26}$. Caricatures show different ways the fir tree attempts to avoid being cut down (from the tree's point of view - how nice to be ugly; there is no more terrible festival than Christmas, etc.). "Discreditation" of the tree is popular - people like to publish photographs and drawings showing a small, ugly tree, hanging upside down, decorated using improper objects (Fig. 16), built of empty or full bottles of alcoholic beverages (a very widespread motif) or metal, as well as different foodstuff; a tree vandalised by a cat, a tree falling over, etc. Of course, interest of the people is also attracted by unusual house lighting decorations, using indecent symbols or texts. Also this proves that the Internet joke culture is a secondary one, alternative to traditional culture.

The Snowman is a characteristic part of the winter landscape, ${ }^{27}$ and sometimes also a member of Santa's team. The Internet jokes most

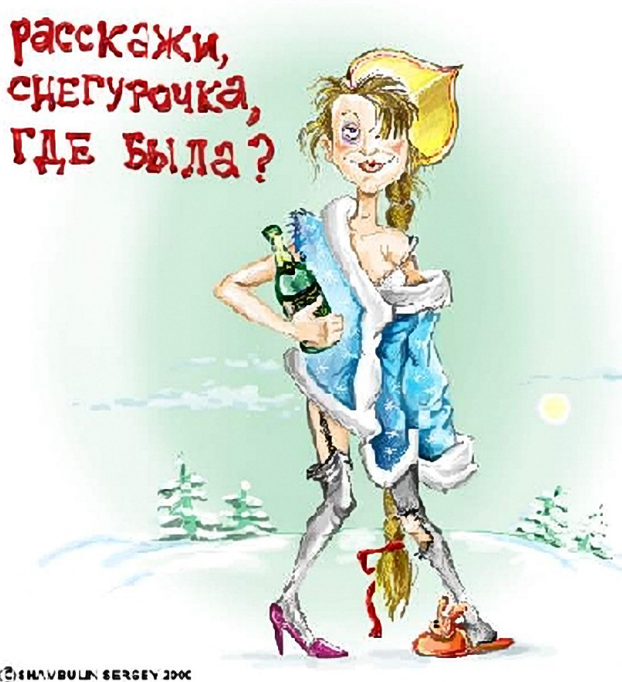

Figure 15. Tell me, Snegurochka, where have you been? (Source: http: / / bayanov.net/funpic/newyear $/$ ? $s=09)$ The song gained popularity after being used in the episode 8 of the animation series " $N u$, pogodi!" ("Just wait!") (1974), see http://www. youtube.com / watch? $v=n 5$ DeorAy8lY.

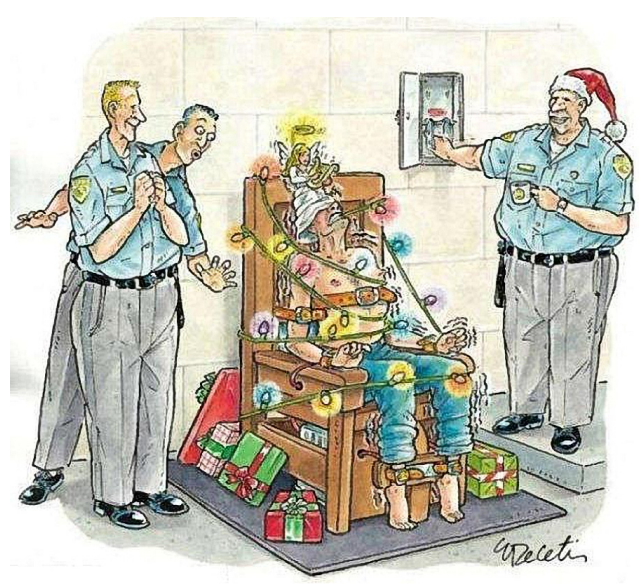

Figure 16. "Christmas tree". (Source: http:// kartinki.smeha.net / novogodnie/113.html) 
frequently deal with the sexuality of these cold snow figures - that carrot is placed not as the nose, but "lower" (Fig. 17), the snow men and snow women having sex (be quick so "the thing" does not melt because of friction), there are photographs of snow figures resembling humans holding bottles of alcohol or in explicitly sexual poses, genitals as huge snow figures. Painted with red the snowmen either are bleeding or become bloodthirsty monsters. Also the snowmen's body transformations are treated, emphasising the difference from the

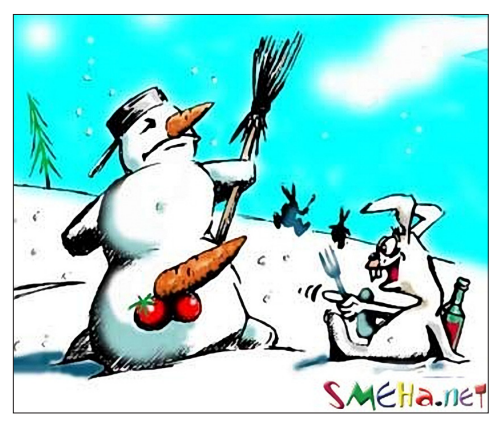

Figure 17. Carrot stuck in the wrong place? (Source: http:/ / kartinki.smeha. net/novogodnie/27.html) humans - snowmen's Kama Sutra, buttocks in place of the head - "a snow MP", fear of melting (a dog peeing on it, a hairdryer as a lethal weapon), a funeral of a snowman (six men carrying a bucket of water), etc. In addition, this displays the intent of creators of these figures (and lovers of the images) to oppose the over-simplified and romanticised culture of childhood and Christmas, making these snow figures "adult", along with the wish to use them for public and anonymous joking about supposedly forbidden topics.

The elves work as producers of gifts at the Santa's workshop (but they also go on strike, are illegal labour, etc.). Unlike their dangerous predecessors in mythology of different European peoples, under the influence of mass media the elves have become jolly kids, but within the further development in the joke culture they have turned into disobedient and naughty "children". In a similar vein angels (as present at the Christian story of Jesus' birth) in the "modern Christmas stories" have become characters not alien to earthly passions.

Along with the above different, other winter-related, images are published - showing extreme amounts of snow or lack thereof, cars stuck in ice or hit by falling icicles, falling skiers, walkers stumbling and falling on ice-covered street, etc. Every year humorous greetings are created, centred on the corresponding animal of the Chinese horoscope, such as rat, pig, etc. And in the conclusion images of Santa returning to his home in the north, pulling the sleigh filled with drunk reindeer, Santa (alone or accompanied by reindeer, elves or girlfriends) on vacation in some southern resort, as well as scenes of celebration from the other side of the equator.

Some conclusions. On 27 December 2005, an interactive question was asked in the Latvian TV1 programme "100 grami kultūras": What Christmas greeting would you prefer? The answers (phone voting, choosing one of three options) were as follows: winter landscape - ca. $40 \%$, religious motif - ca. $20 \%$, a parody on Christmas theme - ca. 40\%. However, regarding the Internet images related to Christmas and Santa Claus, discussed by the author of the present article, 
the proportion of jokes and parodies is (or appears to be) higher. What then is the butt of these jokes associated with Christmas, Santa and the related characters and events? Naturally, these cannot be strictly separated and every particular joke may contain a combination of the following:

1) Plain jokes - exploring and trying the humorous potential and limits for each character and theme within the traditions of humour (similar to those of the related themes: sexuality, "pee and pooh", drunkards, blondes, politicians, the returning husband, etc.). These are dominated by the internal driving force of the joke tradition, not external social contexts.

2) Carnival-like activities - in the period of a threshold moment social values are "turned over". In order to let the New Year come, the old year must be symbolically "killed" (the latter embodied by Santa Claus, Father Christmas, the horoscope animal of the previous year, etc.). Similarly - in order to introduce new, more up-to-date traditions the older ones must be "killed" or ridiculed. Thus these are the ancient structures in a modern form.

3) The closer to modernity, the more features of a trickster appear in the image of Santa Claus. It is probable that this falls along the line with the secularisation of the festival and the interests of the merchants in creating an optimistic, merry, comic-book-hero-like image close to children's culture, promoting and personifying shopping and the cult of gifts.

4) Critical irony regarding what is happening to Christmas in the modern culture - we are neither laughing at the festival itself nor at the ancient symbols and values connected to them, actually the laughter indicates our disquietude regarding the developments related to these values - on the contrary to what these developments should have been. Ironic distancing in laughter is a form of resistance where no other resistance is possible.

5) Response to extreme commercialisation, secularisation and stress. The modern Christmas tradition (as opposed to the one at least believed to be inherited from the two to three generations long gone) are characterised by: a) obligatory shopping, sending of a multitude of greetings, complicated preparations - and the continuous resulting pressure involved; b) obtrusive presence of the festive symbols in the public space throughout the Advent; c) aggressive idea of the "correct Christmas" imposed by mass media (within one's family circle, in prosperity, giving gifts to one's family, decorating the house, cooking the meal, visiting relatives) - those people who for some reason would not fit into this framework are subjected to additional pressure (it has been said that the number of suicides is the highest around Christmas); d) desecration, secularisation - the more ancient and traditional religious and family or community rituals (and "even more ancient pagan traditions") are replaced by the "shopping religion". Jokes, including the very "dark" ones, function as means of overcoming the pressure and crises. 
In this context the four video clips described at the outset of the present article could be a response to (or ironic treatment of) Santa's over-mythologisation (demythologisation - destruction of outdated myths in order for those to be replaced by other, newer ones) (Clip 1, see endnote No. 5); over-canonisation of Christmas traditions, making them seem boring and uninteresting (Clip 2, see endnote No. 6); buying expensive and potentially dangerous gifts for Christmas, i.e. commercialisation (Clip 3, see endnote No. 7); extremely obtrusive and uniform "beautiful scenery" during Advent and Christmas (Clip 4, see endnote No. 8).

What could be peculiar about the functioning of these globally known jokes in modern Latvia? The next research topic could be: which jokes of this international offer are chosen and used by the inhabitants of Latvia, which ones do they find funny and which - boring, incomprehensible or unacceptable. Why the choice? One should clearly differentiate particular age, social and professional groups here. According to my humble observations, e.g. among folklore researchers, anthropologists, sociologists (or the retired - as told about at the beginning of the present article) most of the members of the audience knew rather few of the images I demonstrated, but at least some employees of government institutions and office workers knew nearly all of them. This study can also be turned into a more reflexive one - how I myself as a Latvian (and/ or folklore researcher, middle-aged man, city-dweller, computer user, etc.) feel about, choose and comment these jokes. (There is an opinion that the real essence of a person can easily and truly be judged by the jokes told - establishing what are the person's views - and problems...).

Here we reach the topic promised at the beginning of this article: "Why do I dislike Christmas?" That this occasion creates for me more trouble than joy I had noticed a long time ago - already when I was around 20. With each year it became more burdensome to send the numerous greetings - why should I use exactly this occasion to remind my relatives, friends, acquaintances about my existence, and send formal texts or such composed with great difficulty? What makes me do it? I spent much time on the cards, until I gave up completely. Later only those with an e-mail address or enabled reception of non-text messages on cell phones received some greeting from me, i.e. nearly no-one.

The inhabitants of Latvia (similarly to those of other post-socialism states) have undergone several swift changes in the traditions of Christmas celebration (Fig. 18). Under Soviet rule Christmas was celebrated at home: unofficially and

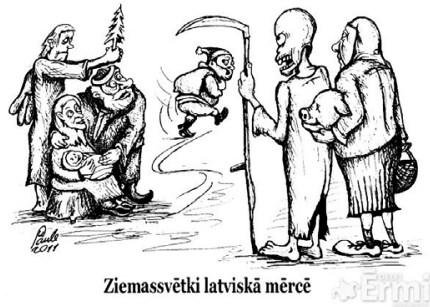

Figure 18. Christmas in "Latvian style". Santa Claus between the Christian and the pagan traditions. (Source: http: / / ermi.delfi.lv/?actio $n=$ view\&id $=85540 \&$ title $=$ ziemassv etki-latviska-merce-u-saulitis) 
quietly, those clinging to the tradition were elderly people who remembered the festival from the pre-war period. In the time of change around the turn of the 1980s and 1990s (my children were small then, and we formed traditions of our own family, uniting individual childhood experiences), it was difficult to separate Christmas and New Year traditions, ${ }^{28}$ and the children demanded similar gifts for both occasions. It is possible that my "Christmas trauma" was created due to situations when living on a modest scholar's salary I had no money for gifts after paying the bills. I have had to spend the time of Advent in Germany several times, and there I found annoying the intense presence of Christmas symbols, decorations and music in the public space for such a long time - a whole 1/12 of a year. Later, back in my homeland I felt more painfully the "pretension" of Christmas to be the main festival of the turn of the year, though I knew from my childhood that the most important Latvian seasonal festivity is Midsummer. In Germany I experienced the situation where I was alone on Christmas Eve - I could personally feel the psychological risks for an individual left outside the "correct situations" imposed by mass media, unable to spend the holiday with one's family and the closest persons. Therefore, when looking into the history of Christmas traditions I was probably looking for some indications that these traditions are not that general, eternal and self-evident as understood by those around me. Also the interest in the jokes discussed may have been not only purely scholarly, but indirectly related to my problems. Folklore and jokes are the means with the help of which people try to regain a mental balance, compensate for what they lack - or have in abundance - in their real lives.

Jokes are extremely situation-bound and deeply related to different contexts. The material chosen by me and the attempt at its explanation are just a possibility of interpretation. I admit that this very material can be interpreted in a completely different way. And there is another possibility, half-jokingly suggested by my colleague Dace Bula upon seeing my presentation at the Christmas meeting at the Archives of Latvian Folklore: maybe we do not need to study and explain everything, maybe even a scholar has the right to simply enjoy these jokes... So, Merry Christmas!

\section{ACKNOWLEDGEMENTS}

The present article is based on the paper presented at the International Academic Interdisciplinary Conference FROM LANGUAGE TO MIND 3, on 10th-11th September 2009, Tartu, Estonia. Participation of the author at the conference was funded within the framework of the bilateral exchange agreement of the Latvian Academy of Sciences and the Estonian Academy of Sciences. 


\section{NOTES}

1 The main object of my studies and occasionally presented study courses comprises traditional and modern narratives. However, I have had to pay some attention to the Christmas-related topics nearly every year. I have presented public lectures, spoken on the radio and TV. If the lectures happen to be close to the aforementioned festivity, I have discussed this topic with the students (including two such discussions in a multi-ethnic setting in Germany, University of Münster 1997/98 and 2001/02).

2 Similar to the: http://ru.wikipedia.org/wiki/рождественский рассказ, last accessed on 30 March 2012. In my study of Internet folklore I have drawn not only the material, but to a great extent also the research and cultural background information. I am fully aware that references to Wikipedia and similar sources in a scholarly article are "not good style", nevertheless: 1) it offered readily accessible and conveniently arranged basic information on the symbols and traditions I tried to study; this information was - of course! - later checked in more serious printed media; 2 ) in our day Wikipedia's texts form their own secondary tradition - frequently they are the source for articles in mass media, further forming knowledge and views.

3 One version of my presentation, close to shown at the International Academic Interdisciplinary Conference FROM LANGUAGE TO MIND 3 on 10th -11th September 2009, Tartu, Estonia, can be found here: http://failiem.lv/u/cvcggak, last accessed on 30 March 2012.

4 The term is used, e.g., here: http://www.netlore.ru/, (last accessed on 30 March 2012), similarly: http://en.wikipedia.org/wiki/Internet_humor, (last accessed on 30 March 2012), etc. (cf. Brednich 2005: 7-27). Because of the volume of the article here I try to avoid touching upon office lore, Internet jokes and humour theories.

5 See, for instance: http://www.youtube.com/watch?v=sz-xEo2RzHg, (last accessed on 30 March 2012), http://autsch.de/20198/weihnachtsmann_auf_klo/, (last accessed on 30 March 2012). The clip is extremely popular, can be found on different websites. (Usually I indicate its address on YouTube, hoping that this larger site will keep it longer. Besides, it offers some statistical data - though this may be not clearly objective, as the same clip can be uploaded several times with different titles). It must be added that ads can be a very interesting part of Internet communication, if the people consider them interesting and forward (both as files and links). Indeed, it is extremely likely that such clips are consciously developed for the Internet (like beer ads, for example), as their style differs from the official TV commercials.

${ }^{6}$ http://autsch.de/clips/werbung/21228_weihnachtsrocker/, last accessed on 30 March 2012.

7 http://www.youtube.com/watch?v=TXMX_xm7IRo, (last accessed on 30 March 2012), there are other similar jokes along these lines.

8 http://www.youtube.com/watch?v=XZAC4_wPXVI, last accessed on 30 March 2012. The musical material does not appear to be created for the particular clip, as it can also be found elsewhere, belonging to the vast "fart culture", also used in other clips: http://www.youtube.com/watch?v=Vg9eZxpV3VA, last accessed on 30 March 2012, etc.

9 The first versions of the presentation used material from several sites which have changed rather little since my initial study (around 2005): http://joki.oho.lv/default. 
php?grupaid=1, http://www.allfunpix.com/christmas/, http://funpic.hu/en/categories/ santa-x-mas, http://kartinki.smeha.net/novogodnie/, http://www.esche-world.de/ lustigebilder/weihnachten/. All websites last accessed on 30 March 2012.

${ }^{10}$ For instance: http://caricatura.ru/, http://www.delfi.lv/jokes/, last accessed on 30 March 2012.

${ }^{11}$ http://www.netlore.ru/oleni, last accessed on 30 March 2012.

${ }^{12}$ http://en.wikipedia.org/wiki/Christmas_card, last accessed on 30 March 2012.

${ }^{13}$ See on this and the further, as well as the origins of the image which I do not consider necessary to retell here: http://en.wikipedia.org/wiki/Santa_Claus, (last accessed on 30 March 2012), as well as the related local and national entries. One of the most important studies that initiated historical research of Christmas-related traditions is the one by Ingeborg Weber-Kellerman (1978). See also Sirpa Karjalainen (1996).

${ }^{14}$ Entering the name of Santa Claus (or some of his counterparts) in an Internet search engine the top of the list offers pages related to commerce - "the most valuable addresses" (e.g. www.santa.com; www.santa-claus.com (last accessed on 30 March 2012)) are used for Internet stores and travel agents - even if these are made interesting for children. The most recent tradition is to create a "national Santa Claus" postal address and home in every country "with self-respect", see, e.g., http://en.wikipedia.org/wiki/ Veliky_Ustyug, http://ziemassvetkuvecitis.lv/, last accessed on 30 March 2012.

${ }^{15} \mathrm{http}: / /$ www.youtube.com/watch?v=nO4zhi4rd3M, last accessed on 30 March 2012

16 This character is relatively recent - Rudolf the Reindeer first appeared in 1939 when the manager of Chicago supermarket chain Montgomery Ward ordered a Christmas story to be written by a 34-year-old writer Robert L. May. The author wrote it in the form of rhymes to his 4-year-old daughter. The publishing house sold 2.4 million copies of the book and by 1946 already 6 million were sold. The author of this poem used several earlier texts mentioning the names of reindeer pulling Santa's sleigh. http:// en.wikipedia.org/wiki/Rudolph_the_Red-Nosed_Reindeer, last accessed on 30 March 2012.

${ }^{17}$ On the other hand, the written folklore repeatedly presents the calculation how fast Santa should go in order to visit all of the children of the world - to keep the speed he would burn together with his sled in the first seconds of such flight: http://www. daclarke.org/Humour/santa.html, last accessed on 30 March 2012. On the contrary to that another site shows Santa's trip online: http://www.noradsanta.org/, last accessed on 30 March 2012.

$18 \mathrm{http}: / /$ www.youtube.com/watch?v=WRF8mVlDdVc, last accessed on 30 March 2012. Russian folklore, in its turn, deals with the idea that having Snegurochka - a young female companion of Ded Moroz, sometimes called his granddaughter - is good, but reindeer - even better.

19 http://www.youtube.com/watch?v=XXkbDdUgU5A, last accessed on 30 March 2012.

${ }^{20} \mathrm{http}: / /$ www.youtube.com/watch?v=pxMe9ulHt1o, last accessed on 30 March 2012.

${ }^{21} \mathrm{http} / / /$ www.snopes.com/holidays/christmas/cross.asp, last accessed on 30 March 2012.

${ }^{22} \mathrm{http} / / / \mathrm{www}$. snopes.com/holidays/christmas/photos/badsanta.asp, last accessed on 30 March 2012. 
${ }^{23}$ The origin of the theme comes from the correspondence of an editor of The Sun with the 8-year-old Virginia in 1897: http://www.newseum.org/yesvirginia/, last accessed on 30 March 2012. It must be added that the theme used in films, etc.: does Santa really exist - has also become a constant one of Christmas jokes.

${ }^{24}$ For instance: http://www.creepysantaphotos.com/, last accessed on 30 March 2012.

${ }^{25}$ Ded Moroz was introduced in Soviet Russia as an alternative to religiously oriented Santa. Ded Moroz brings gifts for the children during the "Fir-tree holiday" on 31 December, mainly at public events in culture houses, those organised by parents, employers, schools and kindergartens. He is accompanied by a small girl - Snegurochka - and a boy - the New Year. The characters gained popularity after 1935 when a suggestion by Iosif Stalin endorsed the celebration of such a festival. Snegurochka is mentioned in Russian folk-tales (N. Afanasiev's collection, 1855-1863) - an old couple makes a girl of snow, who comes to life, but melts in spring. A. Ostrovsky turned it into a play in 1873, and later - in 1881 - N. Rimsky Korsakov composed an opera. For a long time (following Stalin's order), the costume of Ded Moroz was either blue or white, emphasising the difference from the "capitalist" Santa, but gradually the colour red as an important part of the soviet culture was also accepted for his costume. See also http://en.wikipedia.org/wiki/Ded_Moroz, (last accessed on 30 March 2012), and the related entries - it is interesting to compare different language (country) versions regarding the history of these characters.

${ }^{26}$ See also Bernd Brunner (2011); Walter Pötzl (1999: 51-55), and http://de.wikipedia. org/wiki/Weihnachtsbaum, last accessed on 30 March 2012.

${ }^{27}$ If the Internet encyclopaedias can be trusted at all the oldest mention of snowman is found in the works of Shakespeare, but later, for some time, it is not mentioned and depicted. The character gains popularity in connection with the winter landscape in the children books of the 18th century. The snowman by the Christmas tree and on greeting cards was first depicted around 1900. See also: http://de.wikipedia.org/wiki/ Schneemann, last accessed on 30 March 2012.

${ }^{28}$ According to my observations in the beginning of the 1990s there were fireworks in Latvia on both Christmas and New Year's Eve. Even now quite impressive fireworks in Riga are fired at 11 p.m. and not at midnight according to the Latvian time; this means that quite a large number of inhabitants are still watching the Russian TV channels and have closer connections with that country.

\section{REFERENCES}

Brednich, Rolf Wilhelm 2005. www.worldwidewitz.com: Humor im Cyberspace. Freiburg im Bresgau: Herder.

Brunner, Bernd 2011. Die Erfindung des Weihnachtsbaums. Berlin: Insel Verlag.

Karjalainen, Sirpa 1996. The Finnish Santa Claus in Search of a Home. ARV. Nordic Yearbook of Folklore, Vol. 52, pp. 135-144.

Pötzl, Walter 1999. Brauchtum. Von der Martinsgans zum Leonhardiritt, von der Wiege bis zur Bahre. Augsburg: Landratsamt.

Weber-Kellerman, Ingeborg 1978. Das Weihnachtsfest. Eine Kultur- und Sozialgeschichte der Weihnachtszeit. Frankfurt am Main \& Luzern: Bucher. 


\section{FOLKLORE INTRODUCES: INGRID SLAVEC GRADIŠNIK}

\section{MY "ROOTS"}

I was born in Koper, at the seaside, in an area that is officially bilingual, Slovenian-Italian, and situated close to what is now the former Yugoslav-Italian border. In a way I feel this has marked my view, which I could say to have been curious and opening towards the horizon. As a little girl, I was looking from the home balcony towards the Debeli rtič cape, where there remains the open European border with Italy, and beyond toward Grado/Monfalcone - which is as far as you could see on a sunny day. And I kept saying that it was Venice. Far beyond the hills on the north side, also when the weather was nice, you could see the highest Slovenian mountain, Triglav, and far to the right, in the east, there was Nanos, a milestone of a kind between the Primorska region and Central Slovenia. Coming from the southeast and south, the miraculous Istrian landscape was radiating, that is, its Slovenian part that had always been the natural hinterland of three Slovenian seaside towns - Koper, Izola and Piran, as well as the peninsular Croatian part eating into the waves of the northern Adriatic Sea.

A special place of my childhood - apart from Koper - was Trst/Trieste: even in socialism it was a habit (and tradition) for numerous women from the Istrian hinterland to work for wealthy Trieste families

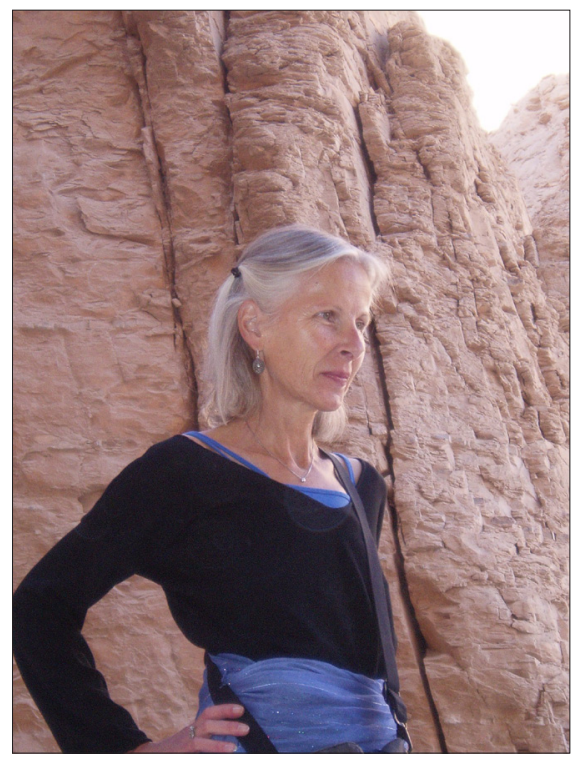

Ingrid Slavec Gradišnik. 
and earn an additional income, both to provide for their own families and to be able to afford all the goods that were not available in the socialist Yugoslavia. Border residents had special passports, the so-called passes (It. lasciapassare), which enabled us to visit Italy four times a month, and later in the 1970s even more often. We would buy washing powder, footwear, textiles in Muggia, a small town ahead of Trieste, and in Trieste itself. Before Euros, in Italy you would pay in lire, which women also earned by taking a kilo of meat, a packet of butter, and eggs to Trieste and exchanging these for household items with drugstore owners. It would be difficult ever to forget the journeys to Trieste by a boat that departed from Koper two or three times daily, and the excellent ice-cream in Trieste, which my mother would buy for me.

During secondary school, I started to see Trieste differently: it was where I would go to buy music (the famed LPs), books, see art exhibitions, visit cinemas and theatres. This, apart from Italian television, was a window on the so-called "Western" world, as well as a reflection of the glitter of Austro-Hungarian monarchy's westernmost part, and to me it still remains an exciting combination of Central and Mediterranean Europe. And also a city where Slovenians have found it hard to reside form the Fascist times onwards!

When in the mid-1970s I came to Ljubljana to study, I noticed that the horizon of people living near the Italian border was a bit "different". It was as if we had been carrying in us a different spirit that was difficult to grasp. I found the decision about what to study easy and difficult at the same time. With my interests going in the cultural and humanistic direction, as well as languages (I had been learning Italian and English since primary school, also French in secondary school), I knew exactly what not to study. At the Faculty of Arts, I could study anything. I enrolled for the double-subject study of Slovenian language and literature (the major or A subject) and history of art (the minor or B subject).

\section{EDUCATION}

My secondary school teachers were mostly excellent and I was particularly inspired by a young teacher of Slovenian language and literature, who once invited her colleague with a degree in ethnology to our school literary group. This was probably the first time I had heard about ethnology. The talk with him remained somewhere at the back of my mind until the long holidays after the matura exam and before entering the university. Then, travelling around Europe, close to Copenhagen, I found myself in the company of two boys and a girl who studied ethnology. I realised how ethnology was opening up a view 
towards everything I was really interested in: the diversity of cultures, histories, places, people and their fates. And so, when enrolling officially at the university, I swiftly replaced art history with ethnology, and after the first year registered it as the second major (A).

\section{UNIVERSITY}

Many are disappointed with their studies. I wasn't. I kept in mind what the secondary school class teacher told us as a farewell, saying that surely we believed it was the end of annoying classes, but even in what we had chosen to study, we would still find at least half of the classes and obligations to be redundant and off-putting. I have always loved literature, whereas studying the secrets of my mother tongue has given me many valuable things - first, it made me aware of my own literacy, but mostly it made me realize how the world and relations between people in their most part are actually interlaced in the language. Today, for example, this knowledge helps me also with my editorial work. On the other hand, at the Department of Ethnology, there was Professor Vilko Novak, an eminent expert on philology and ethnology, who kept persuading me about the importance of philological education. When I began my studies, he was the only full professor at the department, and lectured on the ethnology of Slovenians, ethnology of Southern Slavs and European ethnology. Naturally, I only began to appreciate him after I finished my studies, and later on in my career path. Except for two or three assistants, the second lecturer at the department was the associate professor Slavko Kremenšek, who had been introducing "revolutionary" views into Slovenian ethnology since the $1960 \mathrm{~s}$. He turned the future development of our discipline away from its traditional ethnographic frameworks, which he achieved particularly by focusing ethnological research elsewhere than solely on the past, on rural areas and the remnants of the "old" culture. To student generations of the 1970s and 1980s, he opened up a perspective on everyday culture, contemporary cultural manifestations and cities, and related past and contemporary cultural phenomena to various generational, social, professional and local groups. It could be said that he provided research into everyday life with social-anthropological foundations, which see culture not as a single and unique entity but as a strongly historically and socially informed phenomenon. He thus balanced the relationship between the discipline's practice and theory. He became my mentor in the noblest sense of the word. 


\section{MY INTERESTS}

I was particularly drawn by theoretical aspects, which was due to several reasons: intimately, I had always been interested in the adventures of the human spirit, and - which is already related to ethnology - in theory I saw the key non-explicated or explicated stock of knowledge, which, apart from the skill of narration, is what to a great extent creates inspiring or lame, "better" or "worse" ethnological/anthropological texts, which are more or less convincing in the sense of thematising both universal and specific phenomena of human existence. The first founding-fathers that I read with such a sensibility, of course, were Malinowski and Lévi-Strauss.

\section{MY BA DEGREE}

My diploma thesis on the Slovenians in Mannheim, Germany, served two purposes: it was prepared in the seminar dedicated to the research of Slovenian emigrants and it integrated my Slovenian and ethnological studies; it was also admitted as a diploma thesis at both departments. My main topic of interest was linguistic communication both in German and in Slovenian, as was then practiced in Slovenian families living abroad due to temporary working migration. In principle it explored bilingual asymmetry, which is typical of migrant communities, but not as a unified concept because communicative practices in the mother tongue and in a foreign language depend largely on the social position, education, social networks, contacts with the country of origin, future plans (to remain abroad or return home), etc., and eventually on the attitude towards the mother tongue and homeland in general.

\section{EMPLOYMENT}

During my studies, I wasn't worrying about what to do for a living. Actually, there weren't many jobs in ethnology: at the time ethnologists would mostly work in museums, in institutes for heritage protection, whereas the majority of them would find jobs based on their education in other specialties. Towards the end of my studies I somehow knew I didn't want to be a secondary school Slovenian teacher. I really wanted and hoped to do something related to ethnology. Already while studying, I helped in the department library on a regular basis, thus learning about library and secretarial duties. Since I was a good student, Prof Kremenšek would have offered me a position as an assistant if it 
had been possible, but it wasn't. As the then librarian was just switching jobs, I thus came to the library after graduating, to the world I love so much - being surrounded by books. I stayed there for four years until a position for an assistant in general ethnology was opened.

\section{PhD RESEARCH}

In the meantime I began my postgraduate studies, the topic of my postgraduate thesis having been the development, or rather, a thorough overview of the tendencies in post-World War II ethnology in Slovenia. The topic then grew so much that the professor advised me to elaborate it as a doctoral thesis. As in the following years I undertook a series of lectures and seminars, which together with other work with students occupied all of my time, and became a mother, I was quite late in obtaining my $\mathrm{PhD}$, only when turning 42 . By then I had thoroughly studied the history of ethnology in Slovenia and abroad, which convinced me of the cumulative nature of knowledge production in humanities, and of the need to balance historicist and presentist approaches in dealing with the history of the discipline. The most valuable of the findings, as I thought and as was later affirmed by research into the formation and work of individual researchers, was that the so-called objective aspects or determinants that institute, co-produce and govern the discipline's trends, coexist with a number of ostensible contingencies of a more subjective nature (individuals' affinities and characters, their views of the world, individual trajectories, interpersonal and institutional networks, reception of discipline's tradition), in short, everything that belongs to self-reflexive research into scholarly practices and the production of knowledge. Also, a part of this, to a certain extent, is the dis/loyalty to the "fashion" in scholarship, which has been a typically global phenomenon, not only today, but even a century or two ago. Science is global or international, therefore local disciplinary traditions get caught in it in a varying dynamics, sometimes sooner, sometimes later, and more or less intensely. After all, this is the starting point and condition for our international communication. And if I had to single out one of the several authors that have made an important contribution to expand the field of issues related to the discipline's history, it would surely have to be George W. Stocking, Jr.

Even in the most difficult times - which for our forerunners were the decades following World War II, for which it often seems that the socialist regime was firmly closing the door to the experts hoping for a comparative dialogue, they were actually able to find a way and ensure it. In this respect, the Yugoslavian regime as compared to other countries of the so-called Eastern, socialist block, 
was "softer". My generation experienced hard times, but of course to a much lesser extent, in the 1980s when the "Yugoslav crisis" was severely limiting our financial options. The majority was thus mostly keeping in touch with the international science through reading rather than mobility. It is difficult to imagine it today how valuable each foreign book or journal was to our libraries that had to buy it.

\section{WORKING AT UNIVERSITY}

I was employed by the Faculty of Arts for almost two decades. This was an exceptional time for my maturing, both professionally and personally, and marked by my studies as well as generations of students. When taken seriously by the lecturer, teaching is demanding and strenuous. In recent decades, this responsibility might have grown due to the exceptional production of findings in the discipline and outside it, making it quite difficult to follow. In such circumstances we can only dream of the meticulousness of our older professors. Today, we are faced with a much different style of production within the discipline, often much shallower and more cursory as compared to the impressions acquired when reading older texts. However, a teacher first and foremost has to open the doors and windows to knowledge, curiosity, and responsibility, but also sensitivity both to the distinctions in the issues being raised today and to the style of research.

\section{WORKING AT A RESEARCH INSTITUTE}

Somehow, I also experienced this when changing jobs. That is to say, about a decade ago I moved from the university to a research institute with different work routines. Here I am allowed more time, which I missed while lecturing, so enabling me "slower" and more in-depth study and writing.

\section{OUR INSTITUTE}

The Institute of Slovenian Ethnology at the Research Centre of the Slovenian Academy of Sciences and Arts, where I work now, alongside the Institute of Ethnomusicology, is the central solely research-oriented institute for ethnology and folklore studies. Similar to university, where teaching is connected to research, the latter here is connected to teaching, although the scale is 
smaller. Namely, many researchers teach as external or guest lecturers at four Slovenian universities (Ljubljana, Maribor, Koper, Nova Gorica - the latter hosting a special RC SASA postgraduate programme). I also kept lecturing in Ljubljana for a year, then several years in Koper, at the Faculty of Humanities, where there is a department for cultural studies and anthropology. Research and teaching is a good and tempting combination, enabling the researcher to transfer their findings and test them in a way, particularly as regards their relevance and applied aspects. Above all, working with students forces you to keep in touch with the latest results in domestic and foreign scholarship. And simply enables you not to grow old.

As I have said already, the nature of work in a research institute is much different. In Slovenia, research institutes are financed through local and international research project tenders, therefore our survival depends on the success of our applications. Sometimes, this means cruel battles and competition, as in principle there is no stable finance for continuous research. I am particularly referring to fundamental research, which provides for a continuity of research relevant to the national culture, the knowledge of which is crucial for any intercultural comparison. The institute is currently implementing the research programme "Cultural Spaces and Practices: Ethnology and Folklore Studies" (2009-2014), with everybody employed at the institute participating in it (currently there are 17 people, of whom eight are $\mathrm{PhD}$ researchers, four young researchers, a documentation assistant, a secretary, a librarian, a research assistant and a technical assistant), and several projects with researchers participating based on their specific competences. This is the reason that our work unfortunately is often more fragmentary than we would have wished for, as intense input is required within several research projects. On top of the fact that the institute takes care of its archives and documentation, it keeps its own library and a special audiovisual laboratory that develops visual researches into culture and provides a large video archive. Senior researchers also serve as mentors to young ones who are training for their own academic career, completing their doctoral theses. We edit two scientific journals (Traditiones and Studia mythologica Slavica) and three book series (Opera ethnologica Slovenica, Ethnologica - Dissertationes and Slovenski pravljičarji [Slovenian Storytellers]).

Our editorial work is demanding in the sense of the amount of time it takes. I am particularly glad for both our journals to have an international profile, which has been achieved by being open thematically and having a rigorous editing process. Authors of articles are Slovenian and foreign researchers. We also publish topical volumes, often in English, to reach as many readers as possible in the international scholarly community. Also helpful in this view is our international editorial board with eminent foreign experts, two Slovenian 
academicians and experienced former editors. Except for the most recent year, the articles are also available on-line on the journal's homepage.

\section{PROFESSIONAL \& PRIVATE LIFE}

Ethnologists mostly believe ethnology to be life itself. And being unable to delineate my professional and personal life clearly, this is how I see it myself. At the institute I have my working space, which I use thoroughly in the morning, sometimes also in the afternoon and even on Saturdays and Sundays, if necessary. But this is far from saying that my work and my thoughts stop and switch over when I step out of the door of the institute. We cannot be like always in the field. Currently I have been involved in two new research projects exploring the transformation of festive practices and the issue of evaluating the relationship between nature and culture, i.e., natural and cultural heritage, with Triglav national park serving as an example, while I also continue researching the history and methodology of ethnology in Slovenia in a comparative European context.

On top of this fundamental work, the researcher often gets burdened with a plethora of minute, often bureaucratic tasks, which are also of key importance for the institute to function smoothly, while some others might support local ethnology at least indirectly. Considering all this, there is only little time left for leisure - for the family, walks, reading. I am thus looking forward to summer ever again, when I have the time to relax for a week or two in Slovenian mountains or somewhere in the Mediterranean, preferably in a quiet place somewhere on Croatian or Greek islands. But even then my spectacles have ethnological lenses.

\section{REFERENCES}

BA, 1981: Slovenci v Mannheimu. Poskus etnološko-jezikoslovne predstavitve. [Slovenians in Mannheim: An attempt at ethno-linguistic presentation.] Department of Ethnology, Faculty of Arts, University of Ljubljana.

Publ.: Slavec, Ingrid: Slovenci v Mannheimu. [Slovenians in Mannheim.] Ljubljana, 1982.

PhD, 1998: Med narodopisjem in antropologijo. Teoretsko-metodološka vprašanja in odgovori v etnologiji na Slovenskem. [Between narodopisje and anthropology: Theoreticalmethodological issues in Slovenian ethnology.] Department of Ethnology and Cultural Anthropology, Faculty of Arts, University of Ljubljana. 
Publ.: Slavec Gradišnik, Ingrid: Etnologija na Slovenskem. Med čermi narodopisja in antropologije. [Ethnology in Slovenia: between the reefs of narodopisje and anthropology.] Ljubljana, 2000.

\section{EDITED AND CO-AUTHORED BOOKS}

Slavec, Ingrid (et al., eds.). Etnološka stičišča / Zbieżności etnologiczne/ Ethnological contacts - 1. Ljubljana, 1988.

Slavec, Ingrid \& Dolžan Eržen, Tatjana (eds.). Zgodovinske vzporednice slovenske in hrvaške etnologije - 5. [Historical parallels of Slovenian and Croatian Ethnology.] Ljubljana, 1988.

Kremenšek, Slavko; Slavec, Ingrid \& Dolžan Eržen, Tatjana (eds.). Etnologija in domoznanstvo. [Ethnology and Heimatkunde.] Ljubljana, 1989.

Hribar, Daša; Jezernik, Božidar; Ostromecka-Fraczak, Božena \& Slavec Gradišnik, Ingrid (eds.). Etnološka stičišča / Zbieżności etnologiczne / Ethnological contacts - 3. Ljubljana, 1991.

Bogataj, Janez \& Slavec Gradišnik, Ingrid (et al., eds.). Kolesar s Filozofske. Zbornikv počastitev 90-letnice prof. dr. Vilka Novaka. [The cyclist from the Faculty of Arts: Papers honoring the 90th anniversary of Professor Vilko Novak.] Ljubljana, 2000.

Hudelja, Mihaela; Hazler, Vito \& Slavec Gradišnik, Ingrid. Podobe pokrajin 1956-1970. Etnološka fototeka Vilka Novaka. [Images of regions 1956-1970: Vilko Novak's ethnological photographs archive.] Ljubljana, 2001.

Slavec Gradišnik, Ingrid \& Ložar-Podlogar, Helena (eds.). Pretrgane korenine. Sledi življenja in dela Rajka Ložarja. [Displaced roots: the life and work of Rajko Ložar.] Ljubljana, 2005.

Slavec Gradišnik, Ingrid \& Ložar-Podlogar, Helena (eds.). Čar izročila. Zapuščina Nika Kureta (1906-1995). [The magic of tradition: the legacy of Niko Kuret (19061995).] Ljubljana, 2008.

Slavec Gradišnik, Ingrid (ed.). Etnološki pogledi in podobe. [Ethnological perspectives and images.] Ljubljana, 2009.

Slavec Gradišnik, Ingrid \& Radojičić, Dragana (eds.). Srbi v Sloveniji, Slovenci v Srbiji. [Serbs in Slovenia, Slovenians in Serbia.] Ljubljana, 2010.

Slavec Gradišnik, Ingrid (ed.) \& Ivančič Kutin, Barbara. Živa pripoved v zapisu. Kontekst, tekstura in prekodiranje pripovedi Tine Kravanja iz Bavšice. [A written record of live storytelling: context, texture, and transcoding of stories told live by Tina Kravanja from Bavšica.] Ethnologica - Dissertationes 3, Ljubljana, 2011.

\section{SELECTED ARTICLES}

„Historična etnologija“ ali o etnologiji kot vedi o preteklosti. [«L'ethnologie historique» ou l'ethnologie comme étude du passé.] Traditiones 1987, Vol. 16, pp. 51-72. 
Etnološko preučevanje etnične identitete slovenskih izseljencev. [Ethnological research of ethnic identity of Slovenian emigrants.] Dve domovini [Two Homelands] 1990, Vol. 1, pp. 309-317.

Slowenian ethnology between the past and the present. Ethnologia slavica 1990, Vol. 22 , pp. 217-242.

"The own" and "the foreign" or on the interpretation of cultural-ethnical-national differences. Etnološki pregled 1990, Vol. 26, pp. 87-98.

O etnologiji in leksikografiji. Slovenski etnološki leksikon med zamislijo in izidom. [On ethnology and lexicography: the lexicon on Slovenian ethnology between conception and publication.] Traditiones 2005, Vol. 34, No. 2, pp. 87-107.

"Narodu v slavo in učenosti v napredek". Recepcija Gregorja Kreka v slovenski etnologiji. ["To the glory of the nation and to the advancement of learning": the reception of Gregor Krek in Slovenian ethnology.] Anzeiger für slavische Philologie 2006, Vol. 33 (2005), pp. 93-113.

Etnološka branja Gregorja Kreka. [Ethnological readings of Gregor Krek.] Traditiones 2006, Vol. 35, No. 2, pp. 205-233.

Scraps of the history of ethnology in Slovenia. Česky lid 2008, Vol. 95, No. 1, pp. 37-62.

Pogledi in podobe. K vprašanjem o produkciji znanja I. [Perspectives and images: fragments of knowledge production in etnology I.] Traditiones 2008, Vol. 37, No. 2, pp. $217-250$.

Slovenian folk culture. Between academic knowledge and public display. Journal of folklore research 2010, Vol. 47, No. 1/2, pp. 123-151.

"Marxistický program" v slovinskej etnológii?. [The "Marxist" agenda in Slovenian ethnology?] Slovensky národopis 2010, Vol. 58, No. 4, pp. 478-495.

Etnologija v Sloveniji in Srbiji. Dve tradiciji “jugoslovanske” etnologije? [Ethnology in Slovenia and Serbia: two traditions of "Yugoslav" ethnology?] Traditiones 2010, Vol. 39, No. 1, pp. 15-30.

On folklore and folklore studies in Slovenia. Balgarski folklor 2011, Vol. 37, special edition, pp. 5-22.

Zadnje desetletje od šestih. Inštitut za slovensko narodopisje ZRC SAZU (1951/20012011). [The last of the six decades: the Institute of Slovenian ethnology ZRC SAZU (1951/2001-2011).] Traditiones 2011, Vol. 40, No. 1, pp. 115-138.

The Institute of Slovenian Ethnology ZRC SAZU (1951-2001). Ethnologia europaea centralis 2011, Vol. 10, pp. 81-86.

\section{CHAPTERS IN BOOKS}

Težnje v povojni slovenski etnologiji. [Trends in post-war Slovenian ethnology.] In: Bogataj, Janez and Marko Terseglav (eds.). Zbornik 1. kongresa jugoslovanskih etnologov in folkloristov: Rogaška Slatina, 5.-9.10.1983: 30. kongres Zveze društev folkloristov Jugoslavije: 18. kongres Zveze etnoloških društev Jugoslavije. Ljubljana, 1983, pp. 148-175.

Marginalia to ethnological writing and description. In: Etnološka stičišča / Ethnological contacts - 1, 1988, pp. 119-128. 
O identiteti etnologije [The identity of ethnology]. In: Rihtman-Auguštin, Dunja (ed.). Simboli identiteta [Symbols of identity]. Zagreb 1991, pp. 32-44.

Med narodopisjem in antropologijo: o razdaljah in bližinah. [Between ethnograhy and anthropology.] In: Muršič, Rajko and Mojca Ramšak (eds.). Razvoj slovenske etnologije od Štreklja in Murka do sodobnih etnoloških prizadevanj. [The development of Slovene ethnology: from Štrekelj and Murko to modern ethnological efforts.] Ljubljana 1995, pp. 125-140.

Redefinicija slovenskega narodopisja v objemu evropske etnologije ali "O bistvu etnografije in njeni metodi" - še enkrat. [The redefinition of Slovenian ethnography in the context of European ethnology: "On the essence of ethnography and its method" reread.] In: Bogataj, Janez et al. (eds.), Slavec Gradišnik, Ingrid (ur.). Kolesar s Filozofske. Ljubljana 2000, pp. 79-103.

Podobe pokrajin in njihovo ozadje. Kulturna območja na Slovenskem. [Images of regions and their background: Cultural areas in Slovenia.] In: Hudelja, Mihaela; Hazler, Vito \& Slavec Gradišnik, Ingrid. Podobe pokrajin (1956-1970). Etnološka fototeka Vilka Novaka. [Images of regions 1956-1970: Vilko Novak's ethnological photographs' archive.] Ljubljana 2001, pp. 25-59.

O Ehrlichu in etnologiji. [On Lambert Ehrlich and Ethnology.] In: Škulj, Edo (ed.). Ehrlichov simpozijv Rimu. [Lambert Ehrlich Symposium in Rome.] Celje 2002, pp. 157-172.

Bogastvo filologije. Murkov pomen za etnologijo v Sloveniji. [The affluence of philology: Matija Murko's significance for ethnology in Slovenia.] V: Matija Murko v myšlenkovém kontextu evropské slavistiky : sbornik studii. [Matija Murko in the intellectual frames of European Slavic studies.] Brno 2005, pp. 100-122.

Etnološki nazori Rajka Ložarja. [Ložar's View on Ethnology.] In: Slavec Gradišnik, Ingrid \& Ložar-Podlogar , Helena (eds.). Pretrgane korenine. Sledi življenja in dela Rajka Ložarja. [Displaced roots: the life and work of Rajko Ložar.] Ljubljana 2005, pp. 283-303.

Slovanski svet v obzorju slovenske etnologije. [The Slavic world in the horizon of Slovenian ethnology.] In: Kaleta, Petr \& Tyllner, Lubomír (eds.). Slovanský svět očima badatelů a publicistů 19. a 20. století. Praha 2007, pp. 209-225.

Med življenjem in znanostjo. Etnološka obzorja Nika Kureta. [Between Life and Scholarship: Niko Kuret's ethnological horizons.] In: Slavec Gradišnik, Ingrid \& Ložar-Podlogar, Helena (eds.). Čar izročila. Zapuščina Nika Kureta (1906-1995). [The magic of tradition: the legacy of Niko Kuret (1906-1995).] Ljubljana 2008, pp. 41-68. 
Ljubljana - preddverje slovenske urbane etnologije. [Ljubljana: an antechamber to Slovene urban ethnology.] In: Čebulj - Sajko, Breda (ed.). Etnologija in regije, Ljubljana, Urbana etnologija in identitete Ljubljane. [Ethnology and regions: Ljubljana: urban ethnology and Ljubljana's identities.] Ljubljana 2008, pp. 17-29.

Institucije in produkcija etnološkega znanja. [Institutions and the production of ethnological knowledge.] In: Divac, Zorica (ur.). Slike kulture nekad i sad. [Images of culture then and now.] Beograd 2008, pp. 65-79.

(with Jurij Fikfak). Gradec in slovensko narodopisje. [Graz and Slovenian ethnography.] In: Karničar, Ludvik \& Rajšp, Vincebc (eds.). Graz und Slowenen: Sammelband zum gleichnamigen Symposium vom 20.-21. V 2010 an der Karl-Franzens-Universität Graz. Wien, Ljubljana \& Graz 2011, pp. 115-129. 


\section{NEWS IN BRIEF}

\section{ALL-ESTONIAN COMPETITION FOR NURSERY SCHOOL LORE COLLECTION}

From October 15, 2010, to January 31, 2011, the Department of Folkloristics at the Estonian Literary Museum and the Estonian Folklore Archives organized a collection competition for nursery school (in Estonia up to age 7) lore. On March 14, the Mother Language Day, a festive meeting took place at the Estonian Literary Museum in Tartu, where Toomas Hendrik Ilves, President of the Republic of Estonia, awarded prizes to the winners of the 2010 folklore collection competition. The best contributors to the Folklore Archives and the most efficient nursery school lore collectors were recognized with thank-you letters and souvenirs.

Children have been in the sphere of interest of Estonian folklorists also earlier; already in the 1920s our first folklore professor Walter Anderson initiated the collection of children's songs. On several occasions all-Estonian school lore collection competitions have been organized, the most recent of which took place in 1992 and 2007. Random, thematic and special-purpose collection actions at nursery schools have been carried out also before, but such a broad-based campaign covering the whole country was the first of the kind.

Approximately 80 nursery school teachers and educators from all over Estonia provided answers to the open-ended questions of the detailed questionnaire. The 67 submitted contributions included 62 individual answers and 5 ones created by teamwork. All the Estonian counties except for Läänemaa and Viljandimaa were represented. The majority of the participants were currently working nursery school teachers; yet, there were also some who had quitted the job. The shortest answer was a letter including only one riddle, whereas the longest ones amounted to half a hundred pages and were remarkable for their good narratives and copious photographic and video materials.

The questionnaire proceeded from the fact that children today spend most of their weekdays at a nursery school. While intercommunicating with their peers and adults, they share and gain knowledge of their traditional national culture. On the one hand, children's lore is something that spreads among them and of which adults sometimes do not have the faintest idea. On the other, it is the lore that adults present to and with children for various (educational, entertainment and other) purposes. In order to get a comprehensive overview of children's and nursery school traditions, we turned for help to teachers, as their role in shaping children's lore is significant and invaluable. In our questionnaire we expected answers within three topics: 1 . festivities and parties, 2 . games, and 3. stories and sayings.

At each topic, our primary interest was to find out how tradition is used in nursery school programmed activities, as it is common knowledge that nursery school curriculum envisages the cherishing and maintaining of traditions. Secondly, we recommended that the teachers observe children in order to learn more about their own lore.

Under the first topic festivities and parties at nursery schools were described. We received a substantial overview of how traditional calendar events are celebrated, such as 
St Catherine's Day, St Martin's Day, All Souls' Day, Christmas, Shrove Tuesday, Easter, Walpurgis Night, etc., as well as what is done to mark, for example, the anniversary of the Republic of Estonia, Valentine's Day, Mother Language Day, Boys' and Girls' Days. In addition to Mother's and Father's Days, grandparents' days have also started to be celebrated. Birthdays are certainly considered to be very important. Hello Kitty and pirates' parties are a sign of the era. The events organized are very creative and many nursery schools have established their own traditions, also continuously coming up with new ideas. These ideas are often influenced by public life, which is acted out at the nursery school. The topic of festivities clearly revealed to what extent families are included in nursery school traditions.

Playing is an agreeable joint activity, an inseparable companion and serious work for this target group. While school lore collection has shown that in the era of the computer and techno culture, the virtual world and the Internet comprise a great part of the child's entertaining play world, then at nursery school children are attracted to the games of the real world. We received descriptions of many traditional games, which are played both inside and outside, as well as counting-out rhymes, which have been passed on from one generation to another. Within this topic there was material about role-plays that have been popular throughout times, such as policeman and bum, doctor, home, etc., but also games that characterize a certain period of time. Some of the games played by children relate to boom toys, such as Bakugan, Hello Kitty, Spiderman and others, TV-shows (Estonian version of Search for a Superstar, etc.) as well as commercials.

Children's play-world is definitely influenced by the surrounding reality, the things that they hear and see; so we discovered how after the storm that demolished the church tower in Väike-Maarja last summer, children started to act out the fall of church tower.

The third bigger sub-topic was dedicated to stories and sayings. We were interested in the usage of proverbs at nursery school; due to their didactic nature teachers often employ them for educational and pedagogical purposes. In all, the teachers wrote down about 300 different proverbs, most of them are archaic and also find representation in the academic publication of Estonian proverbs. The most popular proverbs that are used by nursery school teachers are the following:

1.-2. Pill tuleb pika ilu peale. ('Excessive joy ends with tears.')

1.-2. Töö kiidab tegijat. ('Work praises the doer.')

3.-4. Tee tööd töö ajal, räägi juttu jutu ajal. ('Do work at work's time, talk at talk's time.')

3.-4. Enne mõtle, siis ütle. ('First think, then say.')

5.-9. Harjutamine teeb meistriks. ('Practice makes perfect.')

5.-9. Kes kannatab, see kaua elab. ('He who suffers, lives long.')

5.-9. Kus viga näed laita, seal tule ja aita. ('If something is wrong, come and fix it.')

5.-9. Targem annab järele. ('The wiser one gives in.')

5.-9. Valel on lühikesed jalad. ('Lie has short legs.')

10.-11. Kes ees, see mees. ('The first one wins.')

10.-11. Kui midagi teed, tee hästi! ('If you do something, do it well!')

It is clear that through proverbs positive values are being taught and therefore they are well suited for educational purposes. Besides proverbs and riddles, nursery school teach- 


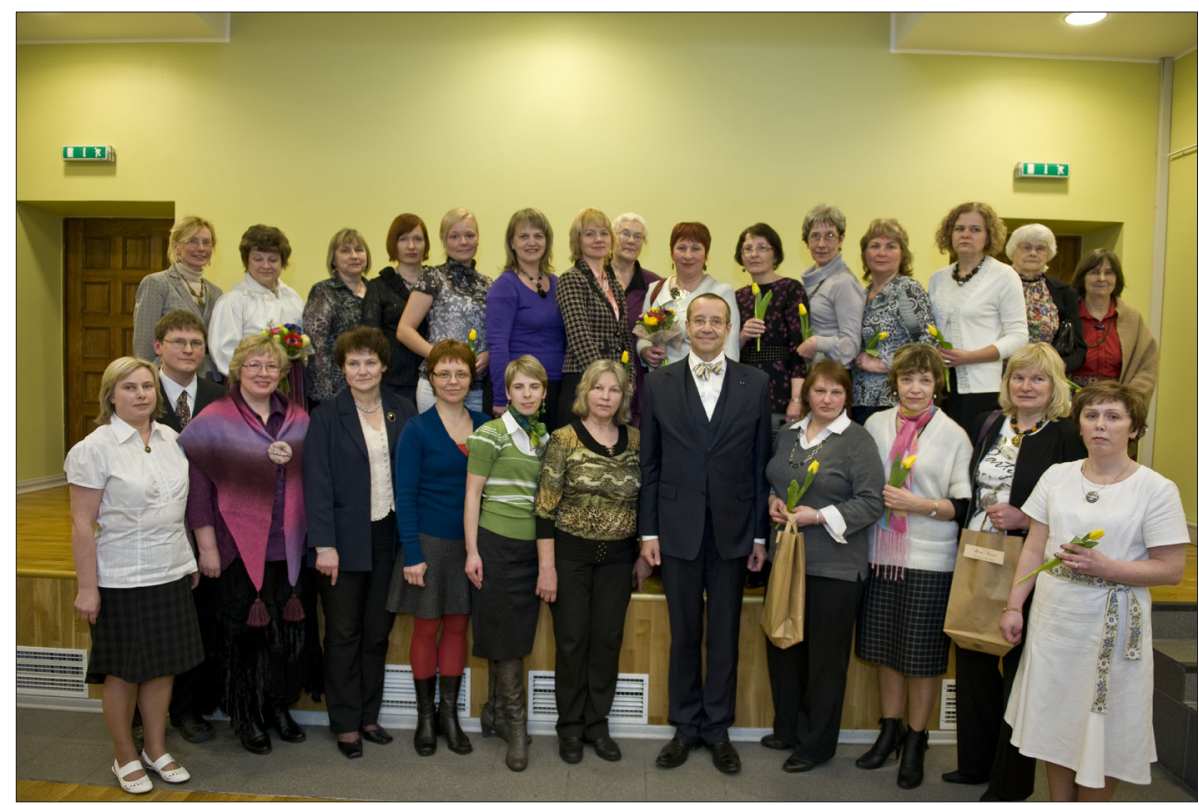

At the festive meeting on March 14, the Mother Language Day, where Toomas Hendrik Ilves, President of the Republic of Estonia, awarded prizes to the winners of the 2010 folklore collection competition, the best nursery school lore collectors were also recognized. Photo by Alar Madisson 2011.

ers wrote down children's funny sayings and expressions, which constitute a voluminous text corpus. This kind of lore, through which we can follow language acquisition and development as well as children's understanding of things, could also be of interest to the representatives of neighbouring disciplines, for instance, linguists and psychologists.

Within this topic questions were also asked about children's fears. The answers revealed that their emotions were largely influenced by the media and movie characters as well as Santa Clause.

In conclusion we can say that today's nursery school is a reflection of our time - diverse and many-sided, full of possibilities, childishly bright, although sometimes also troubled and anxious, yet intertwined with enduring traditions and open to innovations. Children's lore is in constant communication with the adults' world, constituting its miniature model, which clearly expresses adults' values, whether they depend on each individual home separately or society on a wider scale.

Hopefully, answering this questionnaire helped both the teachers and children perceive themselves as tradition carriers and understand even better that tradition and folklore - this is not something grey and old, but it continues to live daily in and next to us.

The assessment process was quite tough. The first criterion to be taken into account was how comprehensive the material was and how well it was presented. Some teachers had used a very creative approach, had interviewed children, analysed their own writing, and elicited the changes that had occurred in traditions during their career. In case answers were equal contentwise, we considered the volume and additional materials, 
photographs, video recordings, and party programmes. So the award-winning writings were both substantial and voluminous.

In several answers we found the indication that Estonian nursery school children are in the habit of saying after a meal, "Aitäh, kõht on täis, mutionu külas käis!” (Thank you, I've had enough, Uncle Mole came to visit!). Thanks to the nursery school teachers who answered our lengthy questionnaire, the folklore archives have had enough for this time as well. All the answers are really valuable to us and will be preserved in the archives for the future generations. The more thorough elaboration and analysis of the material is a future issue.

The organizers are especially grateful to the supporters of the competition: the Cultural Endowment of Estonia, bookshops Apollo and Rahva Raamat, publishing houses Ajakirjade Kirjastus and Koolibri, café Anna Edasi, Aura Centre, Du Nord, Helina Tilk, Piletilevi, newspaper Postimees, and theatre Vanemuine.

You can find nursery school lore homepage at the address http://www.folklore.ee/kp/lp.

Piret Voolaid

\title{
INTERNATIONAL CONFERENCE TRADITION AND \\ CULTURAL HERITAGE: CHALLENGES FOR CREATIVITY AND PERFORMANCE
}

\author{
The Last of the Six Decades: The Institute of Slovenian Ethnology \\ ZRC SAZU (1951/2001-2011)
}

\section{Intro}

Today the Institute of Slovenian Ethnology (ISE) at the Research Centre of the Slovenian Academy of Sciences and Arts (ZRC SAZU) is one of the central ethnological institutions in Slovenia. It was established in 1951, and its beginnings reach back to 1947, when the Commission for Slovenian Ethnography was founded at the Academy of Sciences and Arts.

The foundation agenda of the Commission/Institute was in its greater extent heir of the disciplinary tradition: narodopisje (ethnology) was classified among historical disciplines, its "scientific" status was grounded on positivism, the definition of the subject matter (folk culture) derived mostly from classical bipolar or two-layered typologies of culture, for the definition of folk culture community, ethnic group/nation and tradition were sine qua non. Researchers' activities were related primarily to 'rescuing material', and the empirical style of research predominated. From the methodological point of view other disciplines (esp. philology, historiography, geography, art history, archaeology) impacted the approaches and methods in folk culture research (Slavec Gradišnik 2008a).

Setting the plan for the Commission's agenda, Niko Kuret and Ivan Grafenauer were mindful of the role of academic institutions: the institute should provide for the 
infrastructure needed for the entire process of knowledge production: research, teaching, and dissemination (see Kuret 1972).

Until 1964, academician Ivan Grafenauer led the Commission and then the Institute, which worked until the beginning of the 1950s exclusively with external part-time employees. The first regularly employed researchers were Milko Matičetov (1952) and Niko Kuret (1954), followed by one researcher in the 1960s, three researchers in the 1970 s, four in the 1980s and two in the 1990s. At the beginning of the new millennium (2001), there were nine older and two young researchers employed by the Institute.

Upon the establishment of the Institute, it was conceived as a central research institution (Kuret 1972, 1973, 1974) covering the whole sphere of folk life studies. For almost 25 years the actual research work of the Institute has been performed only in two sections or divisions: the researches of folk literature and oral tradition, and rituals and games.

In 1972, the Institute opened a section for material culture. That same year, the Section for Ethnomusicology was added, and remained its part until the establishment of the independent Institute of Ethnomusicology in 1994 (Ramovš 2001). Since 1983, the Audiovisual Laboratory of the ZRC SAZU, which became part of the Institute in 1999, has offered support for the researches (Križnar 2001). It develops the theory and practice of visual culture studies, provides education in this field and popularises it within the Summer School of the Visual and the Days of Ethnographic Film festival.

For the activities of the Institute, the general institutional framework and national research policy have been and still are relevant. Until 1982, the Institute was affiliated with the Slovenian Academy of Sciences and Arts, and afterwards with the independent Scientific Research Centre (est. in 1981). The science policy has constantly been wavering between the support for institutions and research fields and individual disciplines, which means that it has strived to achieve a balanced development, while sometimes overlooking the character of individual institutions.

In the last 15 years, research has been supported through different programmes and projects (with the funds of the Ministry of Higher Education, Science and Sport, in recent years the independent Slovenian Research Agency, and applied-oriented and other projects have been published by tender by other ministries as well). The former (duration 3-5 years) represent a more stable form of support to fundamental researches conducted by research groups (e.g., institutes), the latter (2-3 years) are usually focused on specific basic or applied researches. Since Slovenia has joined the European integration process, the opportunities for involvement in various European projects have opened up and international connections support bilateral agreements that Slovenia has concluded with numerous countries.

\section{The last decade}

In the last decade (2001-2011), the number of the Institute's personnel did not change substantially: it was reduced from nine to seven, and from the four young researchers, only one remained at the Institute after the completion of the training, and another expert assistant and also a technical assistant were recruited. Currently, the Institute has 17 members: eight researchers with doctoral degrees, four young researchers, a librarian, two expert assistants, a secretary, and a technical assistant. 
Owing to the means of financing research institutions, the dynamics of project applications intensified. In 2001, the Institute ran a research programme (1999-2003) together with three research projects (until 2003-2004) and in the subsequent years, the applications of two research programmes (2004-2008, 2009-2013), six projects, two international projects and a number of bilateral projects were approved.

However, the content is more important than sheer numbers.

The research programme Ethnological Research of Culture in Slovenia and the Slovene Ethnic Territory (1999-2003) was presented as follows: "The programme comprises ethnological research throughout the Slovene ethnic territory, history of Slovene ethnology, visual ethnology, ethnological theory and methodology, and central document collection. Research work is centred on the following sections: the section for material culture (economy, architecture, food culture, clothing culture), the section for social culture (yearly and life cycle customs, masks and masquerading, work customs, family and kinship relations, neighbourhood, inter-settlement and interethnic relations), and the section for spiritual culture (narrative and folk literature, beliefs, mythology, toponymics). The Audiovisual Laboratory conducts filming and visual research projects as well as summer visual workshops." (http://isn.zrc-sazu.si/index.php?q=en/node/19)

The next research programme, Ethnological and Folkloristic Research in Slovenia and in Europe (2004-2008), outlined a broader plan: "The research programme sets forth research themes of the ISE, most of which have had priority status since the Institute's foundation at the beginning of the 1950s [...] as well as new ones: visual research projects, family and kinship, life stories, theory and history of ethnology [...] By becoming part of the European Union, Slovenia is no longer divided by borders. A continuation of ethnological and folkloristic research in areas formerly along and across the borders of Slovenia shall undoubtedly greatly contribute to the understanding of the formation of the new Europe." (http://isn.zrc-sazu.si/index.php?q=en/node/19)

The current research programme Cultural Spaces and Practices: Ethnology and Folklore Studies (2009-2013) is aiming at a more intensive conceptual focus: the ambivalences of multiculturalism and versatile individual and collective identifications. Cultural heritage, folk culture, identity and specific cultural phenomena as unstable and 'in change' categories could not be trapped into limited geographical and social spaces. Instead, we pay attention to the processual, dynamic aspects, which are evident in cultural continuity and change, the vanishing of certain cultural forms, and their re-production [...] Thus, ethnology encounters multilevel identifications and new uses of cultural symbols, traditional and novel, in differently configured cultural spaces, which are more and more European and global.

Finding a balance between the unperformed and "traditional" tasks on the one hand, and the necessary innovations on the other, is clearly expressed in the research projects of the last decade.

The project for the publication of the Lexicon of Slovenian Ethnology (2001-2003) was a huge debt to the disciplinary heritage, since the idea for an ethnological dictionary had conceived the establishment of the Commission for Slovenian Ethnography. With many years of preparations, collecting of materials and providing more than 6000 lexicological texts for this edition, the Institute carried out the mission of the central ethnological institution, because it connected more than 100 authors, ethnologists and other experts from Slovenia and abroad. Until now, the lexicon (Baš et al. 2004) is an unprecedented synthesis of the ethnology of the Slovenians in lexicological and encyclopaedic formats. 
The project Implementation of Information Technology in the Field of Intangible Ethnological and Folklore Heritage (2005-2008) enabled the digitisation of a huge corpus of Slovenian proverbs and sayings, and set grounds for the ongoing research project Slovenian Proverbs as Cultural Heritage: Classification and Corpus Editing (2010-2013). This project is also linked to the original work tasks of the Institute. Its aim is to locate the Slovenian paremiology on the world's paremiological map.

The research project Habitus of the Slovene Entrepreneur between 1960 and 1990 (2005-2008) has introduced the conceptual and methodological innovations: it was a reflection of answers to the questions about the reasons for the relative economic successfulness of Slovenia in the transition period in comparison with other post-socialist countries.

Two more projects have been associated with various aspects of cultural heritage. The work for the Registry of Intangible Heritage (2006-2008) was aimed at implementing the UNESCO Convention for the Safeguarding of the Intangible Cultural Heritage (2003). On the basis of the successfully concluded project, the Institute was given the task of the national Coordinator of the Protection of Living Heritage (2009-2010).

Diverse research ambitions were outlined in the projects Ethnological Views and Images (2004-2007) and Tradition and its Re-Producers (2008-2011): the former reflected on knowledge production in ethnology and folklore studies between the 19th and 21st century, the latter - on constructing and spreading discourses on tradition in academic debates, everyday practices and media communication.

The institute's staff members edit two peer-reviewed journals: Traditiones (39 vols., since 1972) and Studia mythologica Slavica (13 vols., since 1998), and the series Opera ethnologica slovenica (5 vols, since 2003), Slovenski pravljičarji (Slovenian Storytellers, 1 vol., since 2010), Studia mythologica Slavica - Supplementa (3 vols., since 2004), and Ethnologica - Dissertationes (1 vol, 2011), all published by Založba ZRC/ZRC Publishing. The newsletter Slovstvena folkloristika (Literary Folklore, 9 vols.), and the series Glasovi (Voices, 39 vols.; since 1988) and Zakladnica slovenskih pripovedi (A Treasury of Slovenian Tales; 10 vols., since 1999) are published by commercial publishing houses.

The festival Dnevi Etnografskega Filma (Days of Ethnographic Film), the educational summer school Poletna Šla Vizualnega (Summer School of the Visual, organized by the Audiovisual Laboratory), conferences, and other public appearances by the institute's staff members promote their research results in the scholarly community and the general public.

The institute's researchers teach at universities in Slovenia and abroad and are engaged as research advisors.

Alongside connections with a network of institutions and individuals abroad, participation in international conferences, and membership in international editorial boards, international cooperation takes place through international bilateral projects (with Serbia: Serbs in Slovenia, Slovenians in Serbia, 2006-2007, and Cultural and Academic Contacts: Serbs and Slovenians between the 19th and 21st Centuries, 2008-2009; with Slovakia: Slovak-Slovenian Parallels in Ethnology and Folkloristics, 2008-2010; with Bulgaria: Folklore Studies: Historical and Recent Researches in Bulgaria and Slovenia, 2009-2011). 
Two international projects should be mentioned in this context: the project Aquadapt was an interdisciplinary one and the results were published in a monograph Kras: Water and Life in a Rocky Landscape, with an extensive ethnological chapter entitled Water and Culture. The second one is the project Etnofolk on the preservation and enhancement of folk culture heritage in Central Europe.

Ingrid Slavec Gradišnik

\section{MEDICA VIII. INTERDISCIPLINARY CONFERENCE MEDICAL PLURALISM IN THE ERA OF DIGIMODERNISM}

\section{November 28th, 2011. Estonian Literary Museum, Tartu}

Kaarina Rein (Medicine in Tartu before the Foundation of the University and during the Academia Gustaviana Period) suggested that the history of medicine in Tartu began with medieval monastic medicine. An infirmary, an almshouse at the Church of Holy Ghost and a hospital for leprous patients were probably founded in the middle of the 13th century. The first pharmacy in Tartu was founded between 1422 and 1430 by a learned physician Johann Molner, and until the 17th century the owners of pharmacies were the only representatives of academic medicine in Tartu. With the foundation of the University in Tartu in 1632, three professors of medicine from Germany - Johannes Raicus (ca 1580-1632), Johann Below (1601-1668) and Sebastian Wirdig (1613 or 1615-1687) influenced the medical and local intellectual circle in Tartu. It is apparent from their works that J. Raicus found support in his ideas from the teachings of Paracelsus, and J. Below and S. Wirdig were following the humoral pathology. Although the beginning of the academic medical education was promising, for some of the time the professorship of medicine was actually vacant.

Ave Tupits (The Academics and the Recording of Folk Medicine during the Estonian Republic (1918-1940)) gave an overview of Estonian folklorists' interest in folk medicine during the Estonian Republic at the beginning of the 20th century. The folkloristic questionnaires compiled mostly in the 1920s and 1930s and directed towards the archives' correspondents, entailed questions about folk medicine and folk healing methods. Healers, illnesses and common curative practices were in the centre of attention. The academic medical circles also showed interest in the Estonian folk curing methods, and a few collections were started from their side with the Estonian National Museum and the Estonian Museum of Hygiene. Articles and other publications of the 1920 s and 1930s give an insight into the general attitude of the academic medical circles, as well as individual opinions toward folk medicine practices, which were not always in unison. The general viewpoint, however, was that folk healing is degrading and medical professionals will prevail.

Kristiina Johanson (Is it Possible to Identify the Healing Instruments in the Archaeological Material?) touched on the examples from the Stone Age to the Late Iron Age. These healing instruments are not easily identified, since the artefacts used in magical 
and healing practices might not stand out in the overall archaeological complexes. In order to identify these objects, alternative sources might be looked for - folklore texts and written sources from antiquity to the medieval period (e.g. medieval lapidaries). Kristiina Johanson discussed some of the healing materials used according to the 19thand 20th-century folklore texts and then compared the findings from archaeological sites to identify the healing and magical instruments, also demonstrating the apparent or probable healing instruments in photos.

Svetlana Tsonkova (Last Man Standing? Charmers, Illnesses and Healing in Bulgarian Early Modern Daily Life) based her paper on early modern Bulgarian charms and non-canonical prayers, written in Old Church Slavonic language and preserved in manuscripts. She was treating the charms, charmers and crisis situations as cultural phenomena, and as subjects of interdisciplinary research. Svetlana Tsonkova demonstrated the difficulties and possibilities in tracing the specific features of the practitioners and users of charms, non-canonical prayers and other words of power, focusing on conjuring as an everyday practice and strategy to manage critical situations, affecting the health and life of humans and animals. S.Tsonkova sees the charmer as an influential figure, who communicates with the supernatural, influences the reality and is powerful enough to avert danger and death.

Valentina Kharitonova (Russian (Neo)Shamanism in the Last Quarter of the 20th Century: Religion, Creativity and Healing) pointed out the transformations connected to (neo)shamanism, against a background of common changes in religious, cultural and medical spheres in the Russian Federation. V. Kharitonova was looking at (neo) shamanism in the context of religious issues, folk healing in biomedicine, public health, alternative and complementary medicine, as well as state and alternative education, and scientific institutionalizations. She also analysed the personalities of (neo)shamans in comparison with epic and lyroepic singers. V. Kharitonova demonstrated with colourful examples how (neo)shamans create their identity and credentials. The presented materials were collected from different regions in Siberia as well as from Moscow.

Tatjana Bulgakova (Shamanistic Healing from the Position of Transpersonal Anthropology) demonstrated that viewing the shamanistic cure through the lens of transpersonal paradigm gives a chance to view it as a whole psychological experience in the context of traditional magic and mysticism. Through transpersonal approach the shaman and also all kinds of diseases can be seen as experiences of contacts with the layers of psyche that are inaccessible in daily life. Such an approach contrasts to the nature of diseases as seen from the emic position. In view of the shamanic tradition carriers, the reasons or cure for shamanic diseases are not related to human contact but to the creatures (energies) remaining outside the human that can influence the psyche but exist regardless of the human.

Mare Kõiva (Constructive Alternativism and the Healers) demonstrated, based on archival materials and Internet sources on folk healers, how different contemporary healers build up self-presentation, using different interpretations in the context of the surrounding environment and culture. Different healers design their own supporting rituals and social interaction to balance the personality and to solve the health problems within the altered space and place, or within differentiated physical environment and altered mentality. Mare Kõiva demonstrated the rituals and practices developed and used by healers and also discussed the role of healers in the discourse of printed 
medical books. The examples included known and popular Estonian healers Aleksander Heintalu, Luule Viilma, Gunnar Aarma, and also Irje Karjus, who has combined folk knowledge with modern village tourism.

Mihály Hoppál (Experiences with Shamanistic Healers) described different shamanistic healers and their practices within the framework of curative procedures and belief systems. The well-known researcher of shamanism and the president of the Society for Studies in the Field of Shamanism as well as the editor-in-chief of the journal Shaman paid attention to how shamans study popular religion and medicine, and participate in the discourse of the published books. He also spoke about his personal experiences with shamans.

Piret Paal discussed in her poster report (About Keila Nursing Hospital, Caring and Palliative Welfare Services) the importance of palliative medicine and care in the future medicine. She declared that in view of the cultural pluralism of the globalising world also ethnologists, folklorists and medical anthropologists will have an important role to play in the interests of patients and their families. She also suggested that, arising from the dynamics conditioned by the small size of Estonia, a well-organised network of palliative services could even be one of the so-called Estonian Nokias, which means that high quality care services are offered to the citizens and their family members.

Ave Tupits

\section{INTERNATIONAL CONFERENCE ON CHARMS, CHARMERS AND CHARMING}

On October 27-29, 2011, the Marc Bloch Russian-French Centre for Historical Anthropology at the Russian State University for the Humanities in cooperation with the International Society for Folk Narrative Research (ISFNR) and the Russian Academy of Sciences organised a conference on oral charms.

The conference aimed at focussing on one folklore genre, whereby embracing the maximum range of topics: problems, geographical and historical background. The investigation of oral magic has remained on the borderline of several scientific spheres folkloristics, linguistics, history of literature, ethnology and psychology. The conference discussed the following issues: geography and history of the charms tradition, distribution of various charm types; possibilities for systematising and labelling the databases of national charms corpora; charms and mixed forms (Christian prayers and prayer-like charms, apocryphal prayers, curses, etc.); charms in oral and written tradition; magical inscriptions on various objects; medieval charms in archaeological records; social functioning of the charm tradition; charms and their performers; the role of the church and clerics in the spread of charms, their difference in catholic, protestant, orthodox and non-Christian religions; psycho-social sources of suggestion. The participants of the conference discussed how charms worked, why they were relevant, how 'charming with 
words' was practised in contemporary society, and also spoke about video recordings of charming acts and their meaning in charm studies.

The ISFNR Committee on Charms, Charmers and Charming focuses its work on the coordination of charm and incantation studies in different countries, elaboration of methods for their structural and typological description, and compilation of international and local charms indexes, scientific publications and electronic databases. Jonathan Roper (Great Britain/Estonia) has been Chair of the Committee from the very beginning (2007), and the members are Daiva Vaitkevičiene (Lithuania), Mare Kõiva (Estonia), Éva Pócs (Hungary), Emanuela Timotin (Romania) and Andrei Toporkov (Russia). The committee also convened during the conference and decided to admit a new member Haralampos Passalis (Greece).

The committee organises conferences regularly (at least once in two years) and prepares the proceedings for publication. Until today, conferences have taken place in Pecs (2007), Tartu (2008), Athens (2009), Bucharest (2010) and Moscow (2011). Already before the committee had been officially formed (2007), two conferences on the same topics took place in London (2003 and 2005).

On the basis of the previous conferences the following collections have been published: Charms and Charming in Europe (2004, editors Jonathan Roper and Palgrave Macmillan), and Charms, Charmers and Charming: International Research on Verbal Magic (2009, same editors).

The members of the committee prepared for publication a book of English verbal charms ${ }^{1}$, as well as scientific publications on Lithuanian ${ }^{2}$, Romanian $^{3}$ and Russian ${ }^{4}$ charms. The homepage of the committee introduces its activities and provides information about the new publications on magic folklore in different countries (http://www. isfnr.org/index2.html). It also introduces annotated literature about English, Bulgarian, Brazilian, Hungarian, Gagauz, Greece, Irish, Spanish, Latvian, Lithuanian, Mari, Norwegian, Portuguese, Romanian, Russian, Serbian, Slovenian, Ukrainian, French, Swiss and Scottish traditions. The conference presented the first issue of the electronic magazine Incantatio (http://www.folklore.ee/incantatio/01.html).

Before the conference, a collection of papers in English entitled 'Oral Charms in Structural and Comparative Light. Proceedings of the Conference of the International Society for Folk Narrative Research's (ISFNR) Committee on Charms, Charmers and Charming. 27-29th October 2011, Moscow' was published. The editors were Tatyana Mikhailova, Jonathan Roper, Andrei Toporkov and Dmitry Nikolayev. The collection is accessible on the committee's homepage (http://verbalcharms.ru/books.html). However, it has to be mentioned that the content of the collection differs to a certain extent from that of the conference. On the one hand, seven authors (Svetlana Tsonkova, Ekaterina Velmezova, Tatyana Agapkina, Varvara Dobrovolskaya, Ritwa Herjulfsdotter, Katarina Lozić Knezović and Gordana Galić Kakkonen), who had submitted their articles for the collection, were not able to participate; on the other, seven researchers who had not sent their materials (Oksana Tshoha, Katerina Dõsa, Éva Pócs, Maria Kaspina, Elena Minenok, Mare Kõiva, Anna Ivanova) delivered papers at the conference. Anna Ivanova's and Elena Minenok's papers can be read on the homepage http://verbalcharms. ru/books.html. On the same page also Tatyana Agapkina's, Ekaterina Velmezova's, Tatyana Mikhailova's, Andrei Moroz's, Elina Rakhimova's, Andrei Toporkov's and Ludmila Fadeyeva's texts in Russian can be found. 
During three days the participants of the conference listened to 31 papers; 15 authors came from Russia and 17 from abroad (Belgium, Great Britain, Hungary, Greece, Latvia, Holland, Romania, Northern Ireland, USA, Ukraine, Finland and Estonia). The issues dealt with were related to the verbal magic of different traditions throughout history. Although most of the papers were based on European material, the speakers also discussed Syrian charms in the Middle East context (A. Lyavdansky), incantations in the Dead Sea manuscripts (I. Frölich) and Hittite charms (A. Sideltsev). The conference also dwelled upon the relation between charms and prayers, their visualisation in iconographic materials, the individual repertoire of several specialists in magic, the possibilities for synchronising local charms databases and the creation of electronic ones, and so on. Many of the presentations were enlivened by unique video materials (A. Ivanov, V. Klyaus, A. Liebārdis).

Alexey Lyavdansky (Moscow, Russia) in his presentation described Syrian charms, their forms and usage, and also investigated the origin of two charm types. A. Lyavdansky found that the formula 'Gabriel on his [protected person's] right and Michael on his left' is a loan from Arabic and/or Jewish source. Another formula 'Mother who strangles children' usually occurs in the texts where a female demon reveals her names to the protective figure. The figure of the female child-killing demon is universal; yet, the majority of the known texts belong to Mediterranean, Middle East and European cultures. According to A. Lyavdansky, the concept of this demon originated in Mesopotamia, and became rooted in Syria through Aramean culture; also it is possible that this loan comes from Byzantine culture, although this is highly improbable.

The paper read by the Hungarian researcher Ida Frölich (Budapest) described the Judaist incantations in Qumran manuscripts. The four psalms attributed to David reflect the characteristics of magical incantations and contain an invocation to the magical power, descriptions of the demonic harm, the disempowering of the demon and expelling it to the nether world.

Tatyana Mikhailova (Moscow, Russia) spoke about charms against thieves in ancient Rome and modern Russia, paying attention to the functions of personal names in charm texts. In addition to this, she contrasted oral and written tradition. Written incantations were mostly used for retrieving the stolen things and punishing the thief, whereas incantations were supposed to avert theft, i.e., they had a preventive function.

Isabelle Valloton (Ghent, Belgium) discussed Russian spells against snakes, comparing them to Egyptian and Mesopotamian ones. She phrased the assumption that some motifs of Russian incantations can belong in old Egyptian and Mesopotamian texts, and, as a result of cultural contacts in the Hellenistic period, they might have reached Greece and from there on to the Slavic peoples.

Haralampos Passalis (Thessaloniki, Greece) tried to contrast narrative charms and myths. The author stated that several parallels can be observed in these texts. Myths provide models for critical situations and also the ways to overcome them. Narrative charms appeal to these mythological precedents. Within the incantation two temporal levels coalesce - the narrative past and the performative present. The charmer adopts the function of a mythological creature to restore the order. Therefore time plays an important role in incantations.

Oksana Tshoha (Moscow, Russia) treated such topics as 'the cow licking a sick calf', 'Christ talking to the Mother of God bewitched by passing angles', etc. 
Ekaterina Dysa (Kiev, Ukraine) maintained in her presentation that in Podolsk and Volynian court materials dating from the 17th-18th centuries charm texts were quite rare, even if the case was about bewitching rituals that would presume their usage, and that the charm texts were incomplete in court minutes. In Hetmanic Ukraine incantations were recorded more often and presumably there existed a special practice for interrogating those accused of witchcraft. These differences in the treatment of incantations can be explained by different cultural and legal systems.

Éva Pócs (Budapest, Hungary) specified the genres of prayers and oral incantations in Hungarian traditional lore, proceeding from the content, form and function of texts. Within the functionally determined incantation genre, part of the texts reflect the features of prayers, whereas others resemble incantations. There is also the third type, which merges the characteristics of both incantations and prayers.

Ludmila Fadeyeva (Moscow, Russia) dedicated her presentation to the theme of joy in charms. She observed that these functional groups originate from book-lore. L. Fadeyeva outlined three basic tendencies in the interaction between the charm tradition and Christian literary sources: 1) formal reproduction of the structures originating in book-lore; 2) independent development of motifs derived from Christian sources; and 3) introduction of non-Christian imagery into plots derived from Christian sources.

Maxim Fomin (Coleraine, Northern Ireland) discussed the motif of an appearing fairy as an omen for perishing in the water. The fishermen who took these omens seriously were supposed to avoid death, whereas the ones who ignored the omens, died.

Lea T. Olsan (Monroe, USA) and Peter Murray Jones (Cambridge, Great Britain) spoke about the motifs and formulas in Latin and English in the 10th-15th centuries. They differentiated between three functional charm groups: for conception, for successful pregnancy and for women in labour. Christian and pagan motifs are closely intertwined in charms. The researchers also described the ritual procedures related to incantations.

Maria Kaspina (Moscow, Russia) contemplated the transformation of charm texts in the old Jewish, Aramean and contemporary Jewish oral tradition. The paper was based on the material collected in Ukraine and Moldavia in 2004-2011.

Toms Kencis (Tartu, Estonia) spoke about Latvian fever charms. He described different types of charms and their geographical distribution and also dwelled upon how the features of fever reflected in beliefs, customs and folktales.

Andrei Toporkov's (Moscow, Russia) paper focussed on the reflection of the subject of 'Archangel Michael defeating fevers' in iconography. When examining the composition, characters and system of symbols in this type of icons, he concluded that oral tradition significantly influenced the adoption of this topic in iconography. Thus, the emergence of this particular image type was rooted in a combination of three factors: 1) the narrative nature of charms, which made them similar to apocryphal narrations; 2) extensive spread of charms in the form of prayers; and 3) matches between the charms' imagery and that of popular beliefs about fevers.

Emanuela Timotin (Bucharest, Romania) elicited three charm types meant to heal fever, which originate in the 17th-19th century Romanian manuscripts. The first type consists in incantations like 'Jesus heals St Peter's mother-in-law from fever'. These charms are characterised by the use of the evangelic formula 'In the beginning there was the word'. The second one is about tying twelve knots on a thread, at the same time 
reading the twelve fragments about the Passion of Christ from the Gospel, and the third one consists in tying three knots on a thread or any piece of fabric.

Irina Sedakova (Moscow, Russia) discussed the methods of relieving pain caused by fear of fright in folk medicine, Andrei Moroz (Moscow, Russia) spoke about herdsmen's otpusks ('release' charms) in ritual and mythological context, and Maria Zavyalova (Moscow, Russia) dwelled upon typical phenomena in spells related to skin sores. Elena Minenok's (Moscow, Russia) paper focussed on spells and charms that became rooted in East Siberia as a result of Stolypin's reforms in 1906-1916 and are still in use in the villages of Irkutsk oblast. Maria Eliferova (Moscow, Russia) spoke about the translation of Russian charms into English and the problems of approach therein.

Henni Ilomäki (Helsinki, Finland) discussed the blood-stopping charm 'Be still, blood, like a wall, like the water in the River Jordan' in East Finland territories. The speaker deduced that the Christian motif has been rooted in Finnish folk medicine through the Swedes and other Christian peoples of Northern Europe, and that it has been influenced by the belief about the magic power of water.

Maarit Viljakainen (Lappeenranta, Finland) concentrated on the charm repertoire of the renowned Finnish folk healer Minna Hauvinen (1837-1914).

Elina Rakhimova (Moscow, Russia) discussed the two branches of epic tradition on the basis of solar imagery, whereas the northern tradition was considered to be more archaic by the author. Rakhimova pointed out the differences in the tradition on the basis of the creation story of the sun, moon and stars, paying special attention to metaphors, paraphrases, alliteration and specific sentence structure.

Jonathan Roper (Tartu, Estonia) compared metrical charms to Anglo-Saxon epic poetry (Beowulf, etc.), as well as to Swedish and Icelandic charms, explaining their common features by genetic connections.

Mare Kõiva (Tartu, Estonia) focussed on the so-called heavenly scripts and books of wisdom where source material for charms has been found; yet, these sources could have been used also as magic objects in several rituals, including healing tradition.

Anca Stere (Bucharest, Romania) in her paper 'Charms as a Vehicle for Political Messages in Communist Romania' claimed that during the communist rule, it was allowed to compile pseudo-folkloristic texts for propaganda purposes. This 'new folklore' was performed on the stage in order to change people's attitudes and create a 'new person'.

Jacqueline Borsje (Amsterdam, Netherlands) introduced, by the example of Irish and Dutch charms, an electronic database and spoke about the transformation of charms from historical reality to the manuscript form, then on to printed text and finally, to electronic text.

Andrey Sideltsev (Moscow, Russia) discussed Hittite charms and their verb aspects: unmarked perfective and imperfective aspects most commonly (but not exclusively) marked by a suffix.

Anna Ivanova (Moscow, Russia) noted that during the last three decades fieldwork folkloristics has become an independent discipline with its own objectives, tasks and methods. The speaker maintained that the main aim of fieldwork is to lose the difference between the internal (practising) and external (collecting, recording) viewpoints in folkloristics. She found that the hypertextual approach is the most suitable here as it enables to view incantations as a continuum divided into certain segments. 
Vladimir Klyaus's (Moscow, Russia) paper focussed on how spell and charm traditions were formed in the region of Chinese cultural contacts and how they were influenced by the colonization of the Argun River region by Cossacks. The first records of frequently used magic spells (concerned with love, healing, cattle-raising and housekeeping) from the Argun region date back to the mid-19th century. Today the charm tradition still persists despite the impoverished repertoire of Argun local healers, who have recently ceased to perform complicated rituals. V. Klyaus assumed that within the last 150 years the spell tradition on the Argun River has undergone the same changes that local customs all over Russia.

Aigars Liebārdis's (Riga, Latvia) paper was based on the materials of a documentary on Latvian Easter traditions, which was filmed in the years 2007, 2009 and 2010. The ritual performed at sunset on Good Friday is supposed to protect domestic fowl from hawks and other raptorial birds.

The roundtable discussion at the end of the conference discussed new charm publications and new perspectives for oral magic. Jonathan Roper introduced the electronic version of the magazine Incantatio, E. Kuznetsova spoke about Tatyana Agapkina's book on East Slav healing spells entitled Vostochnoslavianskie lechebnye zagovory $v$ sravnitel'nom osveshchenii: Siuzhetika i obraz mira (2010) and Andrei Toporkov's book about Russian spells entitled Russkie zagovory iz rukopisnykh istochnikov XVII - pervoi poloviny XIX v. (2010, Russian Manuscript Spells from the 17th to the First Half of the 19th Centuries). Dmitri Antonov introduced the book written jointly with Mikhail Maizuls, entitled Demony i greshniki v drevnerusskoi ikonografii. Semiotika obraza (2010, Demons and Sinners in Old Russian Iconography. Semiotics of Images).

Ekaterina Kuznetsova, Andrei Toporkov

\section{Notes}

1 Roper, Jonathan. English Verbal Charms (FFC, N 288). Helsinki, 2005, 242 pp.

2 Vaitkevičienè, Daiva (comp., ed.) Lietuviu užkalbèjimai: gydymo formulès / Lithuanian verbal healing charms. Sudaré, parengè ir ịvada parašè. Vilnius, 2008, 919 pp.

3 Timotin, Emanuela. Descântecele manuscrise româneşti (secolele al XVII-lea - al XIX-lea): Ediţie critică, studii lingvistice şi filologice. Bucureşti, 2010, 388 pp.

4 Toporkov, Andrei (comp., ed.). Russkie zagovory iz rukopisnykh istochnikov XVII - pervoi poloviny $X I X v$. Moscow: Indrik, $832 \mathrm{pp}$. 


\section{RITUALS AND CUSTOMS AS CULTURAL HERITAGE THROUGH THE EYES OF RESEARCHERS AND PERFORMERS ${ }^{1}$}

On November 11-13, 2011, the Seventh Annual Conference of the International Society for Ethnology and Folklore Working Group (SIEF WG) "The Ritual Year" under the general title Researchers and Performers Co-Designing Heritage took place in Ljubljana, Slovenia. The conference was organised by the Slovene ethnologist Jurij Fikfak (the head of the Organising Committee) and Laurent Sébastien Fournier (France), and hosted by the Institute of Ethnology of the Slovenian Academy of Sciences and Arts. The SIEF conference was preceded by another conference dedicated to the 60th anniversary of the Institute of Ethnology, which was established on October 3, 1951. In this institute several outstanding scholars such as M. Matichetov and N. Kuret worked, and their ideas and publications serve as classical examples in the field of Slovenian ethnological studies. The institute is famous for its periodicals Traditiones, Studia mythologica Slavica, Slovstvena folkloristika, and series Gradivo za narodopisje Slovencev, Opera ethnologica Slavica, Ethnologica dissertationes, and Glasovi ${ }^{3}$.

As the annotation announces, the Seventh Conference of the SIEF WG "The Ritual Year" should have been focused on the triad of performances, performers and researchers, and aimed at shedding light on their interrelations and mutual influences. Nowadays the researchers of the tradition are not the only ones who collect and explore folk culture. Ethnological studies develop the form of mutual assistance. Thus the performers (musicians, folk "actors", craftsmen, etc.) also study rituals and customs, the verbal, gesture and musical parts of the ritual year; even more - they read academic folklore and ethnological publications, and seek contacts with researchers and archival and museum workers. Collaboration helps considerably in exploring, performing and preserving the authentic traditional non-material and material (in terms of traditional crafts and ritual objects) heritage.

During the five sessions 30 papers were presented by scholars coming from Austria, Bulgaria, Slovenia, Scotland, Hungary, Estonia, France, Latvia, Lithuania, Greece, Russia, Sweden, Ukraine, Holland, Norway, Iceland, Czech Republic and the USA. Apart from the major topic, some other folklore and ethnology subjects were discussed, the range and the methodology of which varies. Theoretical presentations or those with dominating empirical data were mostly focused on the triad and certainly dealt with the national heritage. The scholars exchanged their routine in the field research and the ideas on how this experience can be used in the process of revival, re-thinking and re-inventing of the folk national traditional life.

The participants characterised the contemporary situation in this field in their countries with the overview of their previous experience and contacts with the informants in the field and on the stage as well. In the three lectures opening the conference J. Fikfak "Towards Researching Triad Performer, Performance, Researcher", L. S. Fournier "Festive Revivals and Playful Performances as Cultural Heritage in Europe" and the president of the group "The Ritual Year" Emily Lyle (Scotland) "Seasonal Festivals as Props in an "as if" Ritual World" put the major questions, which were then alluded to in other papers. They discussed the language which the performers and the scholars speak when communicating, the quantity and the quality of the folk knowledge that 
both "groups" possess, the interrelation between "as if" and "as is" world, etc. J. Fikfak raised the question as to what extent the scholars and the performers understand each other while discussing different versions of a ritual and its parts and afterwards while performing it. Working with the bearer of authentic knowledge, as Fikfak puts it, is the most significant experience for an ethnologist, a special type of participating in the folk life, which urges the scholar to be flexible and to be able to transform from the role of a bystander to that of a participant.

L. S. Fournier discussed the mechanisms that have been used in the reconstruction of folk cultural heritage in the sphere of the calendar ritual year since mid-1950s. Comparing the field data from a festival in Provence and in Scotland, the scholar showed the universal features that are evident in spite of the differences in the two traditions. The innovations are due to the commercialisation policy in tourism and marketing in the loci. The very notion of the cultural heritage causes problems for the performers who are trying to find the archaic authentic forms of the rituals that are very difficult to understand nowadays. Such rituals are more interesting and valuable for the professionals who are in charge of collecting and popularising them.

E. Lyle drew a parallel between the ritual world seen by the scholars as imagined in the world of children's games, where everything seems to be "as if", and also with the ritual world in the mind of their performers, who accept it "as it is". Kendall Lewis Walton, an American philosopher and the author of the theory of imaginary and makebelieve for art studies ${ }^{4}$ inspired E. Lyle to see the categories of time and space as the "props" for rituals.

Terry Gunnell (Iceland) in his paper "Types of Performance in Shetland Tradition" reviewed briefly several types of guising traditions at Halloween and New Year. The scholar illustrated and interpreted the shift from the local ritual values of the open door and hospitality towards the outside world (tourists, visitors and researchers), which urges implications of the international context.

Accent on the spectacularity of the rituals and the moment potentially interesting for the tourists is supported by the organizations that financially support the performers. This fact was discussed in several papers. John Helsloot (Holland) in his talk "Framing Heritage in the Context of Municipal Subvention. The Case of the Annual St. Nicholas Parade in the Netherlands" added another problem to be taken into account when speaking about the preservation of the authentic tradition - the political correctness. He discussed also the dichotomy of culture and economy and how it works on the level of municipal authorities.

The problems of the carnivals, guising and masking were the main topic of Arunas Vaicekauskas, who in his paper "The Carnival Structure, History and their Symbolic Interpretation: Ivrea Case (Italy)" followed the history of revitalization of the old Italian processions, which have been extremely popular among tourists after the 1970s. The classical structure of the carnival was adjusted to the needs of the modern consumerist society; this way the visitors turned into participants and performers, and the visual appeal became one of the major goals of the celebration. The invention of traditions, often with examples from the local history, is one of the important mechanisms for organising and structuring the procession.

The interaction between the local history and collective memory, folk religiousity and calendar were also investigated in other papers. Evy Johanne Håland (Norway-Greece) 
in her presentation "A Festival Dedicated to the Anniversary of Vision of Agia (Saint) Pelagia" described a unique Greek practice of the veneration of St Pelagia known on the island of Tinos. St Pelagia was a nun who in her dream saw the place of the divine icon of the Mother of God. This find dated 1821-1823 is connected with the fight of the Greeks for independence. Thus the icon turned into the symbol of New Greece after the fall of the Ottoman Empire. The celebration date of this icon is an important holiday in the ritual calendar of the Greeks on Tinos. Greek traditional performances were discussed in the talk "Transformation of the Modern Greek Calendar Customs Associated with Fire: Tradition and Contemporaneity" given by Svetlana Sidneva (Russia). She concentrated on the rituals with fire, such as walking on fire known in Northern Greece on the Sts Elena and Constantine Day, the burning of Judas and carnival fires dzamala (aimed at driving away evil spirits) in Ioannina. These archaic rituals generate new ones, demonstrating a mixture of different cultural traditions with antique and Christian roots. A scholar of the rituals can discover a reflection of new political events: instead of burning the figure of Judas in 2011, the figure of Angela Merkel was destroyed.

Tom McKean (Scotland) delivered a lecture "Stewardship and Evolving Fidelity in a Scottish Fire Festival", which shed light on the maintenance and change in the ritual of "burning the Clavie", emphasising the special role of the main practitioner of the crew. The King of the Clavie is in charge of innovations or preserving the traditional scheme. The pressure of the local authorities to change the date from the "Old New Year" (January 11) to December 31 to meet the touristy needs did not work because of the will of "the King" to keep the ritual authentic.

Several speakers maintained in their papers that the direction of the interaction between the scholar and the performer in the sphere of arts could be changed: the investigator plays the role of the bearer of the traditional knowledge. Nancy McEntire (USA) "Participant-Observation in Ireland's Pubs" and David Stanley (USA) "Structure and Etiquette in the Irish Traditional Music Session" analysed their fieldwork in Irish pubs with local musicians performing folk. The American scholars argued that the tradition is alive and is being passed on from one generation of musicians to another, mostly from the mother to the daughter and from the father to the son. The researchers-musicologists help a lot in these processes, since they possess archives, publish them on sites and keep collecting tunes from various Irish regions. There are some modern modifications in performance, such as a solo turning into a group singing, some new instruments being introduced, etc. The role of the head of the group is also very important - he is in charge of the repertoire, preserving the authentic tunes and communicating with professional musicologists.

Skaidre Urboniene (Lithuania) in her talk "Researcher - Performer Relations in Cross Crafting Rituals in Lithuania" explored two scenarios, within which a craftsman carves an individual (author's) cross or makes a copy of an old sample. In both cases he would seek assistance from a professional ethnologist. If he cannot find any help, the craftsman turns into a researcher himself, going into the field and looking for traditional samples.

The role of the scholars in preserving the authentic guising traditions and making the masks was shown in the paper read by Aida Rancane (Latvia) "Revival of Some Local Masking Traditions in Latvia as the Result of Cooperation between Maskers and Researchers". Ethnologists had to work hard to retrieve into folk processions the tra- 
ditional masks, which at the beginning of the revival of the interest towards masking were mostly ignored.

Aado Lintrop (Estonia) in his intervention "The Great White Leader Visits the Northern Shaman" compared his first experience as part of the "Winds of the Milky Way" film team, which in 1977 conducted several expeditions into Northern Europe and Siberia, with another fieldwork 34 years after. The scholar argued that the filming of a ritual person, especially a shaman, requires from an explorer as an outer person good knowledge of the traditional worldview, customs, etiquette and folklore. An opposite direction of the categories "inner - outer" was depicted in her talk "The "Moral Codex" of the Researcher - Bearer of the Tradition" by Tatiana Minniyakhmetova (RussiaAustria). Being an Udmurt herself and investigating the Udmurtian folk culture made her confront several restrictions. The researcher listed a number of rules that a bearer of tradition as a scholar has to follow when communicating with performers.

Leon van Gulik (Holland) read a paper "Stage-Setting, Performing, and Pretending in the Cosmic Imaginarium. Ritual Space as a Playground for Researchers, Worshippers and their Aspirations", in which he interpreted the performance of rituals and the correlation between real and imaginary worlds, partly using the theory of the psychoanalyst D.W. Winnicot ${ }^{6}$. This paper alluded to the ideas of Emily Lyle, but was based on somewhat different data. The scholar argued that a neo-pagan ritual should be seen as an act of creativity, which, supported by faith and religious views make the real and the imaginary worlds cohere. The neo-pagan rituals as seen by performers and scholars formed the core of Kamila Velkoborska's (Czech Republic) paper "Performers and Researchers in Neo-Pagan Settings". She shared her field material collected during the sessions and rituals of the Czech neo-pagans. The attitudes towards the rituals are different for a practitioner and a scholar. Only trust and faith make the investigator to completely understand the essence of the magic performed by the believers.

A very different topic was investigated and shared by Marlene Hugoson (Sweden) in her talk "You are Cordially Invited to... The Distanced Participation of the 21st Century". The author analysed a totally new type of celebration, made possible due to new technologies. On June 19, 2010, Swedish Crown Princess married Mr Daniel Westling and the wedding ceremony took place not only in Stockholm, but also in the groom's home village Okelbo, where some 7000 people assembled to celebrate together. Thus this event introduced a new way of attracting tourists and creating local history.

Brand new and already very popular Hungarian cultural festivals (National Assembly and Kurultaj) were investigated by Istvan Povedak (Hungary) in the paper "Reinvented-Invented-Copied-Transnational-Cultural" Festivals in Contemporary Hungary". The title of the talk lists many of the mechanisms used to create and organise these national-patriotic festivals, and the author analysed them in detail, while adding such internal characteristics as anti-globalist, anti-communist and close-to-nature ideology. An unexpected turn in the discussed topics was suggested by Irina Sedakova (Russia). In her presentation "The Russian Ritual Year and Folklore through Tourist Advertising" she used the database of several hundreds of touristy spam letters and thus followed the main developments of the calendar celebrations on the changing tourism map of modern Russia.

Reforms in the pre-Christian Icelandic winter traditions, turning them into Christian calendar rites and combining with the St Michael ritual complex were the subject 
of Karen Bek-Pedersen's (Scotland) talk "St Michael and the Winter Nights". Arne Bugge Amundsen (Norway) read a paper "Ritual Reform and Ritual Behaviour", in which the influence of the Lutheran reforms on funeral rites was scrutinized.

Two lectures were given on the ritual year in the educational system. Mare Kõiva and Andres Kuperjanov (Estonia) in their lecture "Back in the First Class! Rituals Connected with Finishing High School" showed some archaic models in modern school celebrations, such as games with water, masking, etc. Jonathan Roper (Estonia-Great Britain) in his talk "The Ritual Year of the University of Tartu" interpreted a very complicated scheme of the customs at the university, which reflects some cults and superstitions, professional interests and academic history.

In the papers of Slovenian ethnologists Mateja Habinc ("Folklorisation of the Carnival vs. Diminishing of St Roch's Day - a Case Study of Socialist Cultural Management") and Marija Klobčar ("Ritualism as a Reflection of Social Transformation and the Researcher's (Lack of) Power”) the influence of the socio-cultural, political and ideological issues onto the local ritual year, processions, masks and folk costumes in the Slovenian villages and small cities was investigated.

Other theoretical and practical issues of correlations between a performer and a researcher as designated in the titles of the papers were discussed by Kinga Gaspar (Hungary) "Self-Reflexivity and "Casting" in Cultural Performances", Mojca Kovačič (Slovenia) "They Told Us That It Was the Right Thing! - Folk Music Performers' Views on Cultural Policy", Oksana Mikitenko (Ukraine) "On the Problem of Performance: Serbian Mourners", and Katya Mihaylova (Bulgaria) "The Wandering Blind SingerBeggar and the Slavic Ritual Year".

As follows from the review of the papers, the triad in the course of the conference lost its three-part configuration, since it gained several other parameters and components, which have to be taken into account while analysing the folk cultural heritage. The activity of various organizations, first of all UNESCO, governmental and local authorities, commercial and touristy needs, and the problems of transmission of the knowledge and education - were touched upon in many papers. As the presenters showed, for the former socialist countries the specific question of drastic changes in the attitudes towards religion plays a significant role, and for all the countries the problems of globalisation, migration and multiculturalism are important. The scholars shared their experience of communicating with the performers in their own countries and depicted the new possibilities introduced by the new technologies.

During the general meetings of the members of the SIEF WG "The Ritual Year" several questions arose. Volume 4 of the series The Ritual Year and Gender (editor Jennifer Butler) ${ }^{7}$ in coordination with the "Cosmos" was presented. The edition contains 23 articles with the Editorial by Jennifer Butler and an article by Emily Lyle "A Farewell and a Welcome", who is taking farewell of being the editor of "Cosmos" and welcoming Mirjam Mencej, its new editor. The articles are follow-ups after the 4th conference of the group in Cork (2007).

Further plans of publications were discussed, and we are happy to announce that the plan has been fulfilled: volume 6 "The Inner and the Outer" has been published in Tartu (editor Mare Kõiva) with 22 academic articles and excellent design with colour illustrations ${ }^{8}$. Volume 7 of the series will be published in Slovenia under the editorship of Jurij Fikfak and Laurent S. Fournier. 
The participants of the conference had the opportunity to go on an excursion and visit some places of archaeological, religious and ethnographic interest. The group enjoyed the so-called martinovanje - the celebration of St Martin's Day with a dinner in a vineyard cottage, listening to Slovenian folk songs and performing their own national songs in response.

The eighth conference of the SIEF WG "The Ritual Year" will be held in Plovdiv, Sofia, on June 26-29. The ninth conference will take place in Szeged (Hungary) and the tenth one in Innsbruck (Austria).

\section{Irina Sedakova, Secretary of The Ritual Year SIEF Working Group, leading research fellow, Institute for Slavic Studies, \\ Russian Academy of Sciences}

Svetlana Sidneva, Docent of the Lomonosov Moscow State University

\section{Notes}

1 The Russian version of the review will be published in the journal "Antropologichesky Forum", Saint Petersburg, September, 2012.

2 On the Sixth Conference of The Ritual Year WG see: Irina Sedakova. The Inner and the Outer in the Ritual Year: Traditions and Today. Folklore, Vol. 46, Tartu.

${ }^{3}$ Information on this Institute see at: http://isn.zrc-sazu.si/.

4 Walton, Kendall Lewis. Mimesis as Make-Believe: on the Foundations of Representational Arts. Harvard University Press, 1990.

${ }_{5}$ More on this see: http://www.hogmanay.net/events/scotland/burghead.

6 Winnicot, Donald Woods. Playing and Reality. London: Tavistock, 1971.

7 Butler, Jennifer (ed.). Gender. The Ritual Year 4 \& Cosmos. Edinburgh, 2011.

8 Kõiva, Mare (ed.). The Inner and the Outer. The Ritual Year 6. Tartu, 2011.

\section{ESTONIAN FOLKLORISTS' 7TH WINTER CONFERENCE}

On February 2-3, 2012, the 7th folklorists' winter conference was held on Rogosi manor, Võru County, South Estonia. The conference was dedicated to the 75th jubilee of our colleague Mall Hiiemäe, who still pursues her research on the topics of traditional place knowledge, perceptions, attitudes and narratives.

Presentations inspired by nature and place folklore continued throughout two long working days. The place lore working group of the Estonian Folklore Archives - the organiser of the 2012 winter conference - involved the audience in the discussion about the meanings of tradition in the dialogue between Man and landscape.

One of the aspects that several papers were focused on was place names and their accompanying narratives. In her paper 'Landscape Elements in Place Name Creation' 


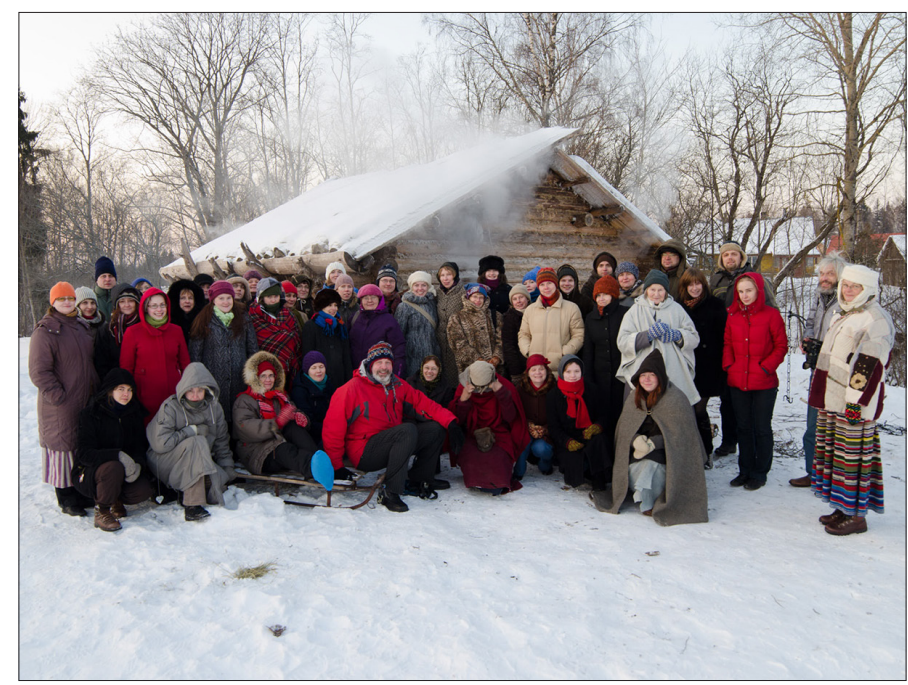

Participants of the 7th folklorists' winter conference. Photo by Aado Lintrop 2012.

Mall Hiiemäe herself discussed small local events, which were given the form of short stories and fixed in the users' memories with (micro)toponyms. According to her, this simple generation mechanism proceeds from everyday needs and mediates information about landscape signs, which become symbolic in the course of customary actions. Reet Hiiemäe provided a retrospective study of classical plague legends ('Päinurme, Pätsavere, Suureluige and Lustivere. Place Specifications in Plague Tradition'). The speaker drew an interesting conclusion that the positioning of the itinerary of the mythological disease spirit makes the "movement" of the illness somewhat more predictable and therefore subject to certain control. Urmas Kalla and Mariko Faster from the Võru Institute participated with their presentations in the field of place names. Urmas Kalla's paper dealt with the toponyms and related narratives from Võnnu parish. On the example of the Suursoo region of the River Emajõgi, the speaker presented the possible relations between places, narratives and place names at a certain moment, summarising it as a paradox: in a certain sense, the "lost" places still exist due to the name system, which helps us remember them. Mariko Faster, whose paper was entitled 'Woman in South Estonian Place Names', claimed that although the database of Võrumaa place names contains only $2 \%$ of toponyms referring to the female sex, it includes interesting layers such as the names of female saints, references to sacrificial springs and eloquent connections, for example in the case of the morrsja(bride)-particle in place names. Naming and names were also in the focus of cultural geographer Taavi Pae's paper. He has discovered about thirty cases of unofficial, tourism-related or fictional place names, such as Eestimaa Šeits (Estonian Switzerland), Setumaa Sahara (the Sahara of Setumaa County), Emajõe Ateena (Athens on the River Emajõgi), Eesti Donbass (Estonian Donbas), which have been formed on the basis of more widely known geographical locations.

The papers delivered by Mare Kõiva, Mare Kalda and Mari Sarv explored the relations of place lore and how it functioned in a certain region. Mare Kõiva ('Castle of 
Paalalinn with and without a Map') and Mari Sarv ('Who Planted this Oak-Tree?') represented the auto-ethnographic perspective at the conference, analysing the places and narratives with which they have personal emotional relations. M. Kõiva discussed on the basis of Põltsamaa narratives how stories about immuring, treasures in the castle basement, underground tunnels and torture chambers reflect in people's undertakings, and positioned the corresponding database on the imaginary line of tradition. M. Sarv concentrated her attention on home lore in Kullamaa commune, speaking about how the narratives of generations continue in certain cases, depending on the influence of the surroundings. Mare Kalda in her paper 'From an Article to a Research. Invisible Place Narratives in East-Viru County' introduced on the basis of selected examples the development features of place lore in East-Viru County. The places and place narratives here have been influenced by two opposites - change (mines and other industrial areas) and permanence (primeval forests and mires) - more clearly than in other regions.

Triin Kusmin from the State Forest Management Centre dwelled upon place lore in a somewhat wider, traditional culture context in connection with an extensive project of mapping and data concentration and the promotion of the objects of traditional culture. Due to the extremely dedicated activity of local investors, a free access database with the descriptions of up to 35,000 landscape objects was completed in the map server of the Estonian Land Board. A month after the conference, Triin Kusmin's activity in the recording of tradition won the folklore prize of the President of Estonia, a national award to recognise the correspondents of the Estonian Folklore Archives.

The paper delivered by Jüri Metssalu, the main organiser of the conference, also focused on place lore, more precisely, the issues related to the holy springs in Juuru parish. The speaker was of the opinion that, although landscapes change, the landscape pattern has generally remained the same; Juuru springs have provided villages with drinking water already from time immemorial. Research has revealed some regularities in the location of holy places: they are usually situated on the borderline of the cultivated land and wilderness (with the exception of holy groves in bogs).

Ergo-Hart Västrik's and Aado Lintrop's research topics proceeded from religious practices. E.-H. Västrik ('Stones and Stone Heaps in Votic Religion') presented data about the Votes' respective attitude towards trees and stones and characterised the corresponding rituals and their descriptions in their historical context (performances at sacrificial stones on church holidays and in Ukkola forest during village festivities). A. Lintrop ('Finno-Ugric Sacred Places') defined a sacred place as an intentionally organised distinct space as opposed to the differently valued surroundings. Withdrawing in circles from the hearth as the centre of the universe, the listeners participated in an imaginary journey in order to understand the traditional space structure of the Udmurt, but also the Mansi and Khanty peoples. Both human beigns and supernatural creatures had their own spheres of influence, and people knew how to ward off alien border crossings. The common sacred places of the whole village were usually situated in the transition area between the village and its farther surroundings.

Semiotician Eva Väljaots used more general categories of perception in her paper entitled 'Perception of Natural Environment by the Example of the Forest and the Sea'. Place narratives enable us to study perceptive experience, as they include both the experience related to staying in a place and its interpretation. E. Väljaots also used the concepts of the border and space structure: in the case of the sea she emphasised the 
meaningfulness of the horizon and the waterline, in the case of the forest - the vertical openings, but also the existence of the depth and the edge. In both environments supernatural creatures and phenomena are a part of our perceptive experience.

Risto Järv's and Sille Kapper's papers dealt with teaching practices and looked for solutions to the problems of terminology creation and continuity in respective fields. S. Kapper ('Conceptualisation and Location-Coherence of Traditional Dance') clearly differentiated between the traditional dance and standardised stage style. She raised an interesting issue concerned with the relations of the traditional dance with the places where these dances are popular. R. Järv in his paper 'Weighing Legends and Lore' voiced a serious concern of the investigators of folk narratives about which term should be used when talking about folk legends. The artificial term muistend has not been adopted into everyday use. However, as was emphasised in the comments from the audience, the conformity of terminology to common usage should not be an aim in itself, as the etic (researcher) and emic (lore group) concept systems are different.

Applied linguist Pille Arnek demonstrated examples of marking methods in a distinct context of language use. Her paper 'Estonian Inscriptions on the Gravestones of 19th-Century North Estonia' explained that usually the person's name, age and date of death were inscribed on the gravestone; later on age was replaced by date of birth and some other abbreviational forms were added. Kadri Tüür with her topic 'Fish Folklore and Lake Lore in Estonian Nature Writing' added analytical diversity to the event. The researcher shared with the audience her observations about folklore narratives in nature writings, which either enliven the descriptions based on scientific facts or help to balance the poetic style. Herbal knowledge and use of herbs in folk medicine was in the centre of attention in Renata Sõukand and Raivo Kalle's research. Ülle Sillasoo was inspired by the depiction of plants and animals in the scenes of the sufferings of Christ, and she concluded that plants and animals in paintings emphasised Christ's blood, death and ascension as well as the fight between Good and Evil.

The first conference day concluded with the presentation of two recent publications: Mari-Ann Remmel's "Päritud paigad. Kohajutte ja legende Rae vallast" ('Inherited Places. Place Narratives and Legends from Rae Commune'), and Anu Korb and Andreas Kalkun's "Siberi setode laulud" ('Songs of Siberian Setos'), which offers a possibility to listen and sing along. The working group of the Estonian Folklore Archives introduced their sphere of work through a slide programme. On their way home the participants of the conference witnessed an unprecedented experiment: despite the temperatures of $-30^{\circ} \mathrm{C}$, some young archaeologists were trying out the olden way of life in a Viking Age house at Rõuge (for more on the experiment, see: http://www.muinasmaja.edicypages.com/blog).

The 7th folklorists' winter conference was a successful and worthy event, and the participants expressed their gratitude towards the organisers Jüri Metssalu, MariAnn Remmel, Kaisa Kulasalu, Pille Vahtmäe and Valdo Valper, as well as the team of assistants (Maarja Aigro, Risto Järv, Annika Kupits, Pille Niin). The conference was supported by AS Hallik from Tamsalu and the Cultural Endowment of Estonia.

The abstracts (printed version financed by Jaan Metssalu) are available at http:// www.folklore.ee/era/tk2012/TK12teesid.pdf.

Mare Kalda 


\section{THESIS DEFENCE: ANDREAS KALKUN}

\section{SETO SINGING CULTURE IN THE STUDIES OF ESTONIAN FOLKLORE: A SUPPLEMENT TO THE HISTORY OF REPRESENTATION}

On 30 August 2011, Andreas Kalkun defended his $\mathrm{PhD}$ thesis Seto singing culture in the studies of Estonian folklore: A supplement to the history of representation at the University of Tartu.

It was a great pleasure to have the opportunity to read and think about Andreas Kalkun's stimulating examination of the history of representations of Seto song in Estonian folkloristics. Kalkun's

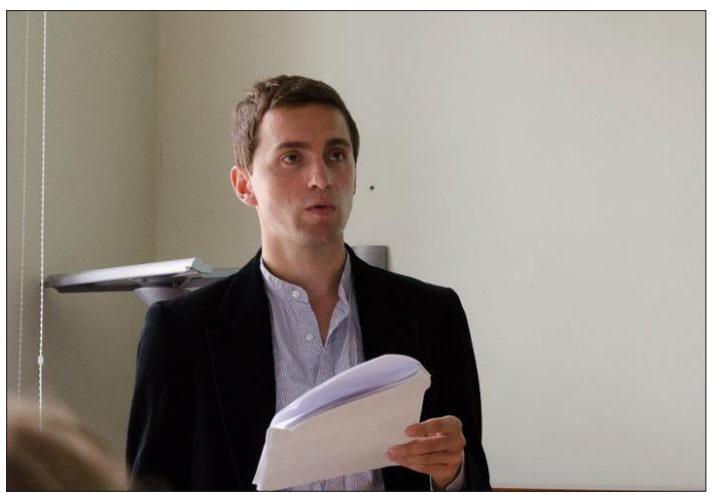
thought-provoking and nuanced study presents an overall theoretical history of folkloristic approaches to Seto song, particularly with respect to the important genre of improvisational songs. Focusing on three moments within the long and storied history of representations of Seto culture and music in Estonian folkloristics, Mr. Kalkun makes real and valuable contributions to the history of the discipline in Estonia. Kalkun's written text is clearly the tip of an iceberg regarding his knowledge of the topic, and I would have truly enjoyed hearing more about some of the topics that I touch on as questions below.

I hope that in time, Mr. Kalkun will produce a version of this fine study intended for a more international readership. And in that expectation, I have geared my comments below as suggestions for what might make the next version of this study (i.e., perhaps a monograph planned in coming years) optimally useful and comprehensible for a foreign audience. Mr. Kalkun's study examines and critiques the field of Estonian folkloristics, as well as the broader intellectual milieu in which the field developed within Estonia. In my comments, instead, I hope to suggest some ways in which Mr. Kalkun's work relates to broader trends in Nordic folkloristics, as well as in the international field of folkloristics in general. I mean my comments to accomplish two tasks: 1 . to create some openings for clarifications or expansions that Mr. Kalkun may want to make in the defense, and 2. to make some suggestions for things to take into account in the eventual international versions of this research that will emerge in coming years. In the US, doctoral dissertation defenses tend to be more collaborative discussions than unidirectional interrogations, so I hope that my comments will stimulate and encourage Mr. Kalkun to share even more of his great learning with the assembled audience.

Chapter 1 of the dissertation presents Seto improvisational songs within the history of the discipline. Mr. Kalkun reviews his own work on Seto autobiographical songs and the issue of improvisation in the study of Estonian (and broader Balto-Finnic) folklore, particularly in the works of Krohn, Hurt, Väisänen, Honko, Timonen, and Kuutma. 
Mr. Kalkun brings in the theories of a number of international scholars, including Eagleton, Ó Giolláin, Clifford, Crapanzano, Ricœur, Foucault, White, Derrida, and Woolf to create a theoretical framework not only for the study of improvisational songs, but also for the dissertation's examination of the history of the discipline, i.e., the two main foci of the study.

One intriguing question that the chapter raises for me is why or how the fairly extensive research on the act of improvisation within folkloristics failed to be applied to Seto songs. In other words, folklorists have certainly looked at improvisation, e.g., in the study of African-American songs and verbal dueling, and in the North European examination of riddles, jokes, Sámi joik, and laments, yet these frameworks were clearly not applied to Seto songs, where improvisation, as Mr. Kalkun notes, came to be regarded as a problem rather than a strength. Part of this failure, perhaps, has to do with the preeminence of the historic-geographic ("Finnish") method in the field of folkloristics in Finland and Estonia during the early twentieth century, and its stress on performers who could be considered "faithful repeaters" rather than "innovators." As Mr. Kalkun's discussion makes clear, such analytical expectations selected for a particular kind of folklore - e.g., genres with seeming stability over time, like ballads and folktales - rather than genres that were/are strongly context-depended and improvisational. However, part of the failure may also stem from the unstable, potentially ironic or even counterhegemonic potential of improvisation within oral tradition: when singers can make up songs about collectors, all sorts of things become possible that are not conceived of in a model of oral tradition as "memories of the past." It seems to me that Mr. Kalkun hints at some of these questions in this chapter, but I should very much like to hear/read more about exactly why or how this central aspect of Seto song tradition became so marginalized. It is a source of truly interesting irony to me as a foreign scholar that much of the early 1970s development of the "performance school" of folkloristics in the United States looked to the Soviet scholar Mark Azadovskij and his 1926 FFC study Eine sibirische Märchenerzählerin, as a model for the call of folklorists to attend to individual variation and the stylistic or personal agendas that may underlie improvisation. Yet this study and its insights on performer variation and improvisation do not seem to have been applied to Seto song within the Soviet Union itself.

The discussion in this chapter of Seto singers' own views of the value of improvisation raises a further possibility of offering a folkloristic framework, which would actually take account of such variation and its meanings within a song culture. Mr. Kalkun's mention of intertextuality in particular suggests to me both John Foley's wonderful concept of immanence in oral epic (e.g., in his book Immanent Art), and Lotte Tarkka's dissertation and subsequent articles on intertextuality in Karelian song genres. In a future version or extension of this study, it might be valuable to look at these theories and what they can tell us about frameworks operating within improvisation as sources of overarching/ underpinning meaning, which help singers produce new works that nonetheless draw on the song tradition for imagery, wording, or overall form. Foley's work adapts the Parry-Lord framework of oral formulaic studies in very useful ways, while Tarkka's work attempts to adapt Kristeva's notions of intertextuality to an oral tradition. I believe Mr. Kalkun's material would provide some very useful perspectives from which to view and possibly improve these frameworks, and it would be interesting to hear his ideas on how an appreciation of Seto understandings of Seto improvisation can improve folkloristic 
understandings of the act of improvisation in general. Here, I believe, Mr. Kalkun has a great deal to offer the field, although most of it is only hinted at in this dissertation.

Chapter 2 examines the textual history of Jakob Hurt's Setukeste laulud (Songs of the Seto people). Mr. Kalkun locates his discussion within the intellectual milieu dominated by the brothers Grimm, and eventually by Kaarle Krohn. Mr. Kalkun's discussion focuses on Hurt's classification of songs in Setukeste laulud and the effects of evolutionary and historic-geographic theories on his perceptions of presentations of Seto song. This part of the dissertation is perhaps the most familiar to scholars from outside of the country. The intellectual framework - evolutionism and the historicgeographic method - are familiar to historians of the discipline, and Hurt fits into a category of "seminal early folklorists" familiar to scholars working on the Grimms, Lönnrot, Krohn, Moe, von Sydow, Olrik, Tang Kristensen, Qvigstad, and others. What I find most interesting about the chapter methodologically is the way in which Kalkun demonstrates the influence of such theories on the very classificatory framework Hurt used to organize his work. In this respect, Kalkun's study echoes on a level that Coppélie Cocq shows regarding J. Qvigstad's presentation of Sámi tales in her Revoicing Sámi Narratives. This chapter offers very solid data and interpretation and will prove useful to the international discussion.

I had several questions as I read the chapter that I would be grateful to know more about. First, in the fascinating discussion of the correspondence between Krohn and Hurt, I was wondering about the influence that this exchange of ideas had on Krohn in his planning for his series FFC. In a recent short article I did for FF Network, I had the opportunity to look at Krohn and his editorship of FFC over time. Clearly, some international scholars got published in FFC and some did not. The transplanted German Walter Anderson does get included with his Kaiser und Abt in 1923, and again in issue No. 141 (1951), perhaps chiefly because he so fully adopted the methods and agenda of Krohn's historical geographic method. (After Anderson, there is a monograph by Loorits (No. 139, 1954), and one by Felix Oinas (in exile; No. 205, 1969), and then more Estonians after the 1980s (Kippar, Hiiemäe, Valk, Kuutma). It would be interesting to know the ways in which Krohn's dealings with Hurt shaped his expectations concerning the value of an international network of folklorists and the feasibility of more-or-less dictating the methodological frameworks of colleagues in different countries. The FFC became a major conduit for the international recognition of specific traditions (and folklorists) and Hurt's role as a model or precursor would be interesting to investigate.

A second question I had in reading the chapter was about the role of Oskar Kallas. Certainly he was involved in the events discussed here, both as Hurt's sometime assistant and as Krohn's brother-in-law, through his marriage to Aino Krohn Kallas. Kallas is discussed somewhat later in the dissertation, in connection with the purchase of Eisen's collection ( $216 \mathrm{ff}$.), but is there more to say about him in the relation of Hurt and Krohn? The discussion of Aukusti Niemi (p. 120) is also valuable, as he was yet another Finn who took an interest in Baltic song and published on the topic (i.e., particularly on Lithuanian dainos (songs) and wedding customs). Personally, I would have welcomed more discussion of Kallas, particularly as he so underscores the political significance of folklore research during this period, as Estonians look to their oral tradition as the basis constructing a self-consciously "national" identity, one which, as Mr. Kalkun shows, involves selectively coopting elements of Seto song tradition. 
The small note (fn 211) on p. 111 on Barons, as well as the occasional discussion of Herder in the text, of course brings up the question of conceptual models coming from the south rather than only from the north. In a broader text aimed at an international audience, this Baltic context would be interesting to examine a little further to explain how or to what extent it was incorporated in Hurt's work or why it was not. It seems to me that Barons offers a very different way of looking at lyric songs than Krohn and that the contrast between these two conceptual models would be really fascinating to bring out further.

Chapter 3 examines A. O. Väisänen's fieldwork among Seto singers and its influence in shaping Estonian approaches to Seto songs. Mr. Kalkun's discussion of Karelianism is excellent, particularly with regard to the questions of how this movement shaped Väisänen's assumptions going into Seto land, and molded the things he looked for and found. What excites me about this chapter is - in addition to what it shows us about Väisänen's influence on Estonian folklore research - how it points to forgotten topics within the history of Finnish folklore research as well. Väisänen, along with many other important scholars of Finnic folk song, has been marginalized or altogether ignored in many histories of the discipline of folkloristics in Finland. I think it is valuable to note that Väisänen's work was shaped by his knowledge of Adolf Neovius's important work on Larin Paraske from 1896: the latter created the idea of an improvising artist in Finnish Karelianist understandings of "the singer", one which influenced Väisänen, as well as later Väinö Salminen and Martti Haavio. Salminen undertook fieldwork among the "Finns" of Värmland (1905), and in Karelia and Ingria in the following decade. Salminen also undertook fieldwork in Estonian Ingria in the early 1930s. This song and singeroriented research - of which Väisänen was an important part - differed markedly from the super-organic model of Krohn, and seems to have influenced Martti Haavio in his Viimeiset runonlaulajat (Last Runo Singers) (1948). Later on Finnish researchers have occasionally returned to the notion of the star performer, almost always in connection with female singers, e.g., Juha Pentikäinen's Marina Takalon uskonto (1971) and Matti Kuusi's Maaria Luukan laulut ja loitsut (1983). But what Väisänen particularly offered was attention to the specifically musicological and interactional aspects of singing. A. O. Väisänen offered a more ethnographic, less logocentric model of folklore research, and he used his representation of an idyllic Setomaa with its lauluemad (mothers of song) as a symbol of what folklorists should be searching out and studying, just as he used his relation with Teppo Repo to suggest the questions that a scholar should ask in the study of instrumental music.

From a comparative, international perspective, two topics occur to me as particularly interesting about this chapter, and I suggest them as topics that Mr. Kalkun may have been thinking of already, or may consider including in future research aimed at an international readership. First, of course, is the notion of selecting a particular local culture as the eventual embodiment of a "national" culture, as in the case of both Karelianism and the Estonian appropriation of Seto culture as exemplary of the Estonian nation. Excellent international comparisons abound, including of course, Göran Rosander's classic article “The 'Nationalization' of Dalecarlia: How a Special Province Became a National Symbol for Sweden" (Arv 1986) and David Whisnant's All That Is Native and Fine about the use of Appalachia as a symbol of "American" folklore in the USA. In their anthology Folk Song: Tradition, Revival, and Re-Creation, Ian Russell and 
David Atkinson include some interesting cases from England, Scotland, and Ireland. And this topic has its share of contemporary research as well, as for instance, Robert Kaiser's article "Homeland Making and the Territorialization of National Identity," in the anthology Ethnonationalism in the Contemporary World, edited by Daniele Conversi (2002). All of this has great significance for the story of Setomaa today in the context of the Estonian-Russian border, and I am certain that Mr. Kalkun would have a lot to say about these complex and interesting questions regarding the symbolic potential of a marginalized community, the politics of representation, and the question of who gets to determine the symbolic "spin" of a culture, something suggested very perceptively in the dissertation's final chapter.

The other comparative topic of interest from an international perspective here is the role of a specifically foreign ethnographer in shaping an internal, national view of a topic. In the history of American culture, of course the French essayist de Toqueville long shaped American understandings of American culture, and in connection with folklore research in particular, the role of the American folklorist Jacob Curtin in shaping Irish understandings of Gaelic lore has been perceptively examined by John Eastlake. I think an Estonian view of Väisänen's role would contribute interesting details to this study of international perspectives and the role of the Other in shaping the viewpoints used within a society to conceptualize itself.

Chapter 4 examines Samuel Sommer's collection of Seto songs and the fate of his archival material, focusing particularly on the roles of Sommer and Loorits in the dispute and the legal struggle that focused on national and personal ownership but that completely ignored Seto ownership of the materials in question. Here, of course, Mr. Kalkun's work holds tremendous interest to scholars of intangible cultural heritage and the process of cultural repatriation, serving as a valuable historical examination of the ways in which in-community interests were overlooked in past folkloristic practice.

In short, I found reading Mr. Kalkun's dissertation an exciting and interesting experience and I have learned a great deal. I look forward to his future contributions to our field, in which his insights into Seto improvisational song, as well as his analysis of the history of the discipline will be of great value. I encourage him to share some of this research with the international readership in some of the ways outlined above and I wish him all success and congratulations in a dissertation well done and deserving of much recognition.

Thomas A. DuBois

Director, Folklore Program University of Wisconsin, Madison, USA 


\title{
BOOK REVIEW
}

\section{PROFOUND INSIGHT INTO THE AMERICAN WORLD OF SPIRITS AND GHOSTS}

\author{
Alan Brown 2011. Ghosts along the Mississipi River. Jackson: \\ University Press of Mississippi, 238 pp.
}

Alan Brown's book brings to the reader a voluminous selection of spirit and ghost stories from America. The author has used the Mississippi River as an imaginary axis to organize his material. After having given a cursory historical overview of the explorers who visited the Mississippi region in the past centuries, of the economic use of the river and the geographical location of the spots described in the book, the author proceeds with his stories. Brown follows the river's course, moving from one state to another,

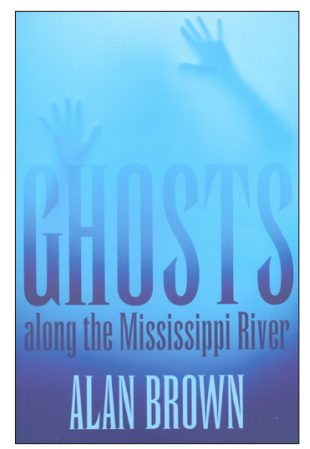
visiting the towns and villages along the riverside, ransacking museums, interviewing the relevant people, and participating in special guided ghost tours, this way collecting stories, historical facts related to them, current and former viewpoints, attitudes and explanatory versions. Additional commentaries are provided by museum workers, parapsychologists, owners of ghost hotels and houses, their visitors and people in the neighbourhood. The original texts are preceded and followed by the author's comments, which offer information about the settlement history of the particular region, life stories of the former residents of ghost houses, and also parallels in the traditional motifs in ghost stories (e.g., the motif of the glass casket). The author's style is neutral and benevolent, and leaves it up to the reader to decide if concrete ghost phenomena should be taken seriously or they have rather persisted due to pre-determined tradition. The ghosts, undoubtedly, make up a motley assortment - black slaves and Native Americans, soldiers and pastors, buccaneers and aristocratic ladies, unhappy lovers and murder victims. It is remarkable that the majority of the ghosts described in the book are also currently active, i.e., people in these spots continue to hear, see and perceive signs of their existence. It is interesting to realize how significant is the role of spiritual creatures in modern American tourism and entertainment business. For instance, for years accommodation businesses have been competing for the title of The Most Haunted Hotel in America; some hotels advertise packages referring to ghost experiences (such as the Ghostly Get-Away Package for Two in Magnolia Mansion; in several towns tourists are offered guided tours of ghost spots, and in addition to all this, ghost houses are eagerly investigated and tested by parapsychologists, herewith confirming the public opinion that in a certain sense these are special and anomalous places.

The book is logical, informative and well readable, and might disabuse some people of the delusion that in developed countries and urban contexts ghost stories ended up extinct long ago. 


\section{OUR AUTHORS}

Laima Anglickienè is Associate Professor at the Department of Ethnology and Folklore, Faculty of Humanities, Vytautas Magnus University, Kaunas, Lithuania. Research interests: contemporary folklore, modern ethnology, ethnic stereotypes.

l.anglickiene@hmf.vdu.lt

Rita Repšienè, $\mathrm{PhD}$, is research fellow and Head of the Department of Modern Lithuanian Culture, Lithuanian Culture Research Institute, Vilnius, Lithuania. Her current research interests include contemporary cultural theory, postmodern cultural anthropology, nationalism, identity, mythology.

r.repsiene@gmail.com

Maria Yelenevskaya is Senior Teaching Fellow at the Department of Humanities and Arts at the Technion - Israel Institute of Technology. Her recent research and publications deal primarily with the use of language in multilingual and multicultural settings and immigration studies.

ymaria@tx.technion.ac.il

Marlene Hugoson is research archivist at the Department of Dialectology and Folklore Research at the Institute for Language and Folklore in Uppsala, Sweden. Her research interest is contemporary society and she has previously published articles and edited books in the ethnological and interdisciplinary field.

marlene.hugoson@sofi.se

Pedro Martins is lecturer, researcher, consultant and translator at the University of Siena and University of Bologna. Graduate studies in law (University of Lisbon), graduate studies in languages and cultures of the modern world (University of Rome "La Sapienza"), postgraduate studies in Portuguese language and culture (University of Lisbon). Research areas: Portuguese and Lusophone studies, (inter)cultural studies, translation studies, linguistic policies.

pscmartins@gmail.com 
Grigor Haralampiev Grigorov defended his $\mathrm{PhD}$ thesis "Literary Anthropology of the Heroic" at the Department of Literary Theory, Institute of Literature, at the Bulgarian Academy of Sciences, in 2007. He has worked as researcher at the National Centre for Intangible Cultural Heritage (2008-2009), as Assistant Professor (2009-2010) and Senior Assistant Professor (from 2011) at the Department of Anthropology of Verbal Traditions, Institute for Ethnology and Folklore Studies with Ethnographic Museum, Bulgarian Academy of Sciences. His scientific focus is on folkloristics, and he is currently investigating the structure and messages of joke cycles and the hidden semantics of some contemporary rituals.

lapamed@gmail.com

Guntis Pakalns is senior researcher, $\mathrm{PhD}$, working at the Archives of Latvian Folklore, Institute of Literature, Folklore and Art, University of Latvia. Main research interests: folk narratives, storytelling, urban legends, history of Latvian folkloristics.

guntis.pakalns@lulfmi.lv

Ana Stefanova is a $\mathrm{PhD}$ student at the Section of Historical Ethnology, Institute for Ethnology and Folklore Studies with Ethnographic Museum (IEFSEM), Bulgarian Academy of Sciences. She works in the field of rituals and fairy tales in prose, using the methods of analytical psychology.

info@photo4art.com 